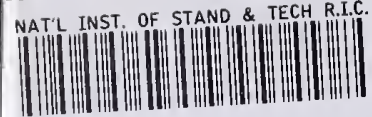 \\ $A 13105 \quad 354517$

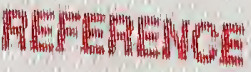 \\ Radiance Temperature Calibrations
}

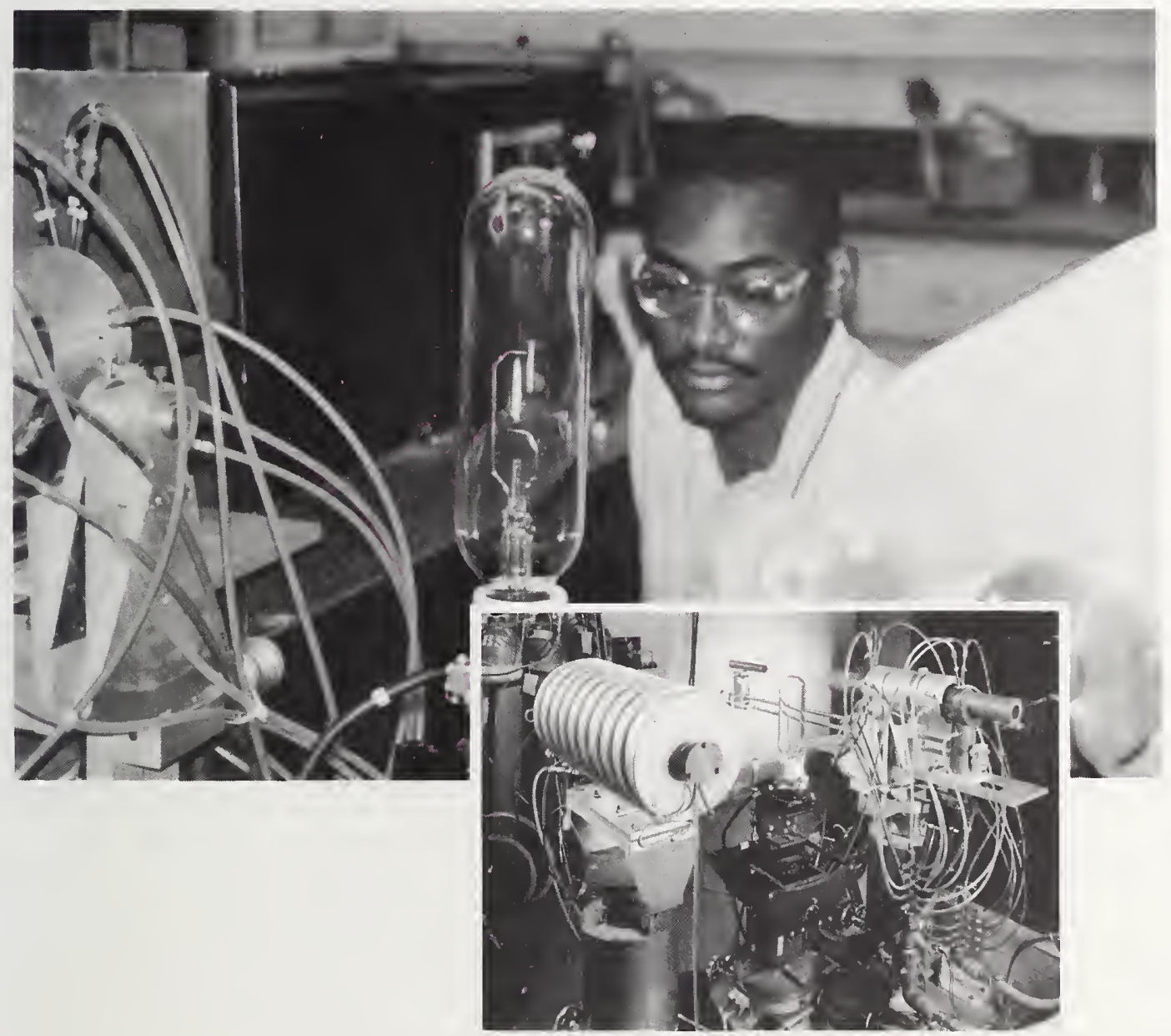

NIST

Special Publication

$250-43$

Charles E. Gibson, Benjamin K. Tsai, and Albert C. Parr

$Q C$

100

457

$10,250-43$

998
U.S. Department of Commerce Technology Administration National Institute of Standards and Technology 
to ensure product reliability ... and to facilitate rapid commercialization . . . of products based on new scientific discoveries."

NIST, originally founded as the National Bureau of Standards in 1901, works to strengthen U.S. industry's competitiveness; advance science and engineering; and improve public health, safety, and the environment. One of the agency's basic functions is to develop, maintain, and retain custody of the national standards of measurement, and provide the means and methods for comparing standards used in science, engineering, manufacturing, commerce, industry, and education with the standards adopted or recognized by the Federal Government.

As an agency of the U.S. Commerce Department's Technology Administration, NIST conducts basic and applied research in the physical sciences and engineering, and develops measurement techniques, test methods, standards, and related services. The Institute does generic and precompetitive work on new and advanced technologies. NIST's research facilities are located at Gaithersburg, MD 20899, and at Boulder, CO 80303. Major technical operating units and their principal activities are listed below. For more information contact the Publications and Program Inquiries Desk, 301-975-3058.

\section{Office of the Director}

- National Quality Program

- International and Academic Affairs

\section{Technology Services}

- Standards Services

- Technology Partnerships

- Measurement Services

- Technology Innovation

- Information Services

\section{Advanced Technology Program}

- Economic Assessment

- Information Technology and Applications

- Chemical and Biomedical Technology

- Materials and Manufacturing Technology

- Electronics and Photonics Technology

\section{Manufacturing Extension Partnership Program \\ - Regional Programs \\ - National Programs \\ - Program Development}

\section{Electronics and Electrical Engineering} Laboratory

- Microelectronics

- Law Enforcement Standards

- Electricity

- Semiconductor Electronics

- Electromagnetic Fields ${ }^{1}$

- Electromagnetic Technology ${ }^{1}$

- Optoelectronics'

\section{Chemical Science and Technology Laboratory \\ - Biotechnology \\ - Physical and Chemical Properties ${ }^{2}$ \\ - Analytical Chemistry \\ - Process Measurements \\ - Surface and Microanalysis Science}

\section{Physics Laboratory}

- Electron and Optical Physics

- Atomic Physics

- Optical Technology

- Ionizing Radiation

- Time and Frequency

- Quantum Physics'

\section{Materials Science and Engineering} Laboratory

- Intelligent Processing of Materials

- Ceramics

- Materials Reliability ${ }^{1}$

- Polymers

- Metallurgy

- NIST Center for Neutron Research

\section{Manufacturing Engineering} Laboratory

- Precision Engineering

- Automated Production Technology

- Intelligent Systems

- Fabrication Technology

- Manufacturing Systems Integration

\section{Building and Fire Research}

\section{Laboratory}

- Structures

- Building Materials

- Building Environment

- Fire Safety Engineering

- Fire Science

Information Technology Laboratory

- Mathematical and Computational Sciences ${ }^{2}$

- Advanced Network Technologies

- Computer Security

- Information Access and User Interfaces

- High Performance Systems and Services

- Distributed Computing and Information Services

- Software Diagnostics and Conformance Testing

\footnotetext{
'At Boulder, CO 80303.

${ }^{2}$ Some elements at Boulder, $\mathrm{CO}$.
} 
NIST Special Publication 250-43

\section{NIST MEASUREMENT SERVICES: Radiance Temperature Calibrations}

Charles E. Gibson, Benjamin K. Tsai, and Albert C. Parr

Optical Technology Division

Physics Laboratory

National Institute of Standards and Technology

Gaithersburg, MD 20899-0001

January 1998

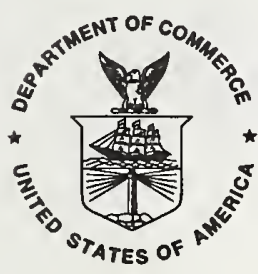

\section{U.S. DEPARTMENT OF COMMERCE}

William M. Daley, Secretary

Technology Administration

Gary R. Bachula, Acting Under Secretary for Technology

National Institute of Standards and Technology

Raymond G. Kammer, Director 
National Institute of Standards and Technology Special Publication 250-43

Natl. Inst. Stand. Technol. Spec. Publ. 250-43, 123 pages (Jan. 1998)

CODEN: NSPUE2

\section{U.S. GOVERNMENT PRINTING OFFICE \\ WASHINGTON: 1998}




\section{PREFACE}

The calibration and related measurement services of the National Institute of Standards and Technology are intended to assist the makers and users of precision measuring instruments in achieving the highest possible levels of accuracy, quality, and productivity. NIST offers over 300 different calibrations, special tests, and measurement assurance services. These services allow customers to directly link their measurement systems to measurement systems and standards maintained by NIST. These services are offered to the public and private organizations alike. They are described in NIST Special Publication (SP) 250, NIST Calibration Services Users Guide.

The Users Guide is supplemented by a number of Special Publications (designated as the "SP250 Series") that provide detailed descriptions of the important features of specific NIST calibration services. These documents provide a description of the: (1) specifications for the services; (2) design philosophy and theory; (3) NIST measurement system; (4) NIST operational procedures; (5) assessment of the measurement uncertainty including random and systematic errors and an error budget; and (6) internal quality control procedures used by NIST. These documents will present more detail than can be given in NIST calibration reports, or than is generally allowed in articles in scientific journals. In the past, NIST has published such information in a variety of ways. This series will make this type of information more readily available to the user.

This document, SP250-43 (1997), NIST Measurement Services: Radiance Temperature Calibrations, is a revision of SP250-7 (1987). It covers the calibration of radiance temperature standards for disappearing filament optical pyrometers, ribbon filament lamps, and radiation thermometers (test numbers 35010C-35070S in SP250, NIST Calibration Services Users Guide). Inquiries concerning the technical content of this document or the specifications for these services should be directed to the author or to one of the technical contacts cited in SP250.

NIST welcomes suggestions on how publications such as this might be made more useful. Suggestions are also welcome concerning the need for new calibrations services, special tests, and measurement assurance programs.

Stanley D. Rasberry

Director

Measurement Services
Katharine B. Gebbie

Director

Physics Laboratory 


\section{ABSTRACT}

This document describes the realization and dissemination of the International Temperature Scale of 1990 (ITS-90) above $700^{\circ} \mathrm{C}$ at the National Institute of Standards and Technology (NIST). By using fundamental principles of blackbody physics, the ITS-90 scale is first fixed at the freezing point of gold $\left(T_{90}=1064.18^{\circ} \mathrm{C}\right)$ and is then extended to temperatures between $700{ }^{\circ} \mathrm{C}$ and $2700{ }^{\circ} \mathrm{C}$ by determining the ratio of the spectral radiance of a tungsten ribbon filament lamp to that of a gold fixed-point blackbody at a wavelength of $655.3 \mathrm{~nm}$. A description of the facilities in the NIST Radiance Temperature Calibration Laboratory is given, along with a discussion of the wavelength calibration, size of source, and linearity issues. The use and calibration of radiance temperature standards are explained. Values of stability and uncertainties in the scale are reported. The expanded uncertainties $(k=2)$ at $800^{\circ} \mathrm{C}$ and $2300{ }^{\circ} \mathrm{C}$ are $0.6^{\circ} \mathrm{C}$ and $1.4^{\circ} \mathrm{C}$ for ribbon filament lamps, $4^{\circ} \mathrm{C}$ and $7{ }^{\circ} \mathrm{C}$ for disappearing filament optical pyrometers, and $2{ }^{\circ} \mathrm{C}$ and $3{ }^{\circ} \mathrm{C}$ for infrared radiation thermometers.

KEYWORDS: gold-point blackbody, International Temperature Scale (ITS-90), pyrometers, pyrometry, radiance temperature calibration, radiation thermometry, tungsten ribbon filament lamps 


\section{TABLE OF CONTENTS}

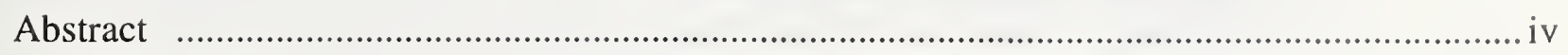

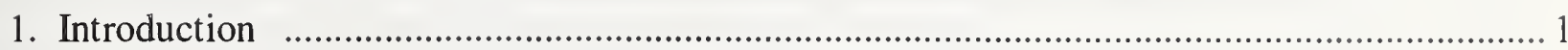

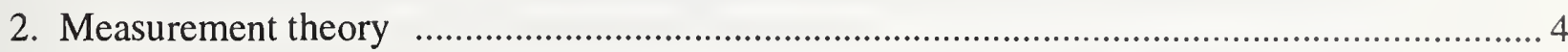

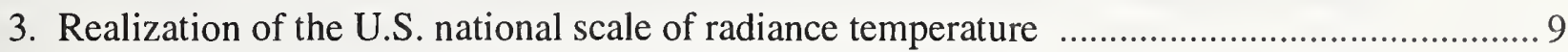

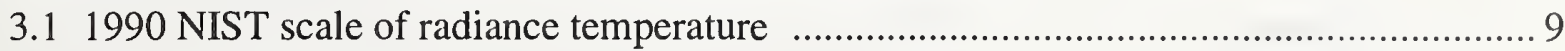

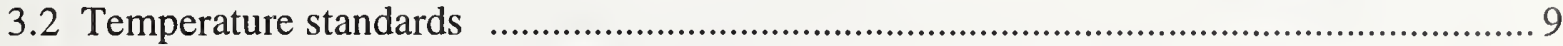

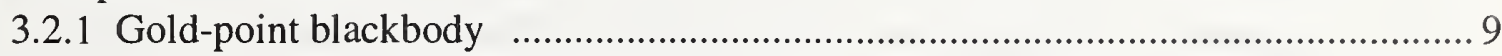

3.2.2 Tungsten ribbon filament lamps …………................................................... 11

3.2.3 Working standard lamps …........................................................................... 14

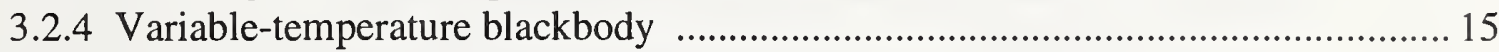

3.3 NIST photoelectric pyrometer …............................................................................. 19

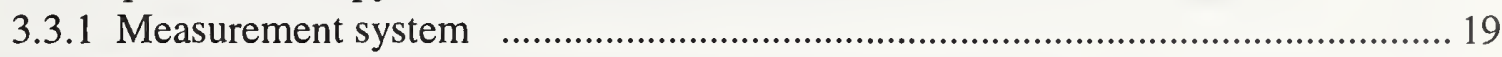

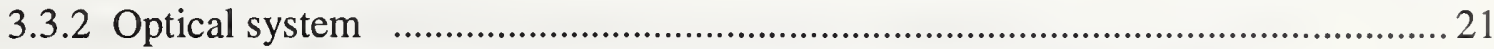

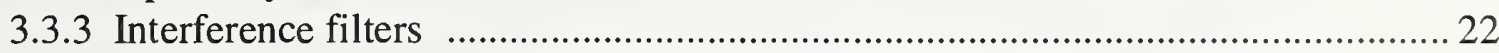

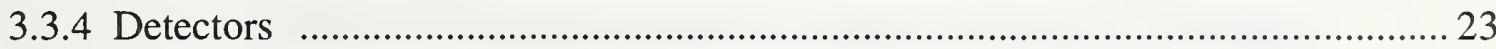

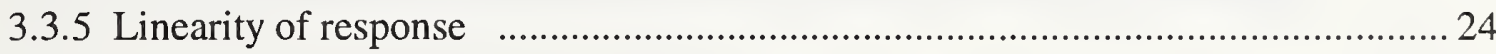

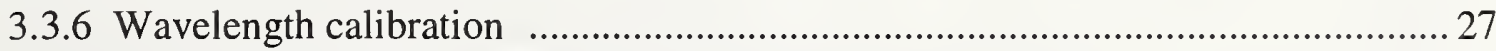

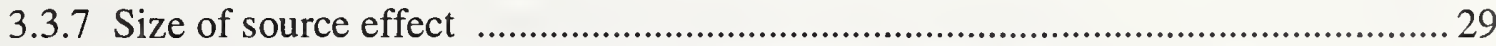

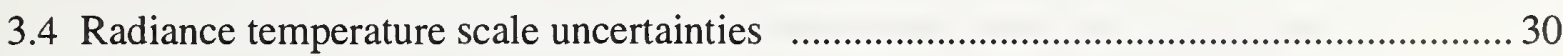

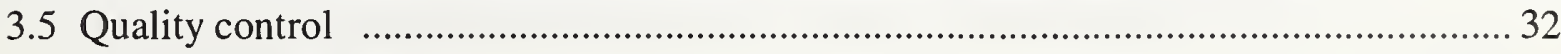

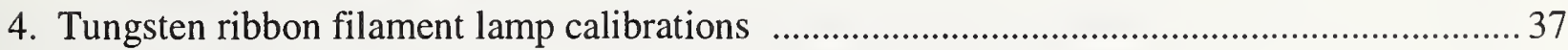

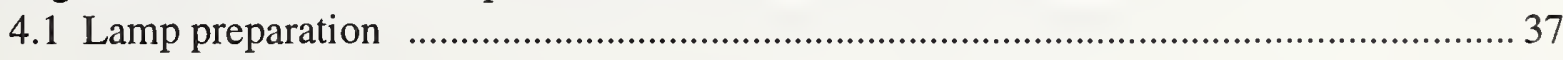

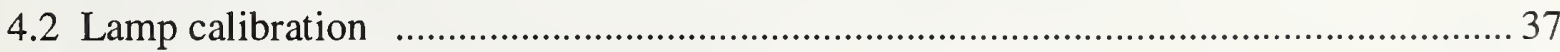

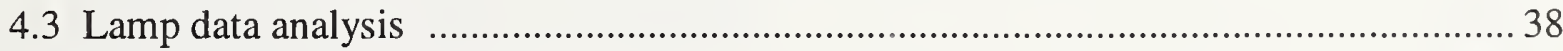

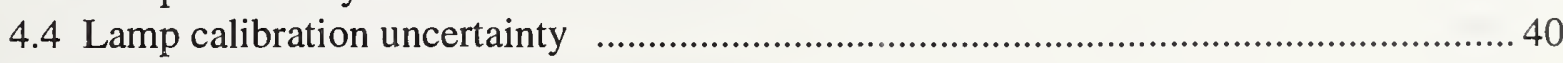

5. Disappearing filament optical pyrometer calibrations …........................................................ 44

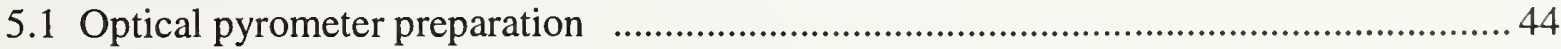

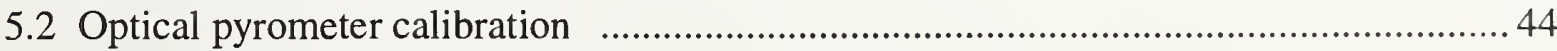

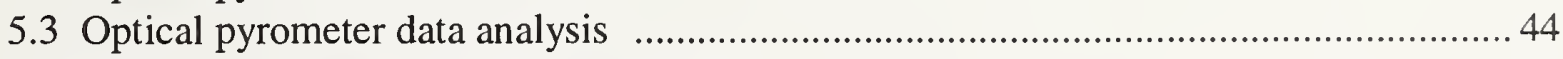

5.4 Optical pyrometer calibration uncertainty ……............................................................ 45 


\section{TABLE OF CONTENTS (continued)}

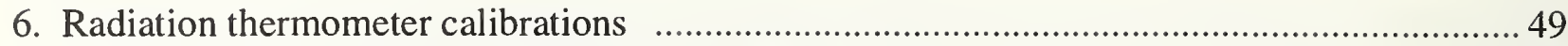

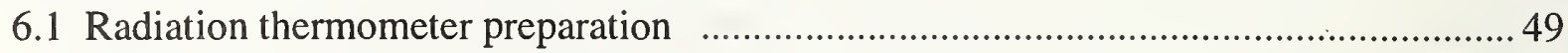

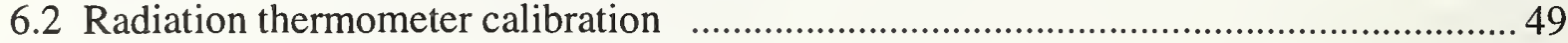

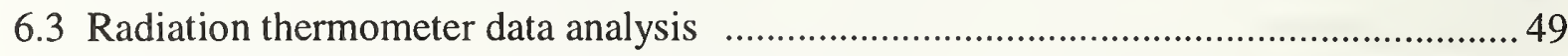

6.4 Radiation thermometer calibration uncertainty ................................................................ 49

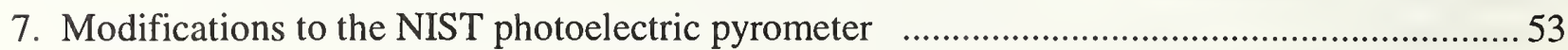

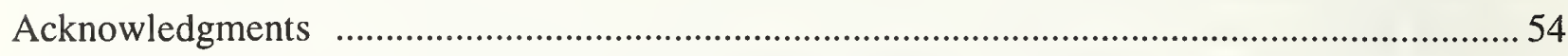

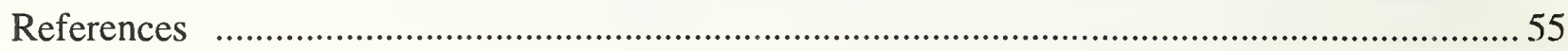

Appendix A: Ribbon filament lamp sample calibration report ……...................................... A1

Appendix B: Optical pyrometer sample calibration report ……................................................

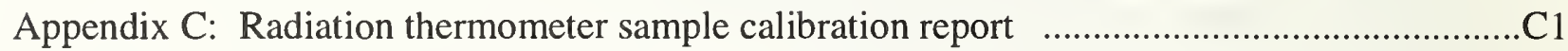

Appendix D: Radiance temperature measurement services laboratory procedure manual ......... D1

Appendix E: How to request radiance temperature calibration services …………………......... 1 


\section{LIST OF FIGURES}

Figure 1 Schematic of optics for the NIST photoelectric pyrometer ........................................ 4

Figure 2 Blackbody spectral distribution. As the temperature increases, the peak moves toward shorter wavelengths, and the slope increases at each wavelength..................... 5

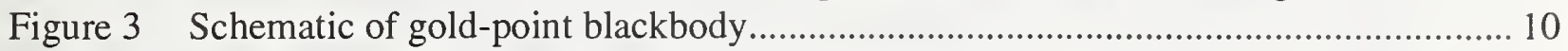

Figure 4 Gold-point blackbody liquid-to-solid phase transition................................................ 11

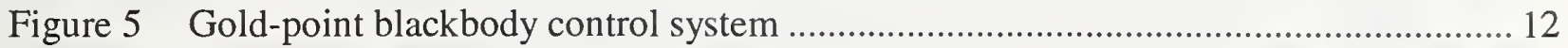

Figure 6 Schematic of lamp current monitoring system....................................................... 13

Figure 7 Typical lamp currents for the General Electric 30A/T24/6 ribbon filament lamp ...... 14

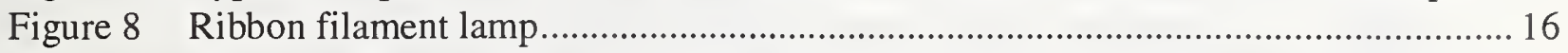

Figure 9 Calibration history of the working standard (no. SL20) ........................................ 17

Figure 10 Schematic of the variable temperature blackbody....................................................... 17

Figure 11 Variable temperature blackbody control system ....................................................... 18

Figure 12 Spatial scan of the variable temperature blackbody at $2000{ }^{\circ} \mathrm{C}$. The temperature

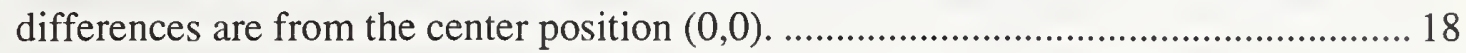

Figure 13 Variable temperature blackbody PID control. After decreasing the set point by $100{ }^{\circ} \mathrm{C}$, the blackbody stabilizes in less than 10 min.............................................. 19

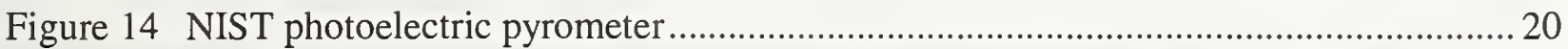

Figure 15 NIST radiance temperature laboratory measurement system ...................................... 21

Figure 16 NIST photoelectric pyrometer filter transmittances. The wavelength of the pyrometer is selected by using a $1 \mathrm{~nm}$ and a $10 \mathrm{~nm}$ spectral bandwidth (SBW)

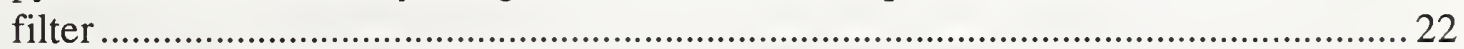

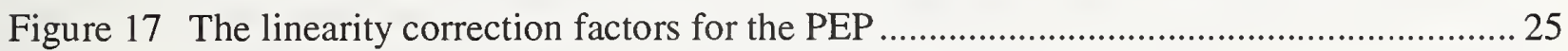

Figure 18 Relative spectral response of the NIST photoelectric pyrometer ................................. 28

Figure 19 The size of source corrections for the variable temperature blackbody to the working standard lamp comparison and the working standard lamp to the

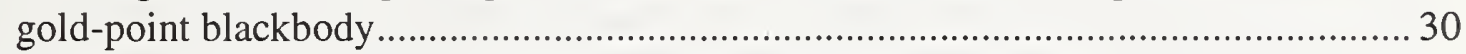

Figure 20 Calibration history of the ribbon filament lamp check standards................................. 35

Figure 21 Calibration history of the radiation thermometer check standard

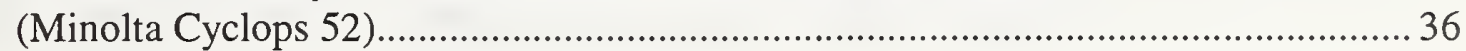

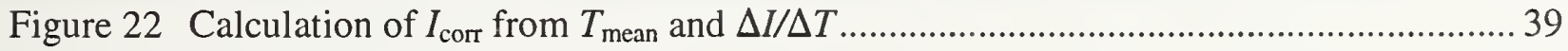

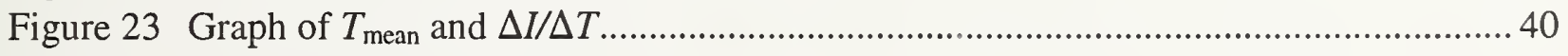

Figure 24 Modified NIST photoelectric pyrometer ........................................................................ 53 


\section{LIST OF TABLES}

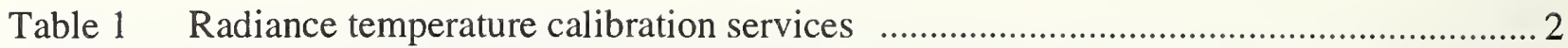

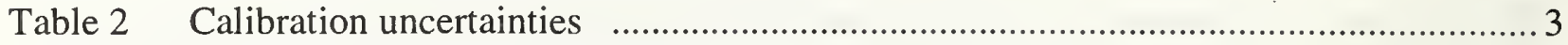

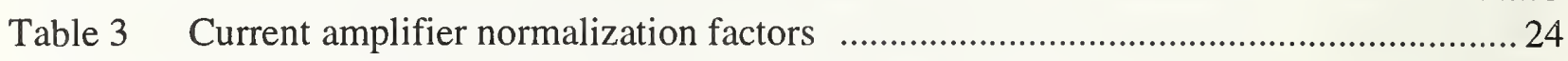

Table 4 Detector system correction factors and linearity coefficients ………........................25

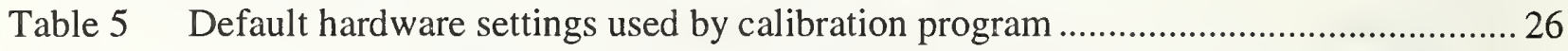

Table 6 Corrections $\left({ }^{\circ} \mathrm{C}\right)$ to the radiance temperature at $900 \mathrm{~nm}$ and at $1000 \mathrm{~nm}$................... 29

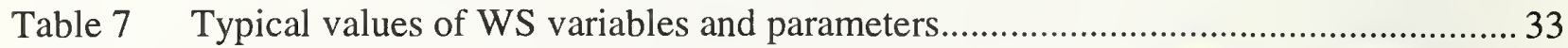

Table 8 Uncertainty budget for the NIST WS lamp spectral radiance realization ..................... 34

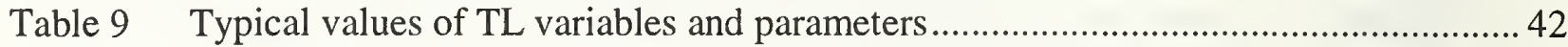

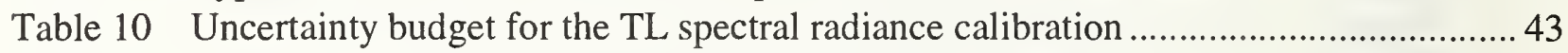

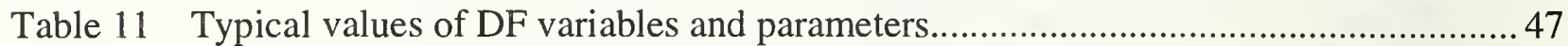

Table 12 Uncertainty budget for the DF spectral radiance calibration ........................................ 48

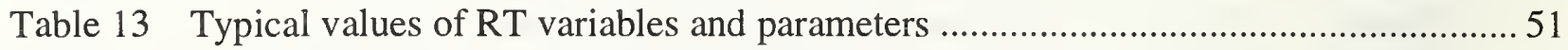

Table 14 Uncertainty budget for the RT spectral radiance calibration........................................52 


\section{Introduction}

The National Institute of Standards and Technology (NIST) is responsible for the establishment, maintenance, and dissemination of the U.S. National Scale of Radiance Temperature through its Radiance Temperature Calibration Laboratory (RTCL), which provides temperature measurements above $700^{\circ} \mathrm{C}$. The 1990 NIST Radiance Temperature Scale [1] is based upon the NIST realization of the International Temperature Scale 1990 [2] using principles from blackbody physics. Beginning with the determination of the freezing point of gold $\left(T_{90}=1064.18^{\circ} \mathrm{C}\right)$, the scale is realized for the range from $700{ }^{\circ} \mathrm{C}$ to $4200^{\circ} \mathrm{C}$ using radiometric methods. The radiance temperature (also referred to as the brightness or apparent temperature) of a radiator is equivalent to the temperature of a blackbody with the same radiant intensity as that of the radiator's surface at a chosen wavelength.

This document describes the determination of the ratio of the spectral radiance of a tungsten ribbon filament lamp used as a temperature standard to that of a gold fixed-point blackbody at a wavelength of $655.3 \mathrm{~nm}$. A description of the NIST RTCL along with the use and calibration of radiance temperature standards therein is presented in detail. Issues relating to the wavelength calibration, size of source, and linearity of the NIST Photoelectric Pyrometer (PEP) are then discussed. Stability and uncertainties in the scale are considered in detail within the framework of the NIST policy on uncertainty statements described in reference [3].

The NIST disseminates the radiance temperature scale by two methods. The first method involves calibrating ribbon filament lamps as radiance temperature standards in the temperature range from $800{ }^{\circ} \mathrm{C}$ to $2300^{\circ} \mathrm{C}$ with expanded uncertainties $(k=2)^{1}$ of $0.6^{\circ} \mathrm{C}$ at $800^{\circ} \mathrm{C}$, and $1.4^{\circ} \mathrm{C}$ at $2300^{\circ} \mathrm{C}$. The second method involves the calibration of customer pyrometers and radiation thermometers. Disappearing filament optical pyrometers are calibrated from $800^{\circ} \mathrm{C}$ to $4200^{\circ} \mathrm{C}$ with expanded uncertainties $(k=2)$ of $4{ }^{\circ} \mathrm{C}$ at $800^{\circ} \mathrm{C}, 7^{\circ} \mathrm{C}$ at $2300^{\circ} \mathrm{C}$, and $25^{\circ} \mathrm{C}$ at $4200^{\circ} \mathrm{C}$. Radiation thermometers are measured from $800^{\circ} \mathrm{C}$ to $2700^{\circ} \mathrm{C}$ with expanded uncertainties $(k=2)$ of $2{ }^{\circ} \mathrm{C}$ at $800^{\circ} \mathrm{C}$, and $3{ }^{\circ} \mathrm{C}$ at $2700^{\circ} \mathrm{C}$.

The radiance temperature calibration services shown in Table 1 are offered through the NIST Calibration Services Program and are listed in the Radiation Thermometry section of the Thermodynamics Quantities Chapter of the NIST Calibration Services Users Guide [4]. A summary of the calibration uncertainties is given in Table 2. This laboratory's quality system is based on the ANSI/NCSL Z540-1-1994 standard and the ISO/IEC Guide 25.

1 Throughout this paper, all uncertainty values are given as an expanded uncertainty with coverage factor $k=2$, thus a two standard deviation estimate. Uncertainties of fundamental units given as a combined standard uncertainty in other documents are restated as an expanded uncertainty $(k=2)$. 
Table 1. Radiance temperature calibration services

Service ID No.

Measurement Description

Calibration reports are issued giving the radiance temperature of the blackbody at $655.3 \mathrm{~nm}$ versus the scale reading, output current, or output voltage.

35010C Radiance Temperature Standard, Disappearing Filament Optical Pyrometer ( $800{ }^{\circ} \mathrm{C}$ to $2400{ }^{\circ} \mathrm{C}, 4$ to 12 points, 1 range)

35020C Radiance Temperature Standard, Disappearing Filament Optical Pyrometer (each additional range up to $4200^{\circ} \mathrm{C}$, only available with No. $35010 \mathrm{C}$ )

35030C Additional Interpolated Values

35040C Radiance Temperature Standard, Disappearing Filament Optical Pyrometer $\left(800{ }^{\circ} \mathrm{C}\right.$ to $4200^{\circ} \mathrm{C}, 3$ or fewer points, 1 range)

Calibration reports are issued giving the radiance temperature of the lamp at $655.3 \mathrm{~nm}$ versus the lamp current.

35050C Radiance Temperature Standard, Ribbon Filament Lamp $\left(800{ }^{\circ} \mathrm{C}\right.$ to $2300{ }^{\circ} \mathrm{C}, 6$ to 16 points)

35060C Radiance Temperature Standard, Ribbon Filament Lamp $\left(800^{\circ} \mathrm{C}\right.$ to $2300^{\circ} \mathrm{C}, 5$ or fewer points)

Test reports are issued giving the radiance temperature of the blackbody at $655.3 \mathrm{~nm}, 900 \mathrm{~nm}$, or $1000 \mathrm{~nm}$ versus the indicated reading, output current, or output voltage.

35070S Special Tests of Radiation Thermometers 
Table 2. Calibration uncertainties

\begin{tabular}{|c|c|c|}
\hline Standard & Temperature Range & $\begin{array}{l}\text { Expanded } \\
\text { Uncertainty }\end{array}$ \\
\hline Ribbon filament lamp & $\begin{array}{l}800^{\circ} \mathrm{C} \text { to } 1600{ }^{\circ} \mathrm{C} \\
1600^{\circ} \mathrm{C} \text { to } 1900{ }^{\circ} \mathrm{C} \\
1900^{\circ} \mathrm{C} \text { to } 2300^{\circ} \mathrm{C}\end{array}$ & $\begin{array}{l}0.7^{\circ} \mathrm{C} \\
1.0^{\circ} \mathrm{C} \\
1.5^{\circ} \mathrm{C}\end{array}$ \\
\hline Leeds \& Northrup & $800^{\circ} \mathrm{C}$ to $1600^{\circ} \mathrm{C}$ & $4{ }^{\circ} \mathrm{C}$ \\
\hline Model 8000 series & $\begin{array}{l}1600^{\circ} \mathrm{C} \text { to } 2100^{\circ} \mathrm{C} \\
1900^{\circ} \mathrm{C} \text { to } 2300^{\circ} \mathrm{C}\end{array}$ & $\begin{array}{l}5^{\circ} \mathrm{C} \\
7^{\circ} \mathrm{C}\end{array}$ \\
\hline $\begin{array}{l}\text { Disappearing filament } \\
\text { optical pyrometer }\end{array}$ & $\begin{array}{l}2400{ }^{\circ} \mathrm{C} \text { to } 2700{ }^{\circ} \mathrm{C} \\
2700{ }^{\circ} \mathrm{C} \text { to } 3200{ }^{\circ} \mathrm{C} \\
3200{ }^{\circ} \mathrm{C} \text { to } 4200{ }^{\circ} \mathrm{C}\end{array}$ & $\begin{array}{l}8{ }^{\circ} \mathrm{C} \\
17^{\circ} \mathrm{C} \\
25^{\circ} \mathrm{C}\end{array}$ \\
\hline $\begin{array}{l}\text { Pyrometer Instrument } \\
\text { Model } 95\end{array}$ & $\begin{array}{l}800{ }^{\circ} \mathrm{C} \text { to } 1400{ }^{\circ} \mathrm{C} \\
1400{ }^{\circ} \mathrm{C} \text { to } 1800{ }^{\circ} \mathrm{C} \\
1800{ }^{\circ} \mathrm{C} \text { to } 2400{ }^{\circ} \mathrm{C}\end{array}$ & $\begin{array}{l}3{ }^{\circ} \mathrm{C} \\
4{ }^{\circ} \mathrm{C} \\
5^{\circ} \mathrm{C}\end{array}$ \\
\hline $\begin{array}{l}\text { Disappearing filament } \\
\text { optical pyrometer }\end{array}$ & $\begin{array}{l}2400^{\circ} \mathrm{C} \text { to } 2700^{\circ} \mathrm{C} \\
2700{ }^{\circ} \mathrm{C} \text { to } 3200^{\circ} \mathrm{C}\end{array}$ & $\begin{array}{l}8^{\circ} \mathrm{C} \\
12^{\circ} \mathrm{C}\end{array}$ \\
\hline $\begin{array}{l}\text { Infrared radiation } \\
\text { thermometer }\end{array}$ & $\begin{array}{l}800^{\circ} \mathrm{C} \text { to } 2000^{\circ} \mathrm{C} \\
2000^{\circ} \mathrm{C} \text { to } 2700^{\circ} \mathrm{C}\end{array}$ & $\begin{array}{l}2{ }^{\circ} \mathrm{C} \\
3{ }^{\circ} \mathrm{C}\end{array}$ \\
\hline
\end{tabular}

The expanded uncertainty (coverage factor $k=2$ ) is equivalent to a two standard deviation estimate. 


\section{Measurement theory}

Temperatures above the freezing point of silver $\left(1234.93 \mathrm{~K}\right.$ or $\left.961.78^{\circ} \mathrm{C}\right)$ are defined on the International Temperature Scale of 1990 (ITS-90) [2] in terms of the ratio of spectral radiances of two blackbody sources, one of which is maintained at the temperature of freezing silver, gold $\left(1337.33 \mathrm{~K}\right.$ or $\left.1064.18^{\circ} \mathrm{C}\right)$, or copper $\left(1357.77 \mathrm{~K}\right.$ or $\left.1084.62{ }^{\circ} \mathrm{C}\right)$. The $1990 \mathrm{NIST}$ Scale of Radiance Temperature (1990 NIST) is a realization of the ITS-90 using a gold fixedpoint blackbody. In this section, the blackbody temperature will be defined in terms of the spectral radiance. Using the signal measurement equation, the measurement equation for the calibration of a transfer standard will be derived.

The signal measurement equation, defined by Nicodemus and Kostkowski in 1978 [5], relates the detector signal output, $S[\mathrm{~V}]^{2}$, to the source flux input parameters through a detector responsivity term, $R_{\lambda}\left[\mathrm{A} \cdot \mathrm{W}^{-1}\right]$, by the integral relationship,

$$
S=\iint_{A} \int_{\lambda} R_{\lambda} \cdot L_{\lambda} \cdot \mathrm{d} \lambda \cdot \cos \theta \cdot \mathrm{d} \omega \cdot \mathrm{d} A
$$

\section{LEGEND}

$\begin{array}{ll}\text { AS } & \text { Aperture Stop } \\ \text { CL } & \text { Collimating Lens } \\ \text { DL } & \text { Diverging Lens } \\ \text { F1 } & 1 \mathrm{~nm} \text { bandwidth interference filter } \\ \text { F2 } & 10 \mathrm{~nm} \text { bandwidth interferenee filter } \\ \text { FS } & \text { Field Stop } \\ \text { OL } & \text { Objective Lens }\end{array}$

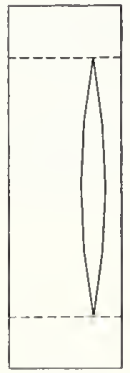

$\mathrm{OL}$

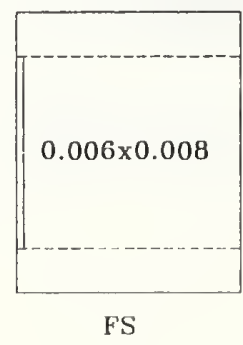

All units in centimelers.

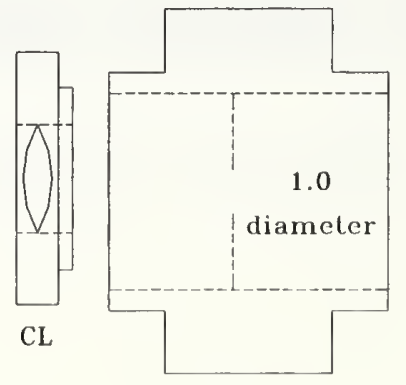

AS

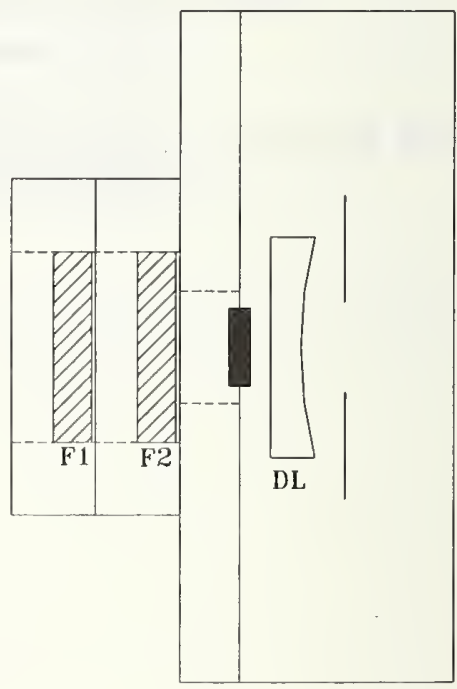

Figure 1. Schematic of optics for the NIST photoelectric pyrometer.

\footnotetext{
${ }^{2}$ As an aid to the reader, the appropriate coherent SI unit in which a quantity should be expressed is indicated in brackets when the quantity is first introduced.
} 
where $L_{\lambda}\left[\mathrm{W} \cdot \mathrm{m}^{-3} \cdot \mathrm{sr}^{-1}\right]$ is the spectral radiance, $\mathrm{d} \lambda[\mathrm{m}]$ is the wavelength band, $\theta[\mathrm{rad}]$ is the angle between the aperture normal and the line connecting the aperture centers, $d \omega[\mathrm{sr}]$ is the differential solid angle originating at the source aperture as defined by the detector aperture, and $\mathrm{d} A\left[\mathrm{~m}^{2}\right]$ is the differential source aperture area. For the NIST PEP in figure 1, the spectral responsivity $R_{\lambda}$ includes the spectral transmittance of the interference filters, the spectral transmittance of all other optical elements, and the spectral responsivity of the detector. In terms of its specific components, the spectral responsivity is

$$
R_{\lambda}=\tau_{\lambda, \mathrm{OL}} \cdot \tau_{\lambda, \mathrm{CL}} \cdot \tau_{\lambda, \mathrm{F} 1} \cdot \tau_{\lambda, \mathrm{F} 2} \cdot \tau_{\lambda, \mathrm{DL}} \cdot \tau_{\lambda, \mathrm{EC}} \cdot R_{\lambda, \mathrm{PEP}},
$$

where $\tau_{\lambda, \mathrm{OL}}$ is the spectral transmittance of the objective lens, $\tau_{\lambda, \mathrm{CL}}$ is the spectral transmittance of the collimating lens, $\tau_{\lambda, F 1}$ is the spectral transmittance of the $1 \mathrm{~nm}$ bandpass interference filter, $\tau_{\lambda, \mathrm{F} 2}$ is the spectral transmittance of the $10 \mathrm{~nm}$ bandpass interference filter, $\tau_{\lambda, \mathrm{DL}}$ is the spectral transmittance of the diverging lens, $\tau_{\lambda, \mathrm{EC}}$ is the spectral transmittance of the evacuated window cell, and $R_{\lambda, \text { PEP }}$ is the detector absolute spectral responsivity.

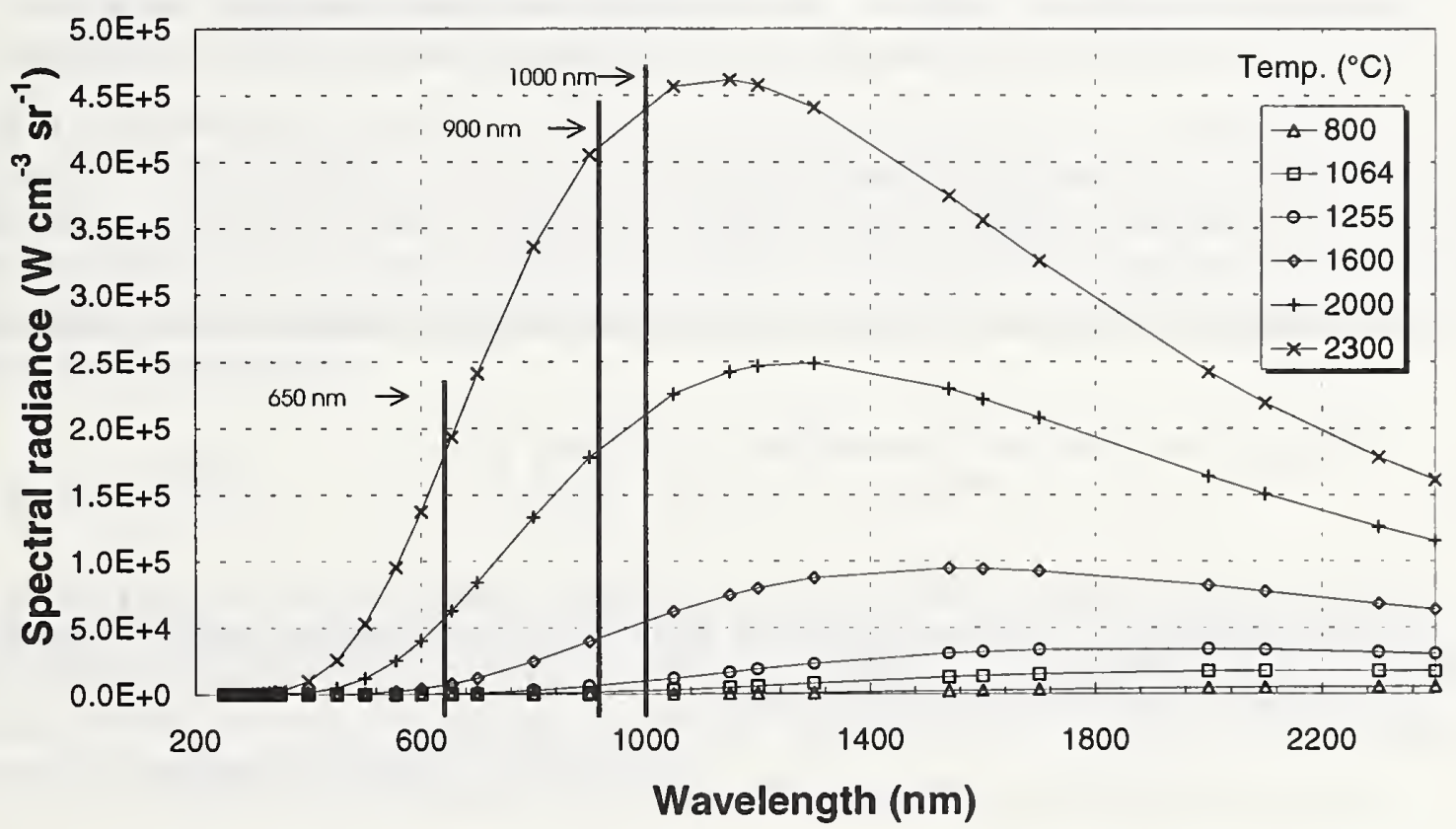

Figure 2. Blackbody spectral distribution. As the temperature increases, the peak moves towards shorter wavelengths, and the slope increases at each wavelength. 
Spectral radiance $L_{\lambda}$ is the radiant power contained in a defined area, solid angle, direction, and wavelength interval,

$$
L_{\lambda}=\mathrm{d}^{3} \Phi / \mathrm{d} A \cdot \cos \alpha \cdot \mathrm{d} \beta \cdot \mathrm{d} \lambda,
$$

where $\Phi$ is the radiant flux [W], $A$ is the source area, $\alpha$ is the plane angle between the surface normal and the direction of propagation [rad], $\beta$ is the solid angle about that direction [sr], and $\lambda$ is the wavelength [m]. A few blackbody distributions from $250 \mathrm{~nm}$ to $2500 \mathrm{~nm}$ between $800^{\circ} \mathrm{C}$ and $2300{ }^{\circ} \mathrm{C}$ are illustrated in figure 2 . For an ideal blackbody in a vacuum environment, the relation between spectral radiance, wavelength, and temperature is given by the Planck equation [6],

$$
L_{\lambda}=\frac{c_{1 L}}{\lambda^{5} \cdot\left(\exp \left(c_{2} /(\lambda \cdot T)\right)-1\right)}
$$

where $c_{1 L}$ is the first radiation constant in radiance form with a value of $119.1044 \mathrm{~W} \cdot \mathrm{nm}^{2}, c_{2}$ is the second radiation constant with a value of $1.4388 \times 10^{-7} \mathrm{~nm} \cdot \mathrm{K}$ [7], $\lambda$ is the wavelength in vacuum, and $T$ is the temperature [K]. The Planck equation in the form of eq (4) is the definition for an ideal blackbody radiator. When using a non-ideal blackbody such as a fixed-point blackbody to realize the temperature scale, the following form of the Planck equation is used,

$$
L_{\lambda}=\frac{\varepsilon_{\lambda} \cdot c_{1 L}}{n_{\lambda}^{2} \cdot \lambda^{5} \cdot\left(\exp \left(c_{2} /\left(n_{\lambda} \cdot \lambda \cdot T\right)\right)-1\right)},
$$

and temperature is defined as a function of spectral radiance using the following equation

$$
T\left(\lambda, L_{\lambda}\right)=\frac{c_{2}}{n_{\lambda} \cdot \lambda \cdot \ln \left(1+\varepsilon_{\lambda} \cdot c_{1 L} / n_{\lambda}^{2} \cdot \lambda^{5} \cdot L_{\lambda}\right)},
$$

where $\varepsilon_{\lambda}$ is the spectral emissivity of the blackbody (which is equal to unity in the case of an ideal blackbody), $\lambda$ is the wavelength in air, and $n_{\lambda}$ is the refractive index of air at $15{ }^{\circ} \mathrm{C}$ and $101,325 \mathrm{~Pa}$. From the Cauchy [8] formula,

$$
n_{\lambda}=1+\left(2726.43+12.288 \mathrm{~nm}^{2} /\left(\lambda^{2} \times 10^{-6}\right)+0.3555 \mathrm{~nm}^{4} /\left(\lambda^{4} \times 10^{-12}\right)\right) \times 10^{-7},
$$

the refractive index of air at $655.3 \mathrm{~nm}$ is about 1.00028 . The temperatures described in this document are radiance temperatures. The radiance temperature of a radiator is equivalent to the temperature of a blackbody with the same radiant intensity of the radiator's surface at a specified wavelength. The relationship between the radiance temperature and the true or thermodynamic temperature of a blackbody is given by: 


$$
\frac{1}{T}=\frac{1}{T_{\lambda}}+\frac{\lambda}{c_{2}} \cdot \ln \varepsilon_{\lambda}
$$

where $T$ is the thermodynamic temperature, $T_{\lambda}$ is the radiance temperature, $\lambda$ is the mean effective wavelength of the NIST PEP $(655.3 \mathrm{~nm})$, and $\varepsilon_{\lambda}$ is the estimated emissivity of the blackbody (0.99).

Determination of the spectral radiance temperature of a working standard (WS) lamp requires measurement of the ratio $r_{1}$,

$$
r_{1}=\frac{S_{\mathrm{ws}}}{S_{\mathrm{Au}}}
$$

of the signals from the transfer standard and the goldpoint blackbody $(\mathrm{Au})$ with the NIST PEP. From eq (2), this measured ratio is actually

$$
r_{1}=\frac{\iint_{A_{A}} \int_{\lambda} R_{\lambda} \cdot\left(L_{\lambda} \cdot \cos \theta_{\mathrm{s}} \cdot \mathrm{d} \omega \cdot \mathrm{d} A_{\mathrm{s}}\right)_{\mathrm{Ws}} \cdot \mathrm{d} \lambda}{\iint_{A_{\mathrm{s}}} \int_{\omega} R_{\lambda} \cdot\left(L_{\lambda} \cdot \cos \theta_{\mathrm{s}} \cdot \mathrm{d} \omega \cdot \mathrm{d} A_{\mathrm{s}}\right)_{\mathrm{Au}} \cdot \mathrm{d} \lambda} .
$$

To simplify the complex expression in eq (10), it is assumed that the spectral radiances $L_{\lambda}$ ws and $L_{\lambda, \mathrm{Au}}$, spectral responsivities $R_{\lambda, \mathrm{WS}}$ and $R_{\lambda, \mathrm{Au}}$, and amplifier gains $G_{\mathrm{WS}}$ and $G_{\mathrm{Au}}$ are independent of both direction and spatial location. Furthermore, these three variables can be defined by unique for the transfer source and the gold-point blackbody at equivalent wavelengths (to be defined later) over the same small wavelength band $\mathrm{d} \lambda$. The solid angle terms can be replaced with the definition of the solid angle,

$$
\omega=\frac{A_{d} \cdot \cos \theta_{d}}{D^{2}}
$$

where $A_{\mathrm{d}}$ is the detector area $\left[\mathrm{m}^{2}\right], \theta_{\mathrm{d}}$ is the angle between the optical axis and the normal to the detector surface [rad], and $D$ is the distance between the detector area and the source area [m]. Assuming that the areas are independent of direction and that the solid angles are independent of area or spatial location, this ratio then becomes

$$
r_{1}=\frac{\left(R_{\lambda} \cdot L_{\lambda} \cdot A_{\mathrm{s}} \cdot \cos \theta_{\mathrm{s}} \cdot A_{\mathrm{d}} \cdot \cos \theta_{\mathrm{d}}\right)_{\mathrm{WS}}}{\left(R_{\lambda} \cdot L_{\lambda} \cdot A_{\mathrm{s}} \cdot \cos \theta_{\mathrm{s}} \cdot A_{\mathrm{d}} \cdot \cos \theta_{\mathrm{d}}\right)_{\mathrm{Au}}} \cdot \frac{D_{\mathrm{Au}}^{2}}{D_{\mathrm{Ws}}^{2}},
$$

where $A_{\mathrm{s}}$ is the source area $\left[\mathrm{m}^{2}\right], \theta_{\mathrm{s}}$ is the angle between the optical axis and the normal to the source surface [rad], $R_{\lambda, \mathrm{ws}}$ is the detector responsivity when viewing the transfer source, and $R_{\lambda, \mathrm{Au}}$ is the detector responsivity when viewing the gold-point blackbody. The spectral responsivities $R_{\lambda, \text { ws }}$ and $R_{\lambda, \mathrm{Au}}$ are assumed to be equal. If the source aperture areas $\mathrm{d} A_{\mathrm{TS}}$ and 
$\mathrm{d} A_{\mathrm{Au}}$, source solid angles $\mathrm{d} \omega_{\mathrm{Ws}}$ and $\mathrm{d} \omega_{\mathrm{Au}}$, and the source inclination angles $\theta_{\mathrm{Ws}}$ and $\theta_{\mathrm{Au}}$ are the same for measuring both the transfer standard and the gold-point blackbody, the measured ratio simplifies to the expression,

$$
r_{1}=\frac{L_{\lambda, \mathrm{ws}}}{L_{\lambda, \mathrm{Au}}}=\frac{L_{\lambda}\left(T_{\mathrm{ws}}\right)}{L_{\lambda}\left(T_{\mathrm{Au}}\right)} .
$$

This relationship is the defining equation for the ITS-90 above $1337.33 \mathrm{~K}$. In terms of eq (4), it can be written at a discrete wavelength, $\lambda$, as

$$
r_{1}=\frac{L_{\lambda}\left(T_{\mathrm{wS}}\right)}{L_{\lambda}\left(T_{\mathrm{Au}}\right)}=\frac{\exp \left(c_{2} /\left(n_{\lambda} \cdot \lambda \cdot T_{\mathrm{Au}}\right)\right)-1}{\exp \left(c_{2} /\left(n_{\lambda} \cdot \lambda \cdot T_{\mathrm{wS}}\right)\right)-1}
$$

where $L_{\lambda}\left(T_{\mathrm{WS}}\right)$ and $L_{\lambda}\left(T_{\mathrm{Au}}\right)$ are the spectral radiances of the two blackbodies at temperatures $T$ and $T_{\mathrm{Au}}, T_{\mathrm{Au}}$ is the temperature of freezing gold defined as $1337.33 \mathrm{~K}$, and $r_{1}$ is their ratio. In principle, a measurement of the ratio at a discrete wavelength with a linear response instrument yields the value of $T$.

The radiance temperature scale is typically maintained and disseminated on tungsten ribbon filament lamps, which possess a repeatable lamp current versus radiance temperature relationship. At the NIST, a pyrometer system is presently being used with a mean effective wavelength of $655.3 \mathrm{~nm}$. This method requires that the pyrometer relative spectral response extends only over a small spectral range, or is known accurately enough to determine the wavelength at which the integrands of eq (10) have the same ratio as the integrals. Equation (13) above is an approximation, and, in practice, corrections, which will be presented in the next section, are used. 


\section{Realization of the U.S. national scale of radiance temperature}

\subsection{NIST scale of radiance temperature}

The reference temperature standard, a gold fixed-point blackbody (Au) with a temperature $\left(T_{\mathrm{Au}}\right)$ of $1064.18{ }^{\circ} \mathrm{C}(1337.33 \mathrm{~K})$, and the Planck radiation law are used to realize and disseminate the 1990 NIST Radiance Temperature Scale. Equation (5) is used to calculate the spectral radiance $L_{\lambda, \mathrm{Au}}\left(\lambda, T_{\mathrm{Au}}\right)$ of the fixed-point blackbody for $\lambda=655.3 \mathrm{~nm}$ in all the measurements of this calibration facility. Measurements are performed from $800{ }^{\circ} \mathrm{C}$ to $2300^{\circ} \mathrm{C}$ for lamps, from $800{ }^{\circ} \mathrm{C}$ to $2700{ }^{\circ} \mathrm{C}$ for radiation thermometers, and extrapolated to $4200{ }^{\circ} \mathrm{C}$ for some disappearing filament optical pyrometers.

The NIST PEP is the transfer device used to compare the spectral radiances of the sources by the direct substitution method. The signals are corrected for size of source, amplifier gain, and linearity. With these corrections, the spectral radiance and the radiance temperature can be determined from eqs (12) and (13). The NIST PEP is a filtered radiometer that uses two interference filters to select the bandpass. The spectral bandwidth is $5 \mathrm{~nm}$ with a mean effective wavelength of $655.3 \mathrm{~nm}$. A photomultiplier tube with an S-20 spectral response is used in the dc mode. The measurement spot size is a $0.6 \mathrm{~mm}$ by $0.8 \mathrm{~mm}$ rectangle.

A high stability vacuum lamp operated at a single radiance temperature of approximately $1255^{\circ} \mathrm{C}$ is the working standard (WS). By equating eqs (9) and (13), the spectral radiance ratio is

$$
r_{1}=\frac{L_{\lambda}\left(T_{\mathrm{WSI}}\right)}{L_{\lambda}\left(T_{\mathrm{Au}}\right)}=\frac{S_{\mathrm{WSI}}}{S_{\mathrm{Au}}} .
$$

After applying correction factors to the signals in eq (15) for amplifier calibration $\left(C_{\mathrm{A}}\right)$, linearity $\left(C_{\mathrm{L}}\right)$, and size of source $\left(C_{\mathrm{S}}\right)$, the spectral radiance of the WS1 lamp can be written as

$$
L_{\mathrm{ws}}=\frac{\varepsilon_{\mathrm{Au}} \cdot c_{1 L}}{n_{\lambda}^{2} \cdot \lambda^{5} \cdot\left[\exp \left(\frac{c_{2}}{n_{\lambda} \cdot \lambda \cdot T_{A u}}\right)-1\right]} \cdot r_{1} \cdot \frac{\left(C_{\mathrm{A}} \cdot C_{\mathrm{L}} \cdot C_{\mathrm{S}} \cdot G\right)_{\mathrm{WS}}}{\left(C_{\mathrm{A}} \cdot C_{\mathrm{L}} \cdot C_{\mathrm{S}} \cdot G\right)_{\mathrm{Au}}} .
$$

References regarding linearity issues are presented in Section 3.3.5. The uncertainty analysis in Section 3.6 can then be derived from eq (15) for the NIST radiance temperature scale up to the calibration of the spectral radiance of the working standard lamp.

\subsection{Temperature standards}

\subsubsection{Gold-point blackbody}

In the RTCL, a gold fixed-point blackbody with a calculated emissivity of 0.9999 , designed and built by the NIST Optical Technology Division, is the primary standard used to realize the 1990 NIST Radiance Temperature Scale. The blackbody in figure 3 consists of a graphite cavity, a crucible of gold, and a cylindrical heat-pipe furnace. The cavity, which is 
$76 \mathrm{~mm}$ in length and $6 \mathrm{~mm}$ in diameter and has a $60^{\circ}$ conical end shown, is made from Ultra "F" grade graphite (spectrographic purities of $10 \mathrm{ppm}$ or less). Surrounding this cavity is a crucible containing $0.99999 \%$ pure gold. The cavity, along with graphite rings and silica glass spacers, is placed in an alumina tube. The front rings define a solid angle with a $f / 6$ field of view, while the back rings support the thermocouple. A furnace (see fig. 3), which consists of a sodium heatpipe heated by two semi-cylindrical ceramic heater elements inside of a mullite tube, is enclosed in a water-cooled housing $(631 \mathrm{~mL} / \mathrm{min})$ and is operated in an argon environment $(37 \mathrm{~mL} / \mathrm{min}$ with furnace door closed and $235 \mathrm{~mL} / \mathrm{min}$ with furnace door open).

The gold-point blackbody liquid-to-solid phase transition is shown in figure 4. The duration of a melt or freeze plateau is approximately $40 \mathrm{~min}$, and the time delay between these observation periods is about $45 \mathrm{~min}$. Measurements during the freeze cycle show a negative slope of $20 \mathrm{mK}$ in $30 \mathrm{~min}$. The blackbody is slowly heated over about $8 \mathrm{~h}$ before reaching the melting point and is typically ramped up over night so that it is held just below the melting point the next morning. After the initial heating at $8 \mathrm{~A}$, the melt cycle is begun by increasing the current to $8.5 \mathrm{~A}$ until the temperature reaches $1071^{\circ} \mathrm{C}$. The freeze cycle is begun by lowering the blackbody current to $7.95 \mathrm{~A}$. Then the blackbody current is raised to $8.5 \mathrm{~A}$ at $1050{ }^{\circ} \mathrm{C}$ to begin the melt cycle again.

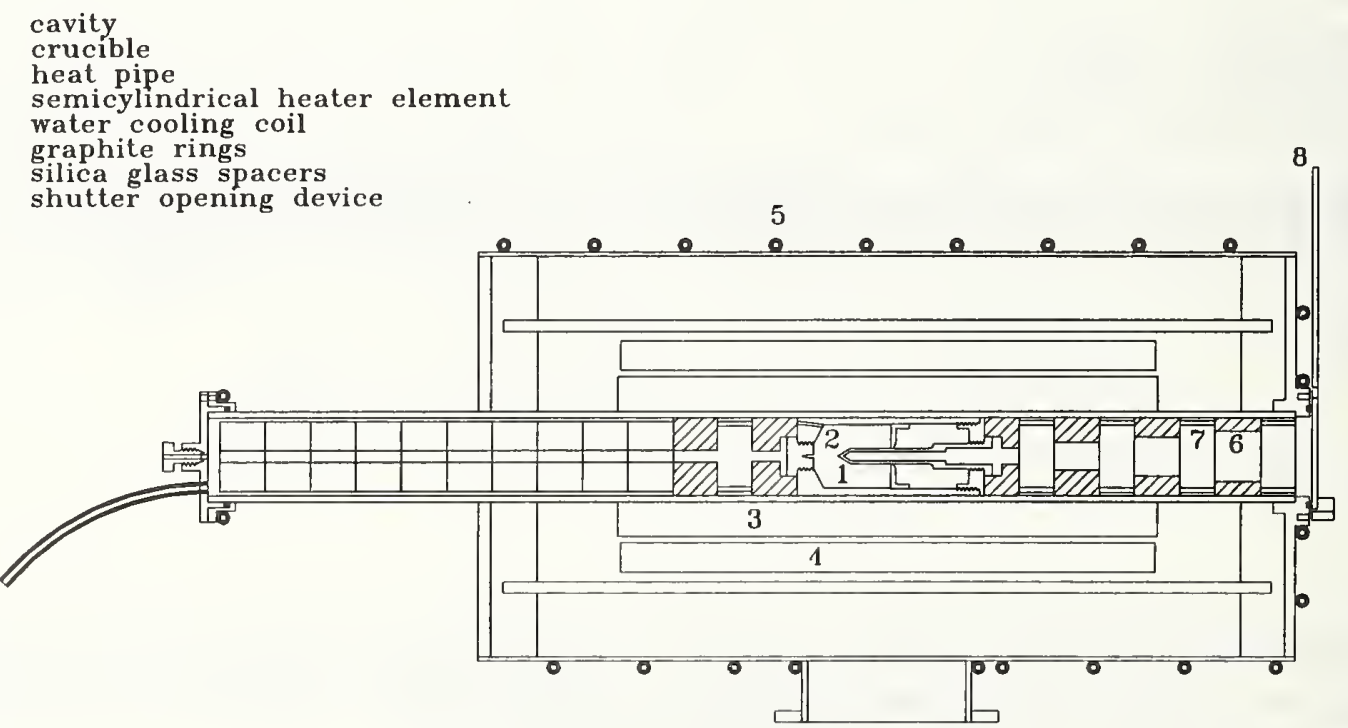

Figure 3. Schematic of gold-point blackbody. 


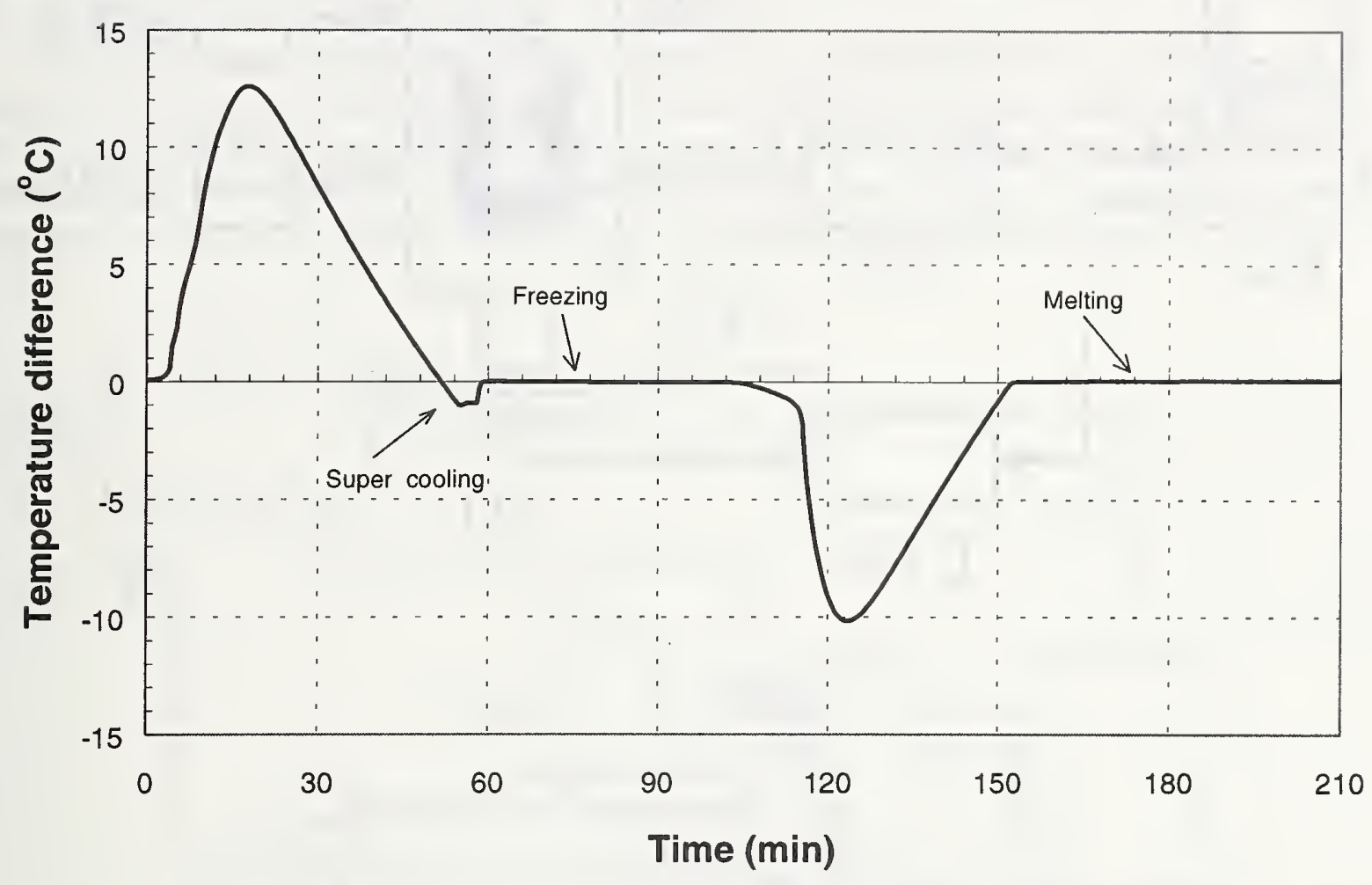

Figure 4. Gold-point blackbody liquid-to-solid phase transition.

The gold-point blackbody control system shown in figure 5 consists of a 286-based personal computer, which regulates the power supply and reads the thermocouple measurements from the digital voltmeter. To monitor the set points, platinum and platinum $/ 10 \%$ rhodium (type $S$ ) thermocouples are inserted into round double bore alumina tubing and are placed in a silica glass sheathing which makes contact with the rear end of the crucible.

\subsubsection{Tungsten ribbon filament lamps}

Because of a reproducible radiance temperature versus lamp current relationship, tungsten ribbon filament lamps are used in the radiance temperature scale realization and are issued as radiance temperature standards. Vacuum lamps are typically used for temperatures from $800{ }^{\circ} \mathrm{C}$ to $1700{ }^{\circ} \mathrm{C}$, and argon gas-filled lamps for temperatures from $1300^{\circ} \mathrm{C}$ to $2300{ }^{\circ} \mathrm{C}$. Gas is introduced into the high temperature lamps to slow down the evaporation rate of the tungsten. The evaporated tungsten atoms collide with the gas atoms, lose their energy, and re-condense on the filament surface before being swept away by convection [9]. 


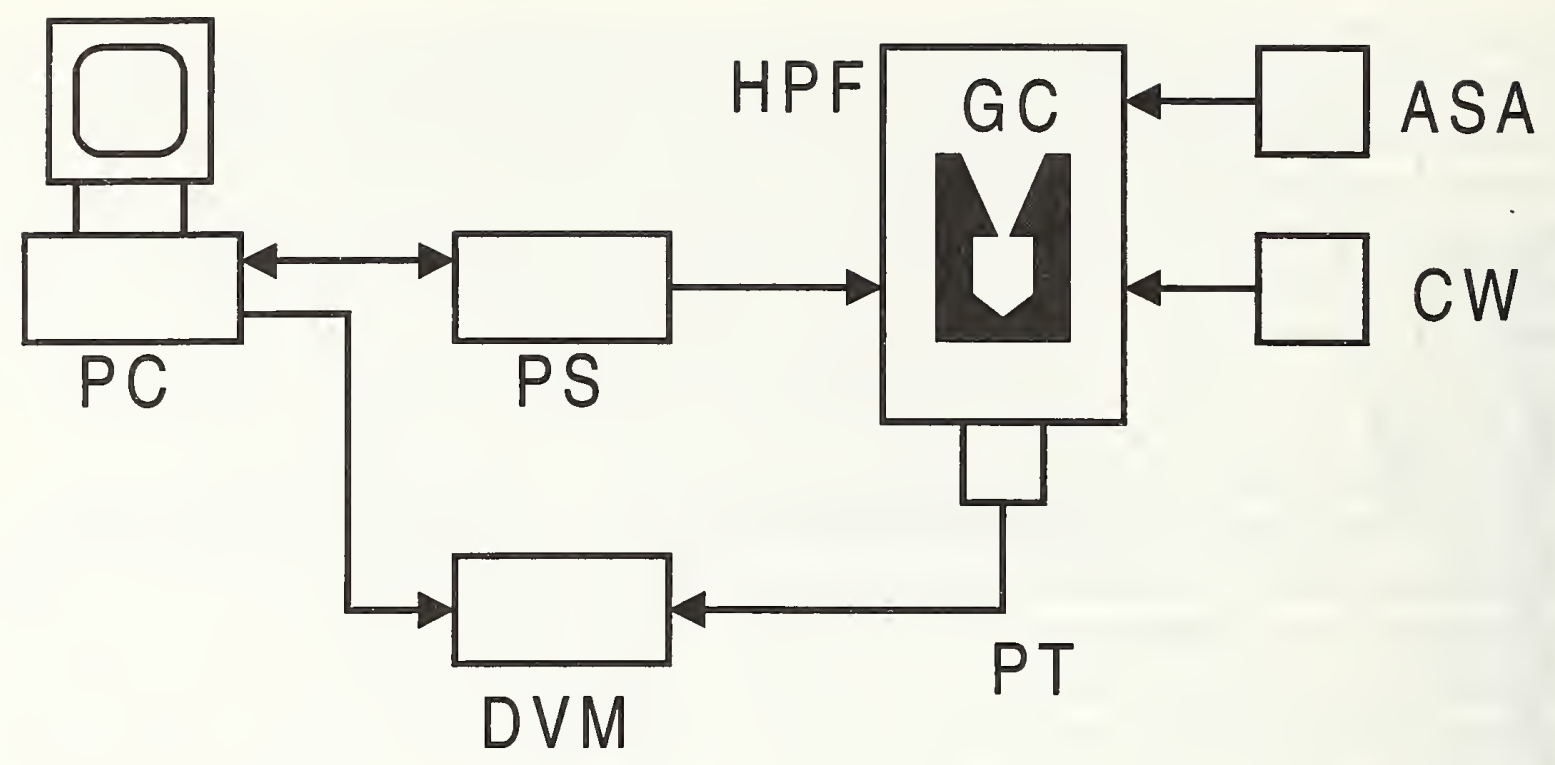

LEGEND

$\begin{array}{ll}\text { ASA } & \text { Argon Supply and Alarm } \\ \text { CW } & 55^{\circ} \mathrm{C} \text { Chilled Water/Cold Water Switch } \\ \text { DVM } & \text { Digital Voltmeter } \\ \text { GC } & \text { Gold-filled Crucible } \\ \text { HPF } & \text { Heat Pipe Furnace } \\ \text { PC } & \text { Personal Computer } \\ \text { PS } & \text { Power Supply } \\ \text { PT } & \text { Pt/Pt-10\% Rh Thermocouple (Type S) }\end{array}$

Figure 5. Gold-point blackbody control system.

The lamps have cylindrical glass envelopes and are operated on direct current with the base facing downward. A computer-stabilized power supply regulates the lamp current to within $\pm 0.2 \mathrm{~mA}$. A schematic of the lamp current monitoring system is shown in figure 6 . The filament is connected to the screw base by wires, which conduct the current and thereby minimize contact problems associated with the screw bases. To achieve the required precise alignment, the lamps are rigidly fastened in source mounts that allow translation along and rotation about three mutually perpendicular axes. Located at the intersection of the center of the lamp filament at the height of the notch opening, the rectangular calibration area on the surface of the lamp filament is $0.6 \mathrm{~mm}$ wide by $0.8 \mathrm{~mm}$ high. The notch is about midway along one edge of the filament. An alignment mark or an etched arrow is placed on the envelope opposite the side viewed by the pyrometer to permit reproducible angular positioning. Then the lamp is rotated so that the arrowhead is centered at the mouth of the notch.

Some lamps use a pointer that is connected to the filament support to indicate the calibration area. The advantage to this approach is a more uniform filament. However, one 
disadvantage is the requirement of predictable filament expansion and contraction for reproducible calibration area indication by the pointer.

Until 1995, the NIST issued General Electric ${ }^{3}$ type 30A/6V/T24 ribbon filament lamps as radiance temperature standards. However, General Electric stopped manufacturing these lamps in 1990. The lamp had a glass cylindrical envelope that was $300 \mathrm{~mm}$ long and $75 \mathrm{~mm}$ in diameter and a filament that was $3 \mathrm{~mm}$ wide and $50 \mathrm{~mm}$ long. Figure 7 shows typical lamp currents as a function of temperature for the General Electric ribbon filament lamps.

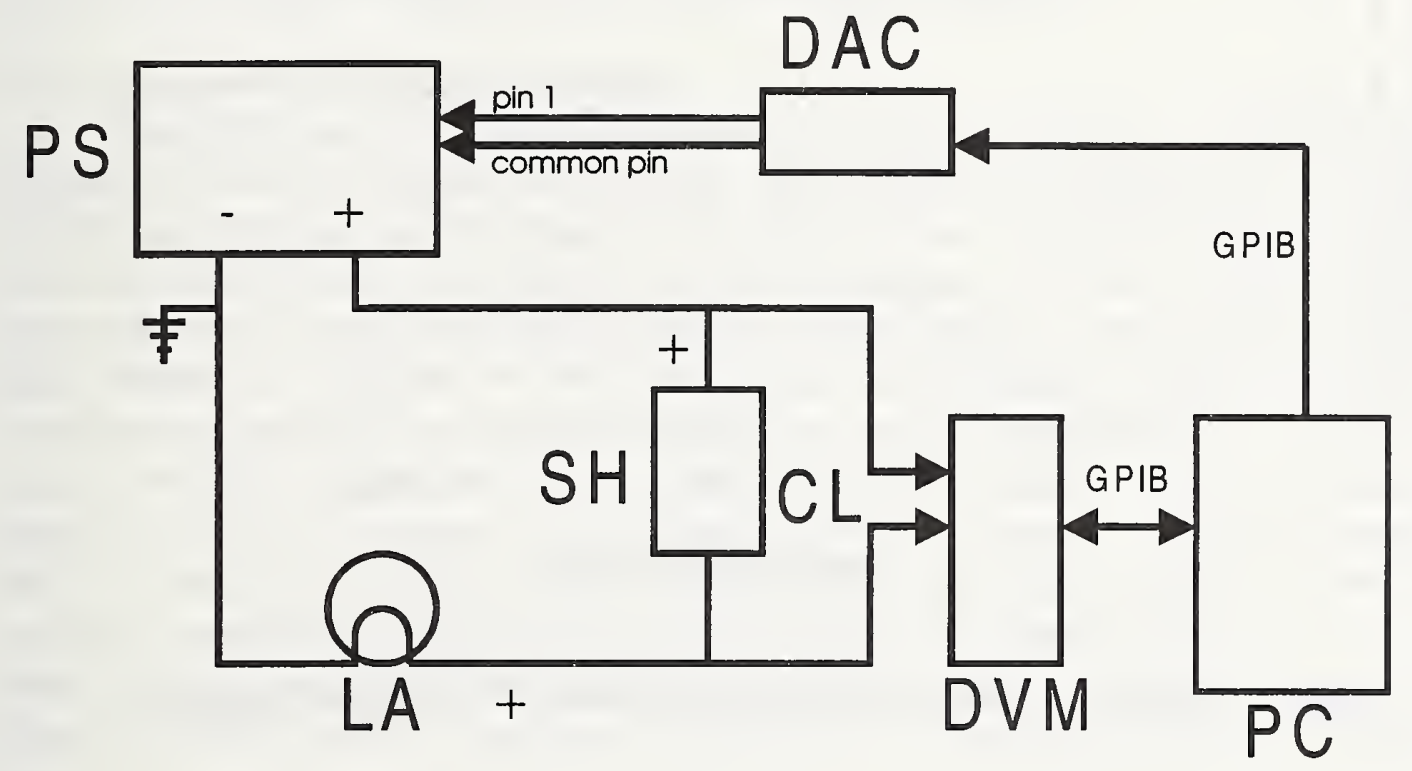

\section{LEGEND}

$\begin{array}{ll}\text { CL } & \text { Current Sensing Leads } \\ \text { DAC } & \text { Two-channel 12-bit D/A Converter } \\ \text { DVM } & \text { Digital Voltmeter } \\ \text { GPIB } & \text { GPIB IEEE-488 Interface } \\ \text { LA } & \text { Lamp } \\ \text { PC } & \text { Personal Computer } \\ \text { PS } & \text { Power Suppy } \\ \text { SH } & 0.1 \Omega \text { Shunt }\end{array}$

Figure 6. Schematic of lamp current monitoring system.

${ }^{3}$ Certain commercial equipment, instruments, or materials are identified in this paper for the sole purpose of adequately describing experimental or test procedures. Such identification does not imply recommendation or endorsement by the National Institute of Standards and Technology of a particular product, nor does it imply that the materials or equipment identified are necessarily the best available for the purpose it serves. 


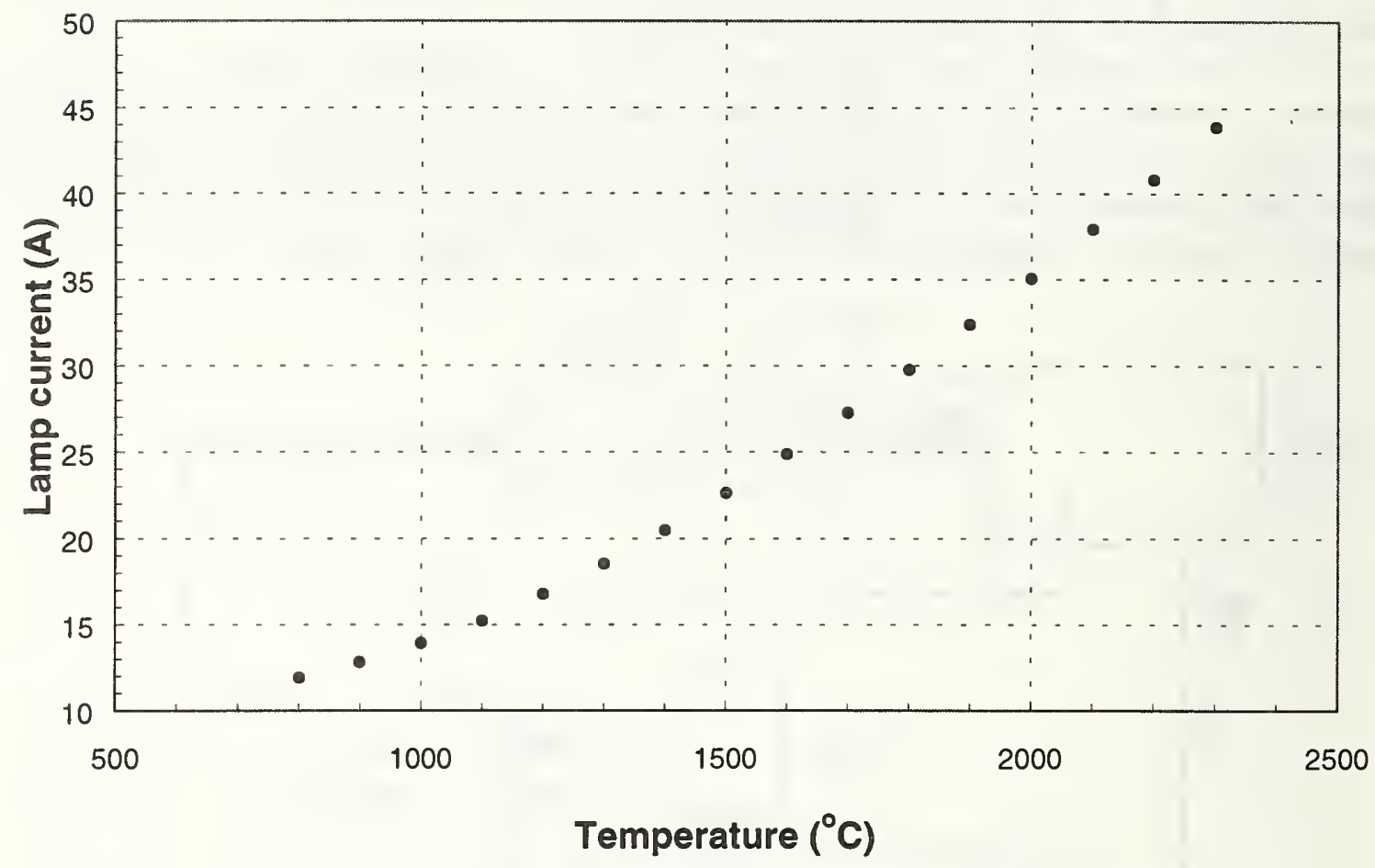

Figure 7. Typical lamp currents for the General Electric 30A/T24/6 ribbon filament lamp.

The NIST is currently issuing U.K. General Electric Company (GEC) lamps, although the lamps are no longer available from this source. The GEC lamps (type 20/G and 20/V) have glass cylindrical envelopes that are $235 \mathrm{~mm}$ long with a $64 \mathrm{~mm}$ diameter. The $20 / \mathrm{V}$ is a vacuum lamp with a filament $1 \mathrm{~mm}$ wide by $50 \mathrm{~mm}$ long and requires about $10 \mathrm{~A} \mathrm{dc}$ at $1500{ }^{\circ} \mathrm{C}$. The $20 / \mathrm{G}$ is a gas-filled lamp with a $2 \mathrm{~mm}$ wide by $30 \mathrm{~mm}$ long filament and requires about $20 \mathrm{~A} \mathrm{dc}$ at $2300{ }^{\circ} \mathrm{C}$.

In 1992, Type TRU 1100-2350 lamps were purchased from the Moscow Lamp Factory (Russia) for testing as radiance temperature standards. Due to a decline in requests for radiance temperature standard lamps, the testing was not done. At $2300^{\circ} \mathrm{C}$, about $25 \mathrm{~A}$ dc current is required from the gas-filled lamp, which has a cylindrical envelope, a $2.5 \mathrm{~mm}$ wide by $20 \mathrm{~mm}$ long filament, and an alignment pointer. The TRU lamps, which have a $35 \mathrm{~mm}$ silica glass window that projects about $5 \mathrm{~mm}$ from the envelope, were used in addition to the GE lamp in the NIST/VNIOFFI spectral radiance intercomparison [10].

The NIST has also bought type 24/G lamps with double silica glass windows from Polaron Engineering LTD (U. K.) for use as working and check standards. These lamps are similar in design and construction to the GEC lamps.

\subsubsection{Working standard lamps}

A vacuum tungsten ribbon filament lamp of the Quinn-Lee type [11,12] is used in the temperature scale realization as the secondary temperature standard which maintains the 
temperature scale between scale realizations and as the transfer standard for calibration measurements. The temperature of the working standard lamp (serial number SL20) is determined by spectral comparison with the gold-point blackbody. A drawing of this lamp is shown in figure 8 . This lamp is operated at a single current $(7.7788 \mathrm{~A} \mathrm{dc})$ to produce a spectral radiance about eight times higher than that of the gold-point blackbody at $655.3 \mathrm{~nm}$ (a radiance temperature of about $1530 \mathrm{~K}$ ). This lamp is stable to better than $0.1^{\circ} \mathrm{C}$ over $100 \mathrm{~h}$ when operated under these single-level conditions. A graph of the calibration history of the working standard from August 1989 to February 1996 is shown in figure 9.

\subsubsection{Variable-temperature blackbody}

The NIST uses a commercial variable-temperature blackbody (VTBB) for its radiance temperature transfer standard (See fig. 10). This VTBB was manufactured by Thermogage Inc. in Frostburg, MD and was supplied with the Type II dual blackbody assembly $(2.54 \mathrm{~cm}$ or 1 in ID cavity), the $48 \mathrm{~kW}$ power supply, a control program, the model 7000-1 (4 range) optical pyrometer, and a digital temperature computer control module. Modifications requested by the NIST include the addition of the water-cooled semi-cylindrical mirrors, and enlarging the extension tube opening to accommodate measurements with the NIST PEP.

The VTBB is operated between $700{ }^{\circ} \mathrm{C}$ and $2700{ }^{\circ} \mathrm{C}$. The ranges, which are selected by placing different size apertures on the optical control pyrometer, are the low range $\left(700{ }^{\circ} \mathrm{C}\right.$ to $\left.1300{ }^{\circ} \mathrm{C}\right)$, the medium range $\left(1300^{\circ} \mathrm{C}\right.$ to $\left.1800^{\circ} \mathrm{C}\right)$, the high range $\left(1800^{\circ} \mathrm{C}\right.$ to $\left.2500{ }^{\circ} \mathrm{C}\right)$, and the extra high range $\left(2500{ }^{\circ} \mathrm{C}\right.$ to $\left.2700^{\circ} \mathrm{C}\right)$. The electrodes are water-cooled by using a $13^{\circ} \mathrm{C}\left(55^{\circ} \mathrm{F}\right)$ chilled water source. Before the blackbody is turned on, argon gas displaces the air in the cavity. When the VTBB cavity is operating, the argon exits from both the front and back extension tubes.

The variable-temperature blackbody control system regulates the blackbody temperature to within $\pm 0.1{ }^{\circ} \mathrm{C}$ (see fig. 11). The NIST measures the uniformity of the center partition of the Thermogage heater elements, and uses those with a spatial uniformity of better than $\pm 0.2^{\circ} \mathrm{C}$ at $2000{ }^{\circ} \mathrm{C}$ over an area of $10 \mathrm{~mm}$ diameter (see fig. 12). The blackbody heats up to the operating point in less than $30 \mathrm{~min}$ and responds quickly to temperature changes (see fig. 13). The day-today stability of the blackbody is better than $\pm 0.3^{\circ} \mathrm{C}$, and the 6-month stability is within $\pm 2{ }^{\circ} \mathrm{C}$.

The VTBB operates between $800^{\circ} \mathrm{C}$ and $2700{ }^{\circ} \mathrm{C}$ with an estimated emissivity of 0.99 from analytical modeling. The temperature distribution within the VTBB cavity is less than $50{ }^{\circ} \mathrm{C}$. The blackbody cavity is composed of a single piece of graphite, which is specially tapered for achieving high temperature uniformity. This graphite tube is cylindrically hollow on both ends to form two $2.54 \mathrm{~cm}$ diameter cavities with a common partition in the center. One cavity is used for temperature control, and the other cavity is the blackbody source. 


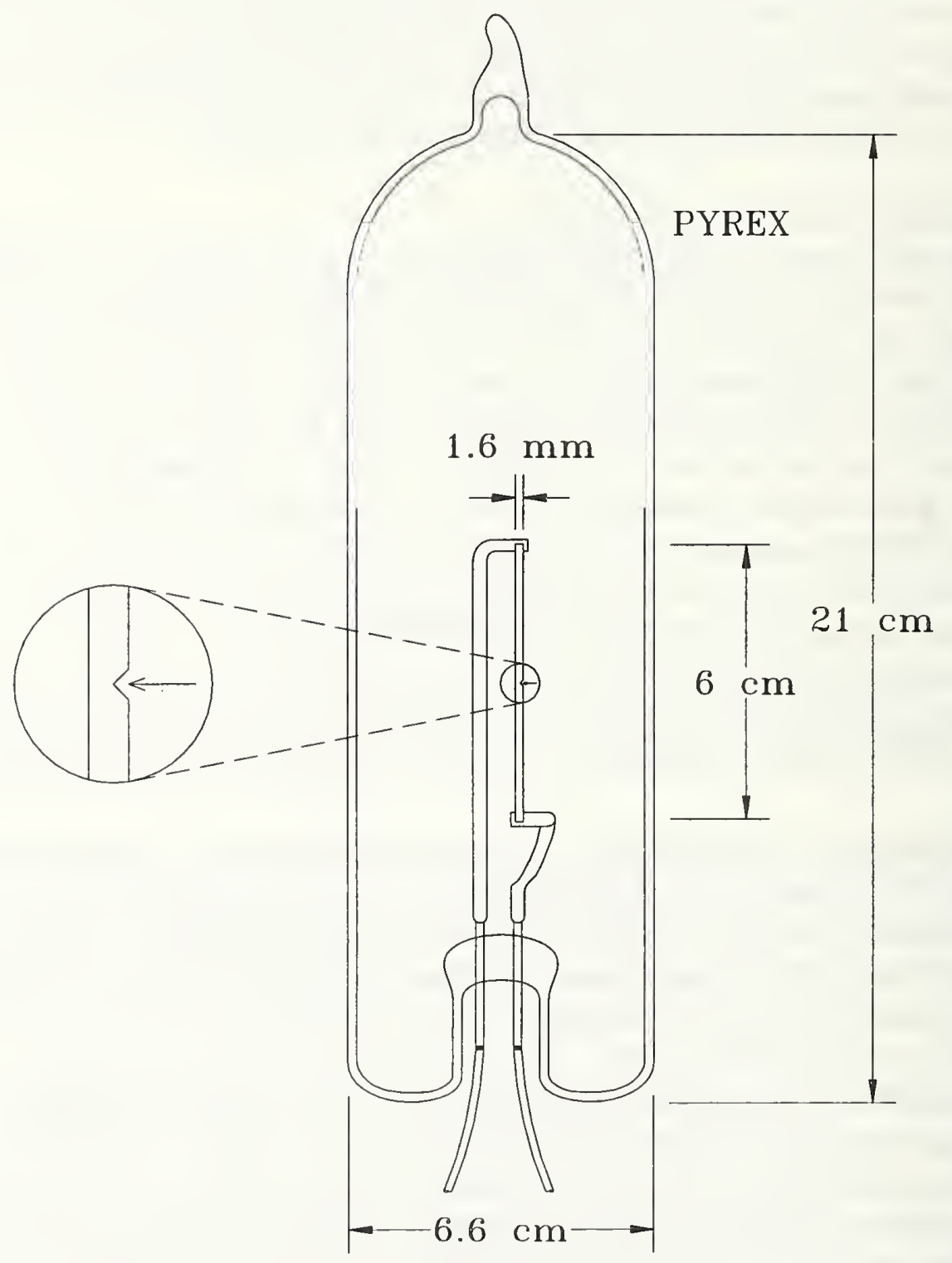

Figure 8. Ribbon filament lamp. 


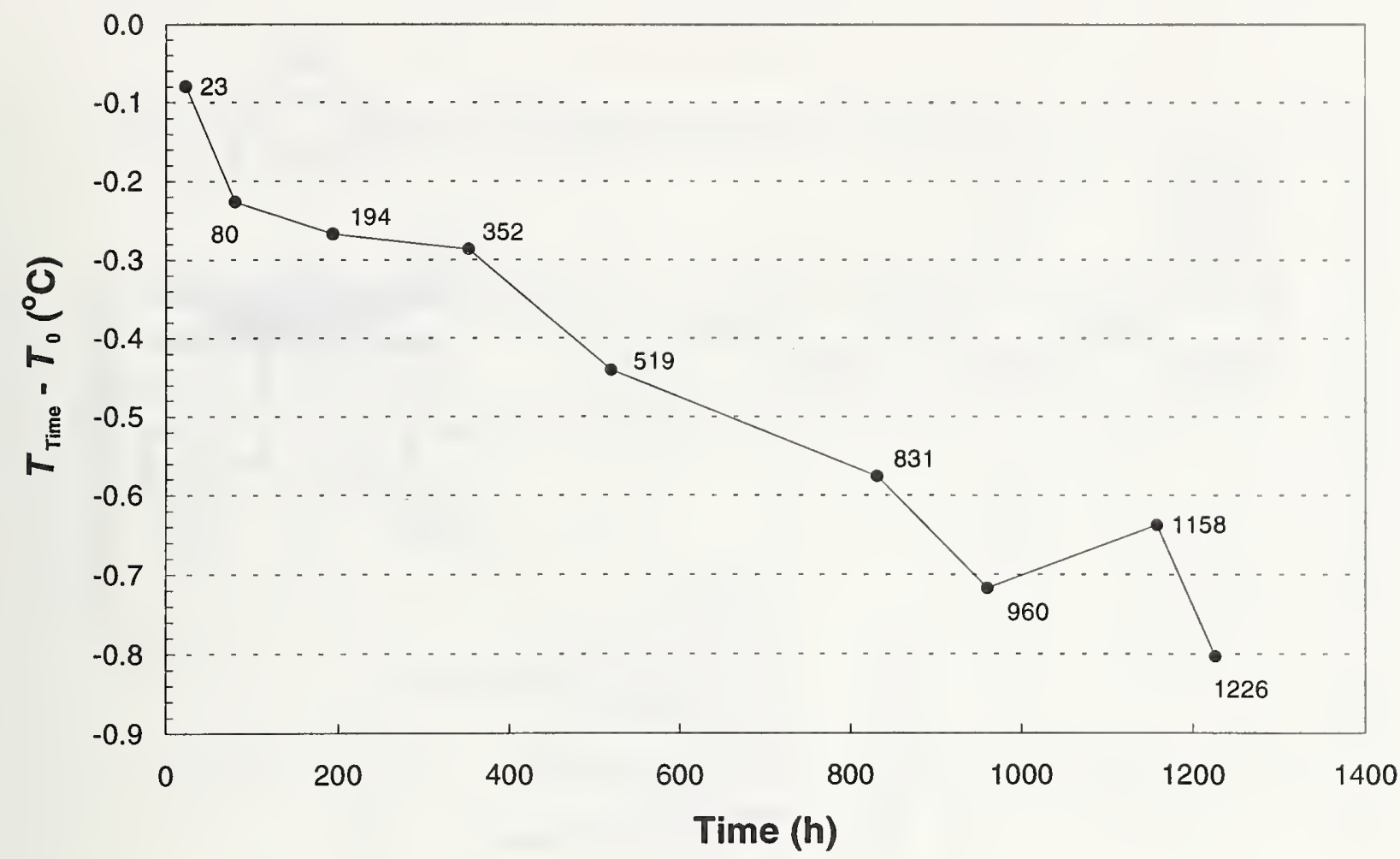

Figure 9. Calibration history of the WS (no. SL20).

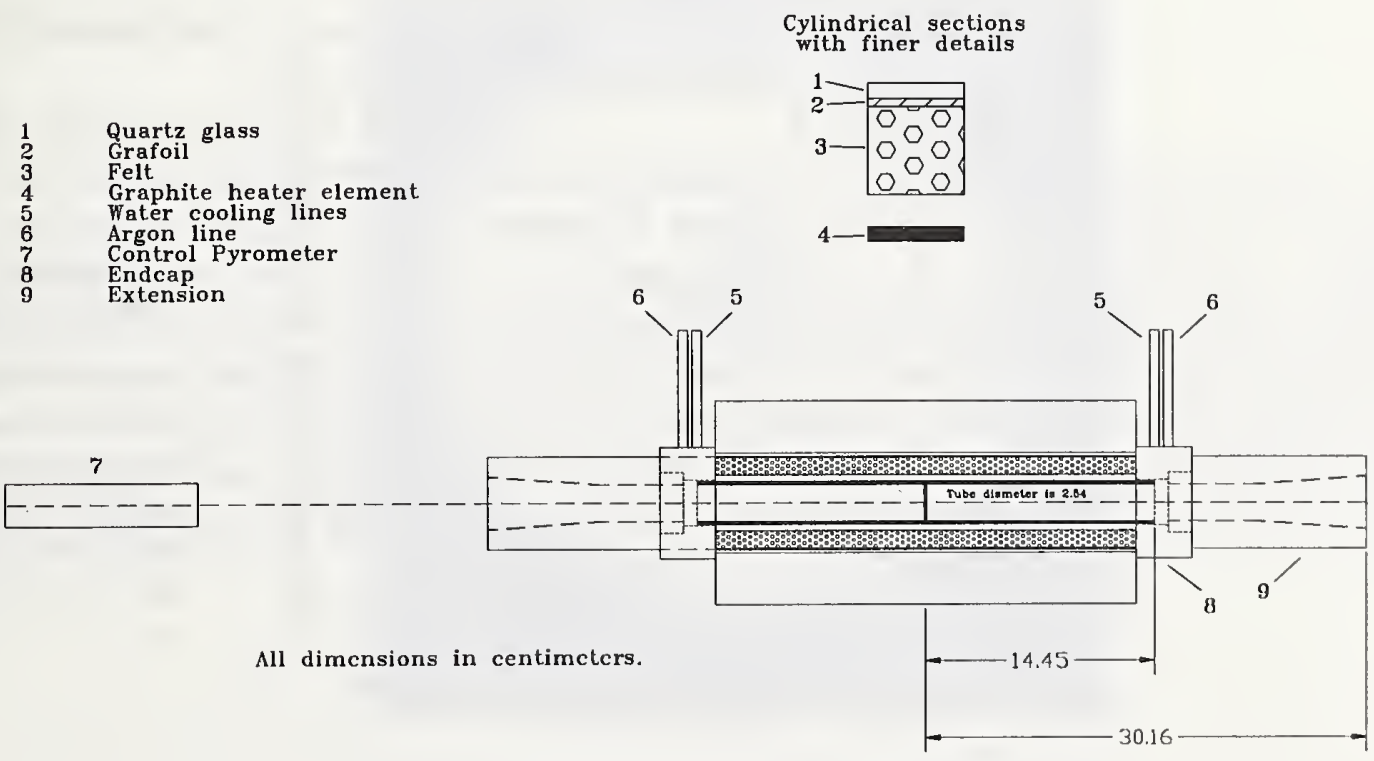

Figure 10. Schematic of variable-temperature blackbody. 


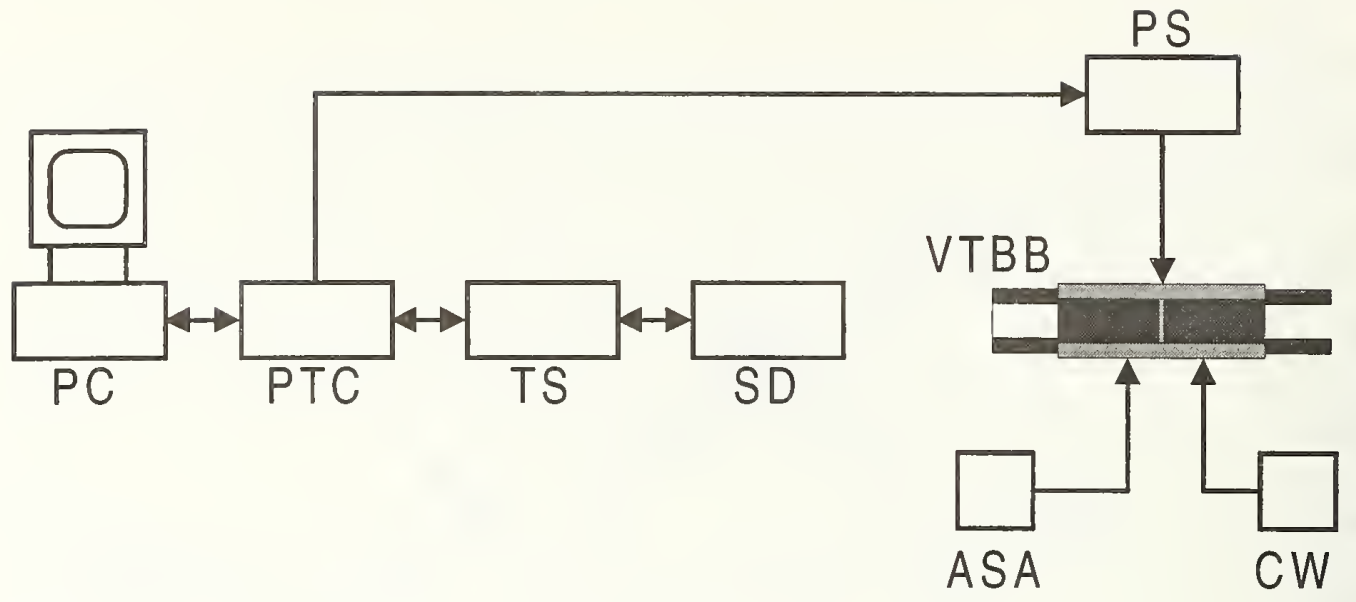

\section{LEGEND}

$\begin{array}{ll}\text { ASA } & \text { Argan Supply and Alarm } \\ \text { CW } & 55^{\circ} \mathrm{C} \text { Chilled Water/Cald Water Switch } \\ \text { PC } & \text { Persanal Camputer } \\ \text { PS } & \text { Power Supply } \\ \text { PTC } & \text { PID Temperature Contraller } \\ \text { SD } & \text { Silican Detectar } \\ \text { TS } & \text { Thermal Stabilizer } \\ \text { VTBB } & \text { Variable Temperature Blackbady }\end{array}$

Figure 11. Variable-temperature blackbody control system.

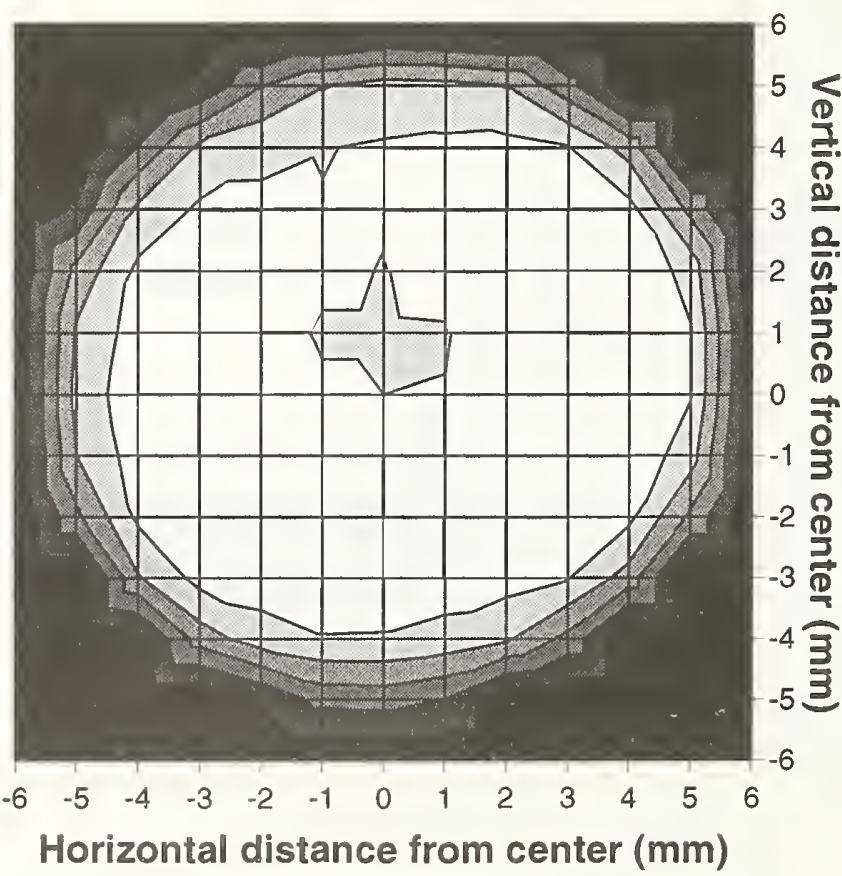

Temperature difference $\left({ }^{\circ} \mathrm{C}\right)$

$\square 0$ to 0.2

口- 0.2 to 0

- -0.4 to -0.2

-0.6 to -0.4

-0.8 to -0.6

$=-1$ to -0.8

Figure 12. Spatial scan of the variable-temperature blackbody at $2000^{\circ} \mathrm{C}$. The temperature differences are from the center position $(0,0)$. 


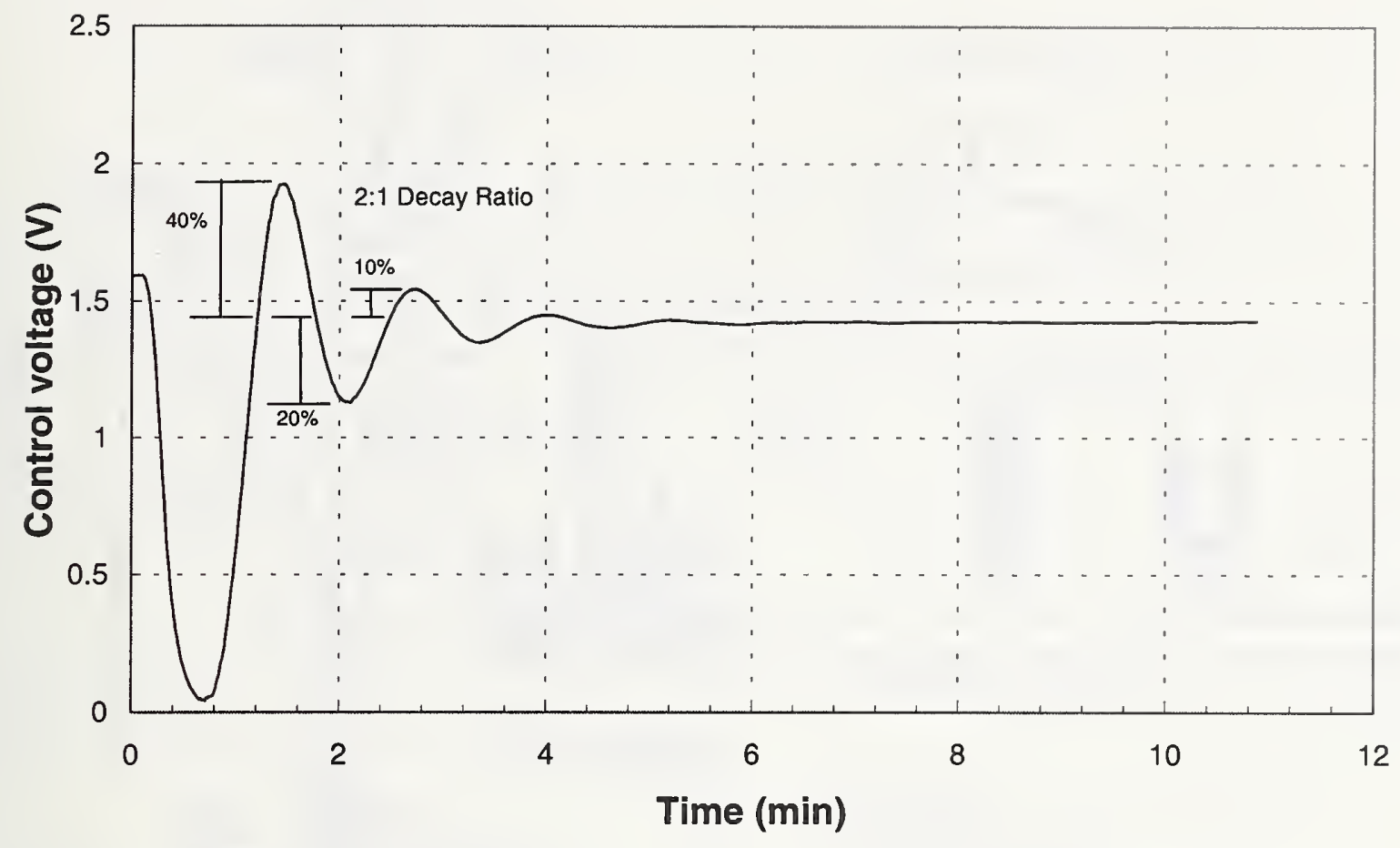

Figure 13. Variable temperature blackbody control. After decreasing the set point by $100{ }^{\circ} \mathrm{C}$, the blackbody stabilizes in less than $10 \mathrm{~min}$.

\subsection{NIST photoelectric pyrometer}

\subsubsection{Measurement system}

The PEP is a NIST designed transfer radiometer, which uses refractive optics to image the source onto the detector. The schematic of the NIST PEP is shown in figure 14. A drawing of the measurement system is shown in figure 15. The measurement system is completely automated and controlled by a personal computer, while the laboratory environment is monitored by temperature and relative humidity sensors. Lamps and blackbodies are positioned onto the optical axis of the PEP using a closed-loop motor controller system that allows positioning to within $0.01 \mathrm{~mm}$. The components of the pyrometer are discussed in the next three sections followed by a discussion of the method used to characterize the system in the last three sections. 

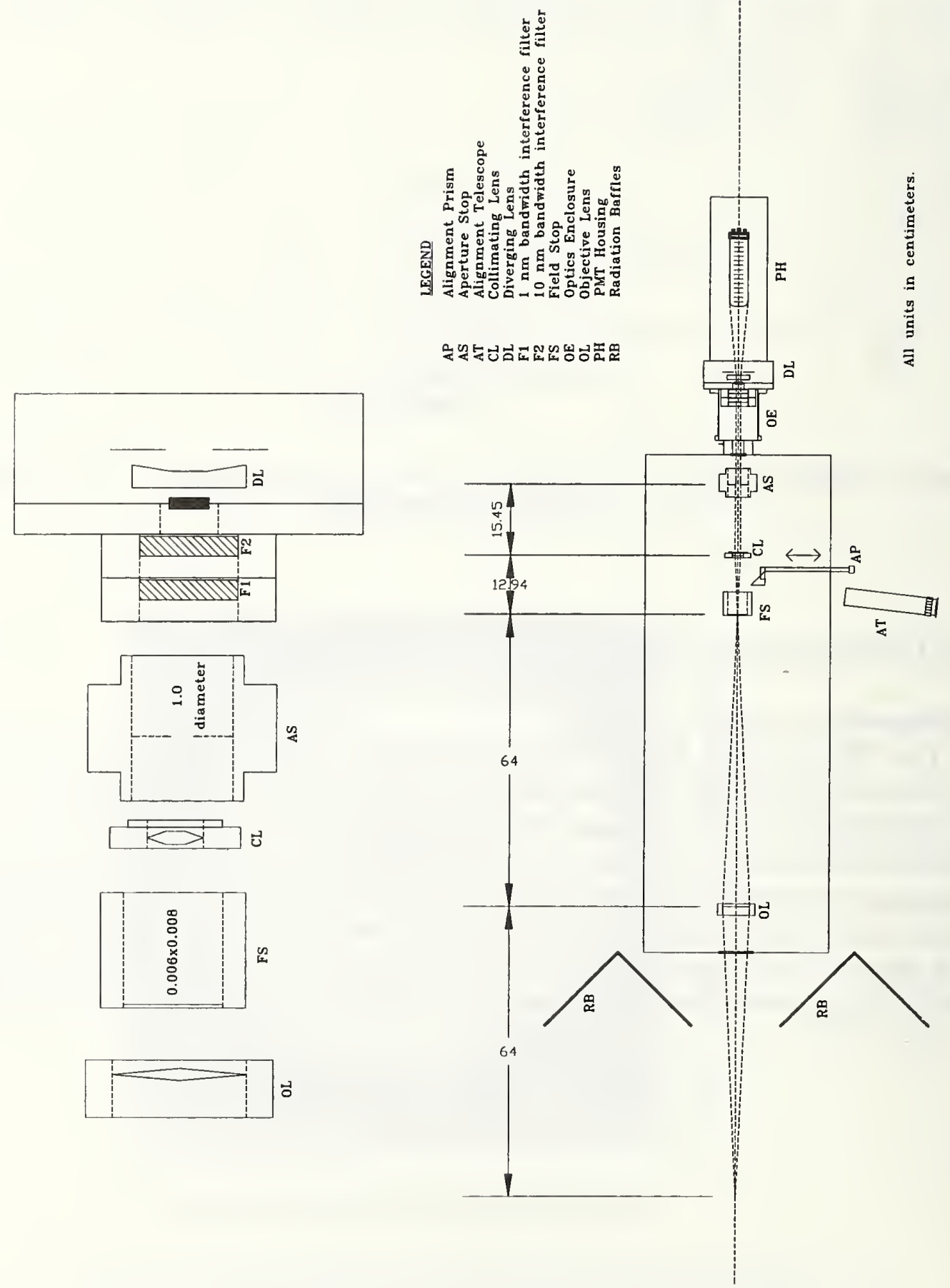

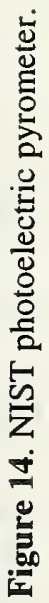




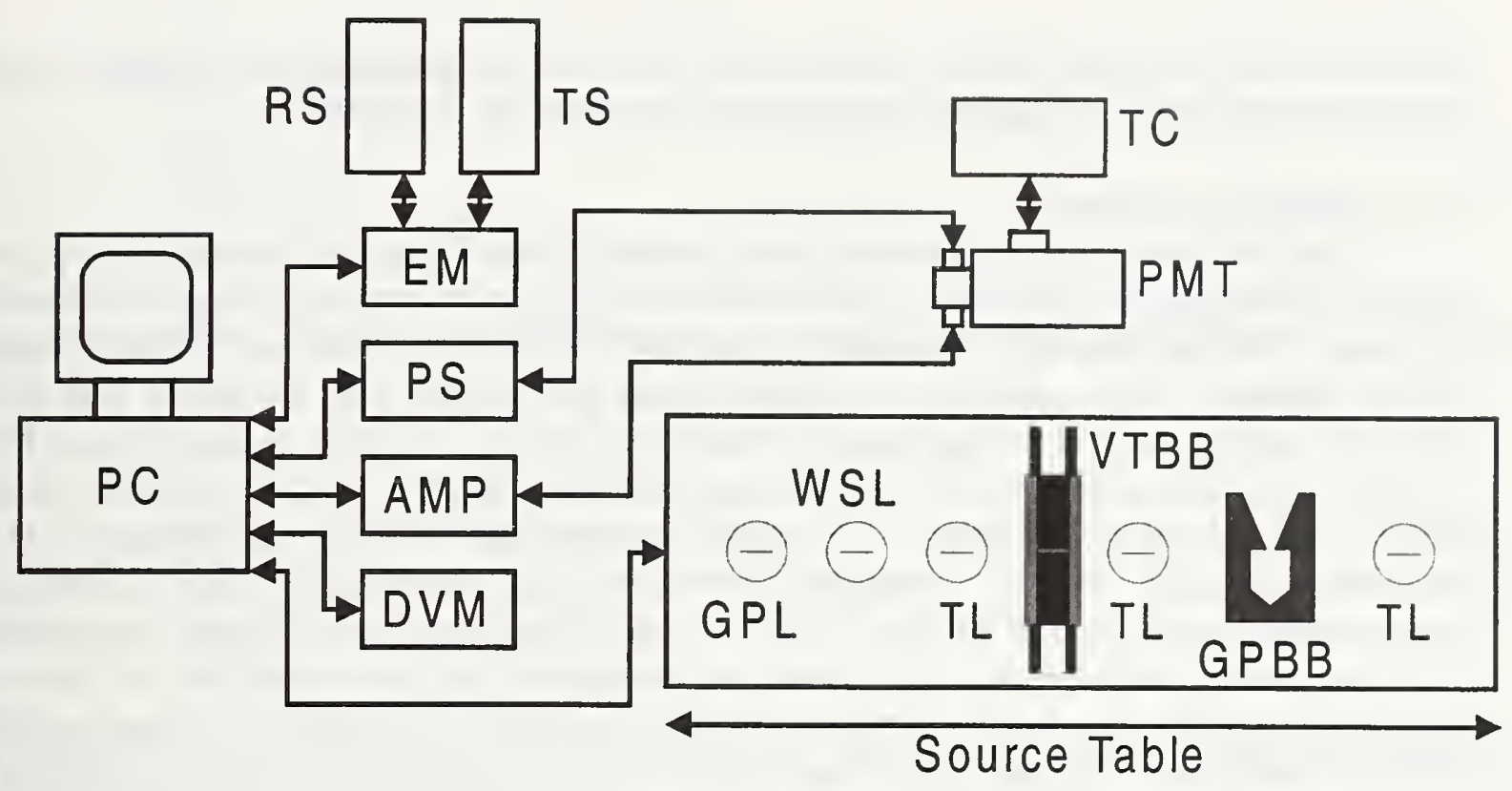

\begin{tabular}{|c|c|c|c|}
\hline \multicolumn{4}{|c|}{ LEGEND } \\
\hline AMP & Amplifier & PS & Power Supply \\
\hline DVM & Digital Voltmeter & RS & Room Humidity Sensor \\
\hline EM & Environmental Monitor & TC & Thermoelectric Cooler \\
\hline GPBB & Gold-point Blackbody & $\mathrm{TL}$ & Test Lamp \\
\hline GPL & Gold-point Lamp & TS & Temperature Sensor \\
\hline PC & Personal Computer & VIBB & Variable Temperature Blackbody \\
\hline PMT & Photomultiplier Tube & WSL & Working Standard Lamp \\
\hline
\end{tabular}

Figure 15. NIST radiance temperature laboratory measurement system.

\subsubsection{Optical system}

The first element is the objective lens (OL) which is a $5.8 \mathrm{~cm}$ diameter bi-convex lens with a focal length of $32 \mathrm{~cm}$. The source is placed at twice the focal length from the lens and is imaged with unit magnification onto the field stop (FS), which is located at the back radius of curvature. The dimensions of the rectangular field stop are $0.6 \mathrm{~mm}$ wide by $0.8 \mathrm{~mm}$ high. The field stop defines the size and shape of the calibration target area. The next element is the collimating lens (CL), which is a $2.45 \mathrm{~cm}$ diameter bi-convex lens with a focal length of $12.94 \mathrm{~cm}$. The field stop is placed at the front focal point of this lens with the result being a collimated beam with a diameter of approximately $1.2 \mathrm{~cm}$. Next the aperture stop (AS) reduces the beam diameter to $1 \mathrm{~cm}$. The beam continues through two interference filters ( $F 1$ \& F2) through a plano-concave diverging lens that spreads the radiant flux over the photomultiplier tube cathode. The beam completely covers the surface of the cathode.

In all cases, the source overfills the objective lens and the aperture stop that corresponds to a system with an $f$-number of 13 . The solid angle $\left(4.67 \times 10^{-3} \mathrm{sr}\right)$ used is a cone having a half angle of $0.0772 \mathrm{rad}\left(4.4^{\circ}\right)$, the apex of which is at the center of the field stop.

To align sources, the field stop is removed, and the alignment prism (AP) is placed in the 
path behind the field stop mount. The operator views the lamp filament or blackbody aperture and moves the filament or aperture to the target area viewed by the PEP.

\subsubsection{Interference filters}

The PEP uses two interference filters centered on $655.3 \mathrm{~nm}$ to produce a very narrow spectral bandwidth filter pack with transmitances in the wings six orders of magnitude lower than the peak. The first filter is a three-cavity type, and the second is a four-cavity type. Both are $5.08 \mathrm{~cm}$ diameter filters made from polished optical quality glass and are coated with a metal film. The regular spectral transmittances of the filters (see fig. 16) were measured from $400 \mathrm{~nm}$ to $1000 \mathrm{~nm}$ in $0.2 \mathrm{~nm}$ steps (with a relative expanded uncertainty of $0.3 \%$ at $655 \mathrm{~nm}$ ) using the NIST Transfer Spectrophotometer for Regular Transmittance described in reference [13]. The expanded uncertainty of the wavelength calibration of the spectrometer used to make these measurements was $0.5 \mathrm{~nm}$ at $655 \mathrm{~nm}$. The first and second filters have spectral bandwidths of $1 \mathrm{~nm}$ and $10 \mathrm{~nm}$, respectively. The central wavelength of the filters measured in series was determined to be $654.9 \mathrm{~nm}$ with a bandwidth of $2.4 \mathrm{~nm}$ when using transmittance data around the peak from $644 \mathrm{~nm}$ to $667 \mathrm{~nm}$. For the full spectral range, the measured central wavelength was $836.6 \mathrm{~nm}$ with a bandwidth of $9.4 \mathrm{~nm}$. The central wavelength $\lambda_{c}$ was determined from the following equation for determining the effective wavelength,

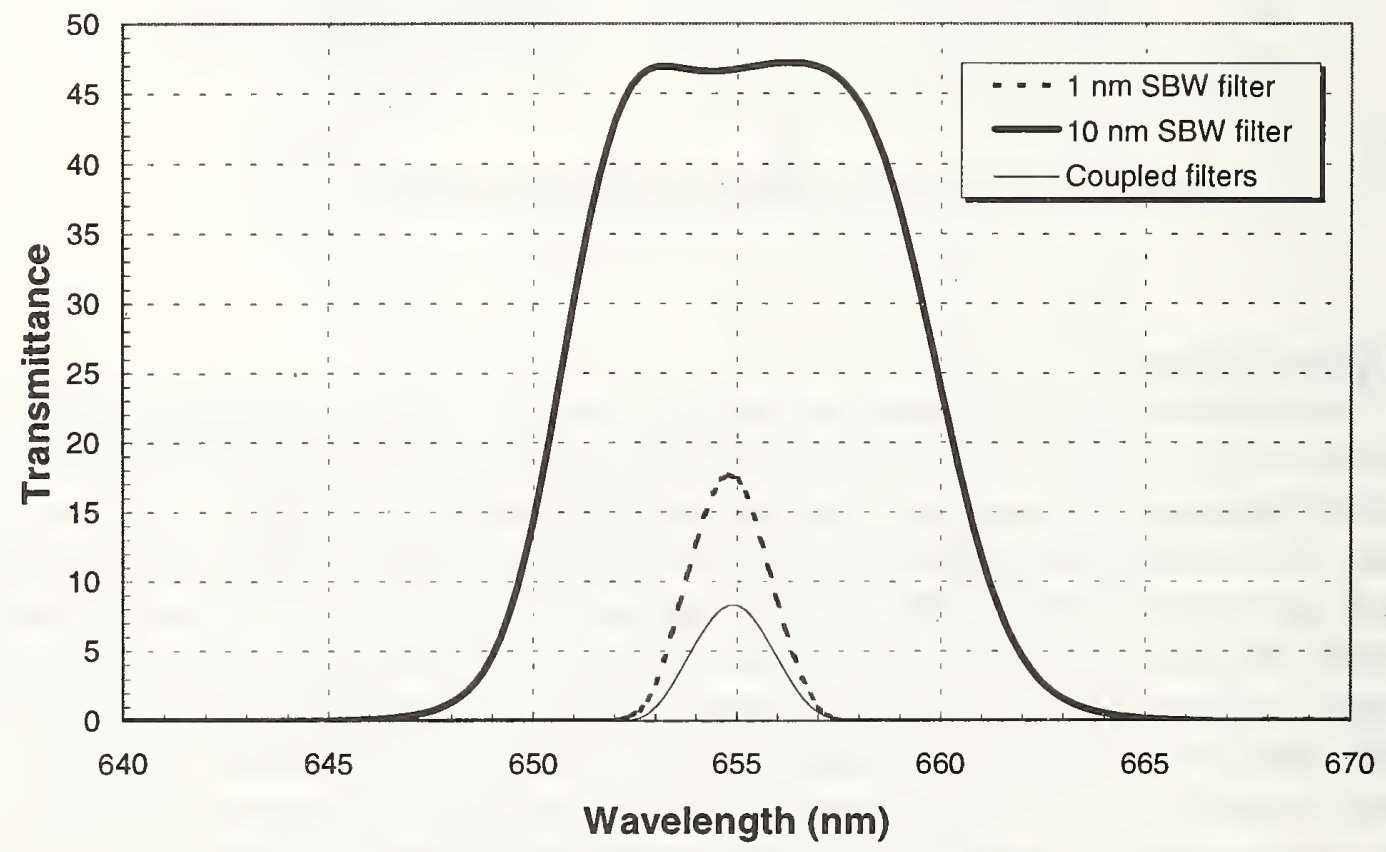

Figure 16. NIST photoelectric pyrometer filter transmittances. The wavelength of the pyrometer is selected by using a $1 \mathrm{~nm}$ and a $10 \mathrm{~nm}$ spectral bandwidth (SBW) filter. 


$$
\lambda_{\mathrm{c}}=\frac{\int_{\lambda} \lambda \cdot \tau_{\lambda} \cdot \mathrm{d} \lambda}{\int_{\lambda} \tau_{\lambda} \cdot \mathrm{d} \lambda} .
$$

By approximating the integral with finite sums over equal wavelength bandwidths $d \lambda, \lambda_{c}$ is found to be

$$
\lambda_{\mathrm{c}}=\frac{\sum_{i=400}^{800}\left(\lambda_{i} \cdot \tau_{i}\right)}{\sum_{i=400}^{800} \tau_{i}},
$$

where the value of $i$ indicates the wavelength in $\mathrm{nm}$. The spectral bandwidth $\Delta \lambda_{\mathrm{s}}$ was determined from the following integral relationship,

$$
\Delta \lambda_{\mathrm{s}}=\frac{\int_{\lambda} \tau_{\lambda} \cdot \mathrm{d} \lambda}{\tau_{\text {peak }}} .
$$

When the integral is converted into finite sums, the SBW becomes

$$
\Delta \lambda_{\mathrm{s}}=\frac{\sum_{i=400}^{800}\left(\tau_{i} \cdot \Delta \lambda_{i}\right)}{\tau_{\text {peak }}} .
$$

\subsubsection{Detectors}

The PEP uses an 11-stage photomultiplier tube with a quartz window and an extended S-20 spectral response to measure spectral radiances. The detector is housed in a thermoelectrically cooled $\left(-25^{\circ} \mathrm{C}\right)$ chamber. The anode current is amplified and converted to a $0.1 \mathrm{~V}$ to $10 \mathrm{~V}$ signal by a programmable dc current amplifier and measured using a high accuracy digital voltmeter, capable of integration times ranging from $0.2 \mathrm{~s}$ to several minutes.

The signals for the test source and the WS lamp can vary by as much as a factor of 1100 . Because several amplifier gain settings are required to cover this dynamic range, all signals are normalized to the $10^{8} \mathrm{~V} / \mathrm{A}$ range. The amplifier normalization factors $C_{\mathrm{A}}$ are determined by measuring the values of the four amplifier feedback resistors. Electrical currents $I$ in the range from $1 \mathrm{nA}$ to $1000 \mathrm{nA}$ are supplied to the current amplifier, and the output voltages $V$ are measured using a digital voltmeter. The resistances $R$, determined using Ohm's law, $V=I \cdot R$, are $R_{7}, R_{8}, R_{9}$, and $R_{10}$, for the $\left(10^{7}, 10^{8}, 10^{9}\right.$, and $\left.10^{10}\right)$ V/A ranges, respectively. The 
normalization factors for each range are shown in table 3.

Table 3. Current amplifier normalization factors

\begin{tabular}{cl}
\hline Range [V/A] & \multicolumn{1}{c}{ Normalization factor } \\
\hline $10^{7}$ & $C_{\mathrm{A}, \mathrm{R} 7}=\mathrm{R}_{8} / \mathrm{R}_{7}=9.9776$ \\
$10^{8}$ & $C_{\mathrm{A}, \mathrm{R} 8}=\mathrm{R}_{8} / \mathrm{R}_{8}=1$ \\
$10^{9}$ & $C_{\mathrm{A}, \mathrm{R} 9}=\mathrm{R}_{8} / \mathrm{R}_{9}=9.9858 \times 10^{-2}$ \\
$10^{10}$ & $C_{\mathrm{A}, \mathrm{R} 10}=\mathrm{R}_{8} / \mathrm{R}_{10}=9.9846 \times 10^{-3}$ \\
\hline
\end{tabular}

\subsubsection{Linearity of response}

The degree of linearity of the PEP response is determined with a NIST designed automated beam conjoiner [14]. A beam from a constant source is split into two branches, whose fluxes are independently attenuated or blocked before recombination and further attenuation. The flux contribution from both branches is equal to the sum of the fluxes from each branch when measured separately (additivity). The device provides 100 levels of flux ranging over a factor of about 500. The levels are presented in random order to avoid systematic errors, and are interspersed with 25 zero flux levels. A personal computer controls the attenuating filters and records the filter positions and radiometer signals. The data is leastsquares fitted to a polynomial response function to determine a correction factor $\left(C_{\mathrm{L}}\right)$ by which the radiometer output signal must be multiplied to obtain a quantity proportional to radiant flux. The correction factor is given by

$$
C_{\mathrm{L}}=\text { flux } / \text { signal }=\left(A_{0}+A_{1} \cdot S+A_{2} \cdot S^{2}\right) / S,
$$

where $A_{0}, A_{1}$, and $A_{2}$ are the coefficients found from the least squares approximation and $S$ is the signal as defined in eq (1). The current values for the coefficients are listed in table 4 . The magnitude of linearity correction factors is graphically shown in figure 17.

The measured instrument response is linear to within $\pm 0.2 \%$ for a range of photomultiplier anode currents from $0.1 \mathrm{nA}$ to $500 \mathrm{nA}$. For currents much less than $0.1 \mathrm{nA}$, the signal is limited by noise. In order to ensure linearity of response, the current is restricted to a maximum of $500 \mathrm{nA}$ by selection of the appropriate photomultiplier tube voltage. Typical default hardware settings used by the calibration program are listed in table 5 . 
Table 4. Detector system correction factors and linearity coefficients

\begin{tabular}{cllccc}
\hline $\begin{array}{c}\text { Gain } \\
{[\mathrm{V} / \mathrm{A}]}\end{array}$ & \multicolumn{1}{c}{$C_{\mathrm{L}}$} & \multicolumn{1}{c}{$C_{\mathrm{L}}$} & \multicolumn{1}{c}{$\begin{array}{c}A_{0} \\
{[\mathrm{~V}]}\end{array}$} & $A_{1}$ & $\begin{array}{c}A_{2} \\
{\left[\mathrm{~V}^{-1}\right]}\end{array}$ \\
\hline $10^{7}$ & $\begin{array}{l}0.9987 \text { for } \\
500 \mathrm{nA}\end{array}$ & $\begin{array}{l}0.9973 \mathrm{for} \\
1000 \mathrm{nA}\end{array}$ & $-2.1274 \times 10^{-8}$ & 1 & $-2.6687 \times 10^{-4}$ \\
$10^{8}$ & $\begin{array}{l}0.9998 \text { for } \\
50 \mathrm{nA}\end{array}$ & $\begin{array}{l}0.9996 \mathrm{for} \\
100 \mathrm{nA}\end{array}$ & $-2.1308 \times 10^{-6}$ & 1 & $-3.8995 \times 10^{-5}$ \\
$10^{9}$ & 1.0002 for & 1.0003 for & $-8.9698 \times 10^{-9}$ & 1 & $-3.1787 \times 10^{-5}$ \\
\hline
\end{tabular}

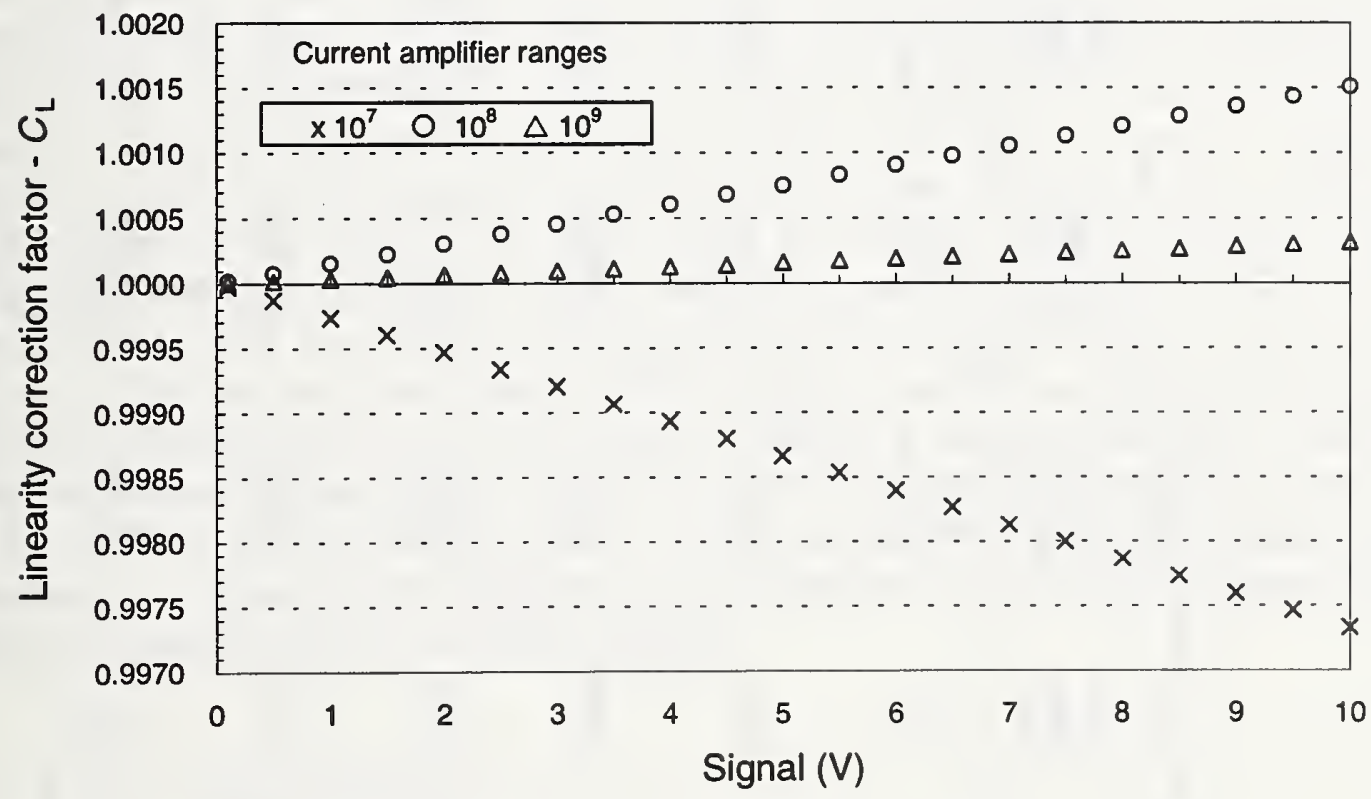

Figure 17. The linearity correction factors for the PEP. 


\begin{tabular}{|c|c|c|c|c|c|c|}
\hline 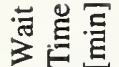 & ్ㅣ & 으 & 으 & $n$ & $n$ & $n$ \\
\hline$\sum_{i}^{E} \geq$ & $\stackrel{p}{r}$ & ஜ & भิ & ঞ্ণ & $\mathscr{\infty}$ & $\mathscr{\infty}$ \\
\hline 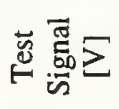 & $\frac{\infty}{\stackrel{\infty}{+}}$ & 胥 & 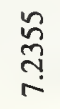 & 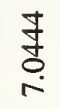 & $\frac{\pi}{0}$ & ర్రి \\
\hline 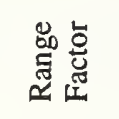 & $\begin{array}{l}\circ \\
\circ \\
\circ \\
\circ \\
0\end{array}$ & - & $\begin{array}{l}\circ \\
\& \\
\stackrel{\circ}{0} \\
0\end{array}$ & - & $\frac{\circ}{\frac{2}{\sigma}}$ & $\frac{\circ}{\stackrel{2}{\alpha}}$ \\
\hline 胥 & $a$ & $\infty$ & $a$ & $\infty$ & $r$ & $r$ \\
\hline 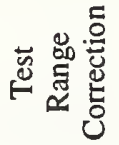 & $\stackrel{n}{\grave{o}}$ & 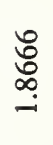 & 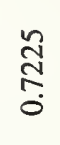 & 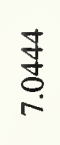 & $\frac{n}{n}$ & $\begin{array}{l}\text { तू } \\
\text { तु }\end{array}$ \\
\hline 总 & 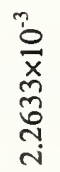 & 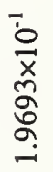 & 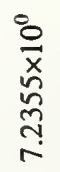 & $\begin{array}{l}8 \\
\frac{0}{x} \\
\frac{8}{2} \\
0 \\
\end{array}$ & 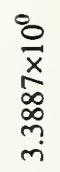 & $\begin{array}{l}8 \\
\frac{8}{x} \\
8 \\
8 \\
\text { i }\end{array}$ \\
\hline 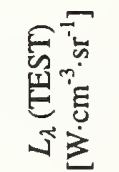 & 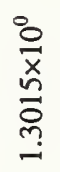 & \begin{tabular}{l} 
O \\
X \\
\multirow{2}{*}{} \\
0 \\
$=$
\end{tabular} & 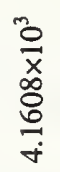 & $\begin{array}{l}0 \\
0 \\
x \\
\hat{0} \\
0 \\
0 \\
\dot{y}\end{array}$ & 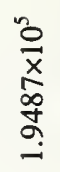 & 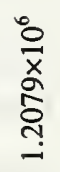 \\
\hline 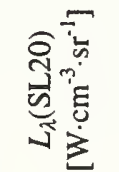 & $\begin{array}{l}\tilde{n} \\
\tilde{b} \\
\tilde{n} \\
n\end{array}$ & $\begin{array}{l}n \\
\delta \\
n \\
n \\
n\end{array}$ & $\begin{array}{l}\tilde{n} \\
o \\
\kappa \\
n\end{array}$ & $\begin{array}{l}\tilde{n} \\
\hat{\delta} \\
\hat{n} \\
n\end{array}$ & $\begin{array}{l}\approx \\
0 \\
\tilde{n} \\
n\end{array}$ & $\begin{array}{l}\tilde{n} \\
\hat{n} \\
\tilde{n}\end{array}$ \\
\hline 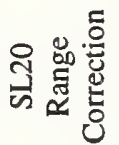 & $\begin{array}{c}\stackrel{\infty}{*} \\
\stackrel{+}{\sigma}\end{array}$ & $\frac{\infty}{\stackrel{\infty}{+}}$ & 。े & $\begin{array}{l}2 \\
\text { g. } \\
0\end{array}$ & $\begin{array}{l}8 \\
\stackrel{0}{0} \\
\stackrel{0}{0}\end{array}$ & $\begin{array}{l}8 \\
\stackrel{0}{0} \\
\stackrel{0}{0}\end{array}$ \\
\hline 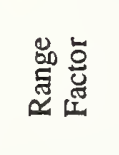 & $\frac{0}{5}$ & $\frac{2}{2}$ & 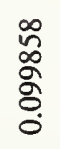 & $\begin{array}{l}\infty \\
\infty \\
\stackrel{2}{\delta} \\
0 \\
0\end{array}$ & $\begin{array}{l}\infty \\
\mathscr{0} \\
\stackrel{0}{\delta} \\
0 \\
0\end{array}$ & $\begin{array}{l}\infty \\
\infty \\
\infty \\
\delta \\
0 \\
0\end{array}$ \\
\hline हू & $r$ & $r$ & $a$ & $a$ & $a$ & $a$ \\
\hline 趈氶之 & $\stackrel{n}{\circ}$ & \% & - & - & ?ִ & $\stackrel{m}{0}$ \\
\hline 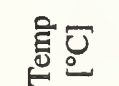 & $\mathbb{\infty}_{\infty}$ & $\stackrel{8}{=}$ & 옴 & ळ & ষ্ల & ఫ్ర \\
\hline
\end{tabular}




\subsubsection{Wavelength calibration}

The mean effective wavelength of the PEP is calculated for temperature from $800{ }^{\circ} \mathrm{C}$ to $3000{ }^{\circ} \mathrm{C}$ by measuring its relative spectral response in the NIST Visible/Near Infrared Spectral Comparator Facility [15]. The collimating lens, aperture stop, optics enclosure, and PMT system of the PEP were set up in the Spectral Comparator Facility and the relative spectral response was measured while maintaining the same system geometry as in the RTCL. The PEP was measured from $400 \mathrm{~nm}$ to $900 \mathrm{~nm}$ in $5 \mathrm{~nm}$ steps and from $630 \mathrm{~nm}$ to $670 \mathrm{~nm}$ in $0.2 \mathrm{~nm}$ steps. The relative spectral response was calculated from the following equation,

$$
R_{\mathrm{PEP}}(\lambda)=\frac{\frac{S_{\mathrm{PEP}}(\lambda)}{S_{\mathrm{m} 1}(\lambda)}}{\frac{S_{\mathrm{W}}(\lambda)}{S_{\mathrm{m} 2}(\lambda)}} \cdot R_{\mathrm{W}}(\lambda) \cdot \frac{G_{\mathrm{W}}}{G_{\mathrm{PEP}}},
$$

where $R_{\text {PEP }}(\lambda)$ is the relative spectral response of the PEP in [A/W] as defined in eq $(2), S_{\text {PEP }}(\lambda)$ is the signal from the PEP in [V], $S_{\mathrm{m} 1}(\lambda)$ is the signal from the monitor detector simultaneous with $S_{\text {PEP }}(\lambda), S_{\mathrm{W}}(\lambda)$ is the signal from the detector working standard (DWS), $S_{\mathrm{m} 2}(\lambda)$ is the signal from the monitor detector simultaneous with $S_{W}(\lambda), R_{W}(\lambda)$ is the absolute spectral response of the DWS, $G_{\mathrm{W}}$ is the calibrated amplifier gain for the DWS in [V/A], and $G_{\text {PEP }}$ is the calibrated amplifier gain for the PEP. The PEP results are relative spectral responses because the measurement was performed in the overfill mode that resulted in a slightly different spot size. From eq (18), the CW was determined to be $655.0 \mathrm{~nm}$ and the SBW was calculated to be $5.0 \mathrm{~nm}$ from eq (20) for data over the $400 \mathrm{~nm}$ to $900 \mathrm{~nm}$ range. The CW was $655.3 \mathrm{~nm}$ with a SBW of $4.2 \mathrm{~nm}$ for the $630 \mathrm{~nm}$ to $670 \mathrm{~nm}$ data. Relative to the peak value, the measured relative spectral responsivity values decrease to about $10^{-4}$ at $5 \mathrm{~nm}$ from the central wavelength and to about $10^{-6}$ at $50 \mathrm{~nm}$ as illustrated in figure 18. Spectral radiance as defined in eq (4) is a function of a single wavelength, $\lambda$. However, the PEP has a finite bandwidth, and the PEP measures radiance as defined by an integral form of the Wien' equation,

$$
L=\int_{400}^{900} \frac{c_{1}}{\lambda^{5} \cdot \exp \left(c_{2} /(\lambda \cdot T)\right)} \cdot R_{\lambda} \cdot d \lambda,
$$

which could be used in the ITS-90 definition of eq (14). In the RTCL, the single wavelength $\lambda_{T_{1}-T_{2}}$ used in eq (4) is be defined as follows,

$$
\lambda_{T_{1}-T_{2}}=\frac{c_{2}}{\ln \left(L_{2} / L_{1}\right)} \cdot\left(\frac{1}{T_{1}}-\frac{1}{T_{2}}\right),
$$


where $\lambda_{T_{1}-T_{2}}$ is the mean effective wavelength, $L_{1}$ is the radiance of the test lamp at temperature $T_{1}$, and $L_{2}$ is the radiance of the WS at temperature $T_{2}$.

All of the temperature measurements are performed for a mean effective wavelength of $655.3 \mathrm{~nm}$, and these corrections are calculated for the VTBB with an emissivity of 0.99 . The spectral radiance $L_{\lambda}\left(\lambda, \varepsilon_{\lambda}, T\right)$ of the blackbody is defined by eq (5) to be a function of the wavelength, spectral emissivity, and the temperature, while the temperature $T\left(\lambda, L_{\lambda}, \varepsilon_{\lambda}\right)$ is defined by eq (6) to be a function of the wavelength, spectral emissivity, and the spectral radiance. The following steps are performed to calculate the corrections at $900 \mathrm{~nm}$ for $T_{0}=1073 \mathrm{~K}$.

$\Rightarrow$ Calculate $L_{0}=1.2856 \mathrm{~W} \cdot \mathrm{cm}^{-3} \cdot \mathrm{sr}^{-1}$, where $\lambda=655.3 \mathrm{~nm}, \varepsilon_{\lambda}=1$, and $T=T_{0}$

$\Rightarrow$ Calculate $T_{1}=1073.53 \mathrm{~K}$, where $\lambda=655.3 \mathrm{~nm}, \varepsilon_{\lambda}=0.99$, and $L_{\lambda}=L_{0}$

$\Rightarrow$ Calculate $L_{1}=68.31 \mathrm{~W} \cdot \mathrm{cm}^{-3} \cdot \mathrm{sr}^{-1}$, where $\lambda=900 \mathrm{~nm}, \varepsilon_{\lambda}=0.99$, and $T=T_{1}$

$\Rightarrow$ Calculate $T_{2}=1072.80 \mathrm{~K}$, where $\lambda=900 \mathrm{~nm}, \varepsilon_{\lambda}=1$, and $L_{\lambda}=L_{1}$

The corrections $T_{2}-T_{0}$ that are added to the radiance temperature at $655.3 \mathrm{~nm}$ to determine the radiance temperatures at $900 \mathrm{~nm}$ and $1000 \mathrm{~nm}$ are given in table 6 . These corrections are equivalent to a spectral radiance correction of $-0.27 \%$ at $900 \mathrm{~nm}$ and $-0.34 \%$ at $1000 \mathrm{~nm}$.

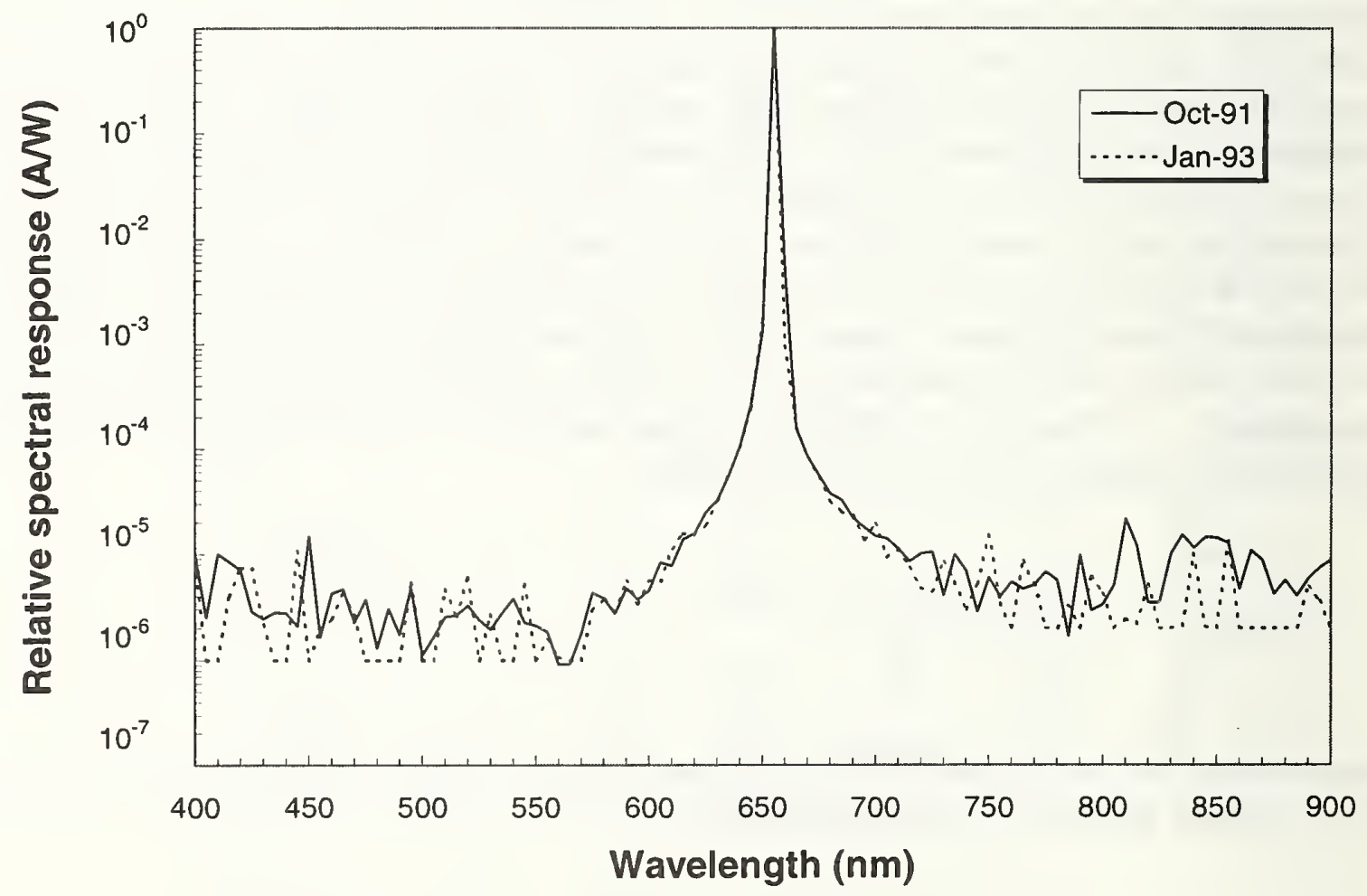

Figure 18. Relative spectral response of the NIST photoelectric pyrometer. 
Table 6. Corrections $\left({ }^{\circ} \mathrm{C}\right)$ to the radiance temperature at $900 \mathrm{~nm}$ and at $1000 \mathrm{~nm}$

\begin{tabular}{ccc}
\hline Blackbody temperature $\left({ }^{\circ} \mathrm{C}\right)$ & $900 \mathrm{~nm}$ & $1000 \mathrm{~nm}$ \\
\hline 800 & & -0.27 \\
1100 & -0.20 & -0.45 \\
1500 & -0.32 & -0.75 \\
1900 & -0.53 & -1.13 \\
2300 & -0.80 & -1.58 \\
3000 & -1.12 & -2.55 \\
\hline
\end{tabular}

\subsubsection{Size of source effect}

Measurements are performed to determine how much of the measured flux is from sources other than the target. This additional flux from outside the target area is scattered into the measured beam by the optical system. The measurement is performed to determine the size of source effect or the sensitivity of the PEP when viewing a $0.6 \mathrm{~mm}$ wide by $0.8 \mathrm{~mm}$ high target area on sources of various sizes. The magnitude of the size of source correction is determined by measuring the spectral radiance of a large uniform diffuse source with various apertures in front of the source. The large uniform diffuse source designed at NIST is used to measure the source of source effect. A $1 \mathrm{~kW}$ frosted quartz-halogen lamp is placed in a $20 \mathrm{~cm}$ by $23 \mathrm{~cm}$ by $20 \mathrm{~cm}$ vented housing. A lens focuses the lamp onto an opening in the housing that is covered by a diffuser. The apertures are on an aperture slide for quick positioning and reproducibility. The aperture sizes measured are a $1.4 \mathrm{~mm}$ by $25.4 \mathrm{~mm}$ slit, a $3 \mathrm{~mm}$ by $25.4 \mathrm{~mm}$ slit, a $15 \mathrm{~mm}$ diameter hole, and $25.4 \mathrm{~mm}$ diameter hole which approximate the sizes of the WS filament, the TL filament, the Au blackbody opening, and the BB opening. The ratio $r_{1}$ is the measurement of the ratio of the WS to the AuBB in eq (9). The size of source correction is calculated from the ratio of the measurements of the $15 \mathrm{~mm}$ diameter hole to the $1.4 \mathrm{~mm}$ by $25.4 \mathrm{~mm}$ slit. The spectral radiance correction was $0.09 \%$, which corresponds to a correction factor of 1.0009 \pm 0.0006 and a temperature correction of $0.10^{\circ} \mathrm{C}$. A negligible difference was observed for the comparison of the measurements of the $1.4 \mathrm{~mm}$ by $25.4 \mathrm{~mm}$ slit and the $3 \mathrm{~mm}$ by $25.4 \mathrm{~mm}$ slit; therefore, the correction factor for ratio $r_{2}$ is 1 . The size of source correction for ratios $r_{3}$ and $r_{4}$ is $-0.13 \%$ which corresponds to a correction factor of $0.9987 \pm 0.0002$. The correction was calculated from the ratio of the measurements of the $1.4 \mathrm{~mm}$ by $25.4 \mathrm{~mm}$ slit to the $25.4 \mathrm{~mm}$ diameter hole. The magnitude of the temperature correction varies from $-0.07{ }^{\circ} \mathrm{C}$ at $800{ }^{\circ} \mathrm{C}$ to $-0.52^{\circ} \mathrm{C}$ at $2700^{\circ} \mathrm{C}$. The size of source corrections are shown in figure 19 . Because of flux contributions from outside the target area, the larger area BB results in a higher temperature. A negative correction is added to subtract the additional flux. 


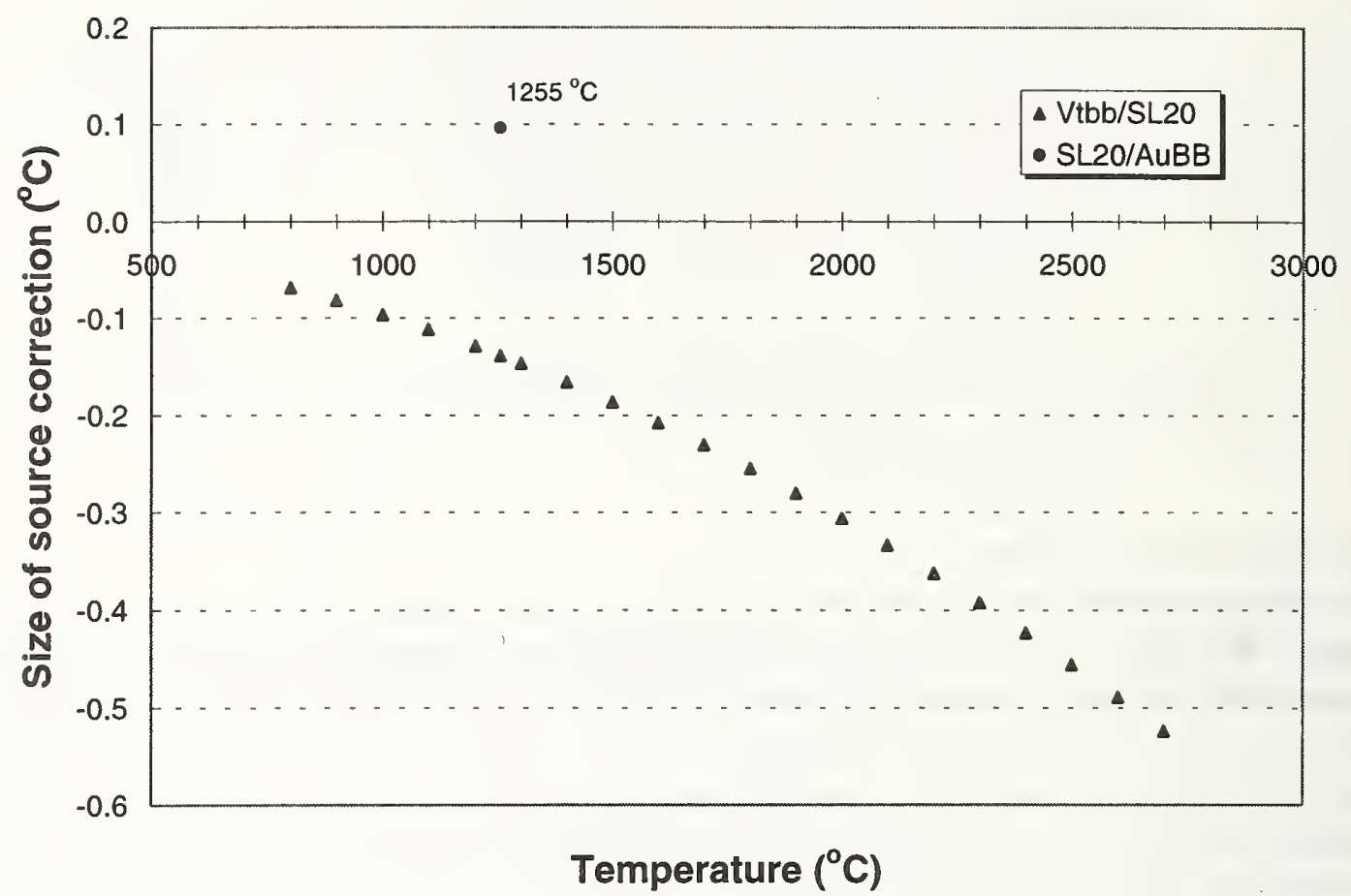

Figure 19. The size of source corrections for the variable temperature blackbody to the working standard lamp comparison and the working standard lamp to the gold-point blackbody.

\subsection{Radiance temperature scale uncertainties}

From the laws of statistical theory, when the covariances of the independent variables are assumed to be negligible, the propagation of standard uncertainty $u(y)$ for a variable $y$,

$$
y=f\left(x_{1}, x_{2}, x_{3}, \ldots, x_{N}\right)
$$

can be defined in terms of the following sum,

$$
u(y)=\left[\sum_{i=1}^{N}\left(\frac{\partial f}{\partial x_{i}} \cdot u\left(x_{i}\right)\right)^{2}\right]^{1 / 2},
$$

where $u\left(x_{i}\right)$ are the standard uncertainties. The uncertainty in the WS lamp spectral radiance, 


$$
\begin{aligned}
u_{0}\left(L_{\mathrm{WS}}\right) & =\left[\left(\frac{\partial L_{\mathrm{WS}}}{\partial n_{\lambda}} \cdot u\left(n_{\lambda}\right)\right)^{2}+\left(\frac{\partial L_{\mathrm{WS}}}{\partial \lambda} \cdot u(\lambda)\right)^{2}+\left(\frac{\partial L_{\mathrm{WS}}}{\partial T_{\mathrm{Au}}} \cdot u\left(T_{\mathrm{Au}}\right)\right)^{2}\right. \\
& \left.+\left(\frac{\partial L_{\mathrm{WS}}}{\partial c_{2}} \cdot u\left(c_{2}\right)\right)^{2}+\sum_{i=1}^{11}\left(\frac{\partial L_{\mathrm{WS}}}{\partial x_{i}} \cdot u\left(x_{i}\right)\right)^{2}\right]^{1 / 2}
\end{aligned}
$$

can be calculated by the root sum of squares (RSS) of the products of partial derivatives with their respective uncertainties. This uncertainty $u_{0}\left(L_{\mathrm{ws}}\right)$ can be derived directly from the measurement equation in eq (16) by using the propagation of standard uncertainty relationship in eq (27). The partial derivatives are those of the spectral radiance with respect to the independent variables in eq (16) and are listed in eqs (29) through (33). The eleven variables in the summation of eq (28) are the following variables: $\varepsilon_{\mathrm{Au}}, c_{1 L}, r_{1}, C_{\mathrm{A}, \mathrm{WS}}, C_{\mathrm{L}, \mathrm{WS}}, C_{\mathrm{S}, \mathrm{WS}}, G_{\mathrm{WS}}, C_{\mathrm{A}, \mathrm{Au}}$, $C_{\mathrm{L}, \mathrm{Au}}, C_{\mathrm{S}, \mathrm{Au}}$, or $G_{\mathrm{Au}}$. Since all of the measurements in the RTCL are based on the WS lamp, the uncertainty analysis of each calibration service (tungsten ribbon filament lamps, disappearing filament optical pyrometers, infrared thermometers) will be completed in Sections 4, 5, and 6 using the uncertainty in $u_{0}\left(L_{\mathrm{ws}}\right)$.

The measurement equation for the radiance temperature scale from the gold-point blackbody to the WS lamp can be represented by eq (16). The partial derivatives of the WS spectral radiance in eq (16) with respect to the variables, $n_{\lambda}, \lambda, T_{\mathrm{Au}}$, and $c_{2}$, are

$$
\begin{aligned}
& \frac{\partial L_{\mathrm{ws}}}{\partial n_{\lambda}}=\frac{L_{\mathrm{WS}}}{n_{\lambda}} \cdot\left[\frac{c_{2}}{n_{\lambda} \cdot \lambda \cdot T_{\mathrm{Au}}} \cdot \frac{\exp \left(\frac{c_{2}}{n_{\lambda} \cdot \lambda \cdot T_{\mathrm{Au}}}\right)}{\exp \left(\frac{c_{2}}{n_{\lambda} \cdot \lambda \cdot T_{\mathrm{Au}}}\right)-1}-2\right], \\
& \frac{\partial L_{\mathrm{WS}}}{\partial \lambda}=\frac{L_{\mathrm{wS}}}{\lambda} \cdot\left[\frac{c_{2}}{n_{\lambda} \cdot \lambda \cdot T_{\mathrm{Au}}} \cdot \frac{\exp \left(\frac{c_{2}}{n_{\lambda} \cdot \lambda \cdot T_{\mathrm{Au}}}\right)}{\exp \left(\frac{c_{2}}{n_{\lambda} \cdot \lambda \cdot T_{\mathrm{Au}}}\right)-1}-5\right], \\
& \frac{\partial L_{\mathrm{WS}}}{\partial T_{\mathrm{Au}}}=\frac{L_{\mathrm{ws}}}{T_{\mathrm{Au}}} \cdot \frac{c_{2}}{n_{\lambda} \cdot \lambda \cdot T_{\mathrm{Au}}} \cdot \frac{\exp \left(\frac{c_{2}}{n_{\lambda} \cdot \lambda \cdot T_{\mathrm{Au}}}\right)}{\exp \left(\frac{c_{2}}{n_{\lambda} \cdot \lambda \cdot T_{\mathrm{Au}}}\right)-1} \text {, and }
\end{aligned}
$$




$$
\frac{\partial L_{\mathrm{WS}}}{\partial c_{2}}=\frac{-L_{\mathrm{WS}}}{c_{2}} \cdot \frac{c_{2}}{n_{\lambda} \cdot \lambda \cdot T_{\mathrm{Au}}} \cdot \frac{\exp \left(\frac{c_{2}}{n_{\lambda} \cdot \lambda \cdot T_{\mathrm{Au}}}\right)}{\exp \left(\frac{c_{2}}{n_{\lambda} \cdot \lambda \cdot T_{\mathrm{Au}}}\right)-1}
$$

The expression in eq (28),

$$
\left|\frac{\partial L_{\mathrm{ws}}}{\partial x}\right|=\frac{L_{\mathrm{ws}}}{x}
$$

represents the partial derivatives of $L_{\mathrm{ws}}$ with respect to $x$, where $x$ is one of the eleven variables in eq (28).

Table 7 details typical values of the variables in eq (16), while table 8 summarizes the uncertainties in eq (28). The uncertainty $u\left(T_{\mathrm{Au}}\right)$ in table 8 is derived from the NIST radiometric determination of the freezing point of gold [16]. The combined uncertainty $u\left(L_{\mathrm{WS}}\right)$ in the spectral radiance of the WS lamp can then be calculated by calculating the RSS from the following expression,

$$
\frac{u\left(L_{w S}\right)}{L_{w S}}=\left[\left(\frac{u_{0}\left(L_{w S}\right)}{L_{w S}}\right)^{2}+\left(\frac{u(\mathrm{DMM})}{L_{w s}}\right)^{2}+\left(\frac{u(\mathrm{LTC})}{L_{W S}}\right)^{2}+\left(\frac{u(\mathrm{LD})}{L_{w S}}\right)^{2}\right]^{1 / 2},
$$

where $u(\mathrm{DMM})$ is the digital multimeter uncertainty, $u(\mathrm{LTC})$ is the lamp current uncertainty, and $u(\mathrm{LD})$ is the lamp drift uncertainty. From tables 7 and 8 , a typical relative expanded uncertainty in the WS spectral radiance is equal to $\left(2.870 \mathrm{~W} \cdot \mathrm{m}^{-2} \cdot \mu \mathrm{m}^{-1} \cdot \mathrm{sr}^{-1}\right) /\left(569.9 \mathrm{~W} \cdot \mathrm{m}^{-2} \cdot \mu \mathrm{m}^{-1} \cdot \mathrm{sr}^{-1}\right)$, or $0.50 \%$. The final value of the WS spectral radiance will be utilized in Sections 4 through 6 to continue the uncertainty analyses for each type of calibration service.

\subsection{Quality control}

The Radiance Temperature Measurements Calibration Service ensures quality measurements through quality system implementation, internal quality control procedures, periodic audits, and interlaboratory comparisons. The Quality System Manual for the Radiance Temperature Measurements Calibration Service is based on the ANSI/NCSL Z540-1-1994 standard [17] and the ISO/IEC Guide 25 [18]. The Quality System Manual is organized into three sections that form a pyramidal shape. The top section is the Optical Technology Division Quality System Policies, the middle section contains the Division Procedures that uniformly apply to all the calibration services, and the bottom section is the Calibration Service Procedures for each calibration service. Additional information on the Divisions Quality System can be found in reference [19]. 
Table 7. Typical values of WS lamp variables and parameters

\begin{tabular}{lcc}
\hline \multicolumn{1}{c}{ Variable } & Symbol & Value \\
\hline Refractive index & $n_{\lambda}$ & 1.00028 \\
Wavelength & $\lambda$ & $655.3 \mathrm{~nm}$ \\
Freezing temperature of gold & $T_{\mathrm{Au}}$ & $1337.33 \mathrm{~K}$ \\
Second radiation constant & $c_{2}$ & $14387.69 \mu \mathrm{m} \cdot \mathrm{K}$ \\
Emissivity of Au & $\varepsilon_{\mathrm{Au}}$ & 0.9999 \\
First radiation constant & $c_{\mathrm{IL}}$ & $1.191 \times 10^{8} \mathrm{~W} \cdot \mu \mathrm{m}^{4} \cdot \mathrm{m}^{-2}$ \\
Ratio of WS signal to Au signal & $r_{\mathrm{l}}$ & 7.764 \\
WS amplifier calibration correction & $C_{\mathrm{A}, \mathrm{WS}}$ & 1 \\
WS linearity correction & $C_{\mathrm{L}, \mathrm{WS}}$ & 1 \\
WS size of source correction & $C_{\mathrm{S}, \mathrm{WS}}$ & 1.0009 \\
WS amplifier gain & $G_{\mathrm{WS}}$ & $1 \times 10^{8} \mathrm{~V} \cdot \mathrm{A}^{-1}$ \\
Au amplifier calibration correction & $C_{\mathrm{A}, \mathrm{Au}}$ & 1 \\
Au linearity correction & $C_{\mathrm{L}, \mathrm{Au}}$ & 1 \\
Au size of source correction & $C_{\mathrm{S}, \mathrm{Au}}$ & 1 \\
Au amplifier gain & $G_{\mathrm{Au}}$ & $1 \times 10^{8} \mathrm{~V} \cdot \mathrm{A}^{-1}$ \\
WS spectral radiance & $L_{\mathrm{WS}}$ & $569.9 \mathrm{~W} \cdot \mathrm{m}^{-2} \cdot \mu \mathrm{m}^{-1} \cdot \mathrm{sr}^{-1}$ \\
\hline
\end{tabular}


Table 8. Uncertainty budget for the NIST WS lamp spectral radiance realization

\begin{tabular}{|c|c|c|c|}
\hline \multirow{2}{*}{ Uncertainty component } & \multirow[t]{2}{*}{ Symbol } & \multicolumn{2}{|c|}{$\begin{array}{c}\text { Expanded } \\
\text { Uncertainty }(k=2)\end{array}$} \\
\hline & & Type A & Type B \\
\hline Refractive index & $u\left(n_{\lambda}\right)$ & & 0.00002 \\
\hline Wavelength & $u(\lambda)$ & & $0.2 \mathrm{~nm}$ \\
\hline Freezing temperature of gold & $u\left(T_{\mathrm{Au}}\right)$ & & $0.23 \mathrm{~K}$ \\
\hline Second radiation constant & $u\left(c_{2}\right)$ & & $0.24 \mu \mathrm{m} \cdot \mathrm{K}$ \\
\hline Emissivity of $\mathrm{Au}$ & $u\left(\varepsilon_{\mathrm{Au}}\right)$ & & 0.0002 \\
\hline First radiation constant & $u\left(c_{1 L}\right)$ & & $440 \mathrm{~W} \cdot \mu \mathrm{m}^{4} \cdot \mathrm{m}^{-2}$ \\
\hline Ratio of WS signal to Au signal & $u\left(r_{1}\right)$ & 0.006 & \\
\hline WS amplifier calibration correction & $u\left(C_{\mathrm{A}, \mathrm{WS}}\right)$ & 0.0001 & \\
\hline WS linearity correction & $u\left(C_{\mathrm{L}, \mathrm{WS}}\right)$ & 0.001 & \\
\hline WS size of source correction & $u\left(C_{\mathrm{S}, \mathrm{WS}}\right)$ & 0.0006 & \\
\hline WS amplifier gain & $u\left(G_{\mathrm{WS}}\right)$ & & $0 \mathrm{~V} \cdot \mathrm{A}^{-1}$ \\
\hline Au amplifier calibration correction & $u\left(C_{\mathrm{A}, \mathrm{Au}}\right)$ & 0.0001 & \\
\hline Au linearity correction & $u\left(C_{\mathrm{L}, \mathrm{Au}}\right)$ & 0.001 & \\
\hline Au size of source correction & $u\left(C_{\mathrm{S}, \mathrm{Au}}\right)$ & 0.0002 & \\
\hline $\mathrm{Au}$ amplifier gain & $u\left(G_{\mathrm{Au}}\right)$ & & $0 \mathrm{~V} \cdot \mathrm{A}^{-1}$ \\
\hline WS lamp spectral radiance & $u_{0}\left(L_{\mathrm{WS}}\right)$ & & $2.754 \mathrm{~W} \cdot \mathrm{m}^{-2} \cdot \mu \mathrm{m}^{-1} \cdot \mathrm{sr}^{-1}$ \\
\hline Digital voltmeter & $u(\mathrm{DMM})$ & & $0.000 \mathrm{~W} \cdot \mathrm{m}^{-2} \cdot \mu \mathrm{m}^{-1} \cdot \mathrm{sr}^{-1}$ \\
\hline WS current & $u(\mathrm{LTC})$ & & $0.570 \mathrm{~W} \cdot \mathrm{m}^{-2} \cdot \mu \mathrm{m}^{-1} \cdot \mathrm{sr}^{-1}$ \\
\hline WS drift & $u(\mathrm{LD})$ & $0.570 \mathrm{~W} / \mathrm{m}^{2} / \mu \mathrm{m} / \mathrm{sr}$ & \\
\hline NIST WS lamp spectral radiance & $u\left(L_{\mathrm{WS}}\right)$ & $2.870 \mathrm{~W}$ & $\mathrm{~m}^{-2} \cdot \mu \mathrm{m}^{-1} \cdot \mathrm{sr}^{-1}$ \\
\hline NIST WS lamp temperature & $u\left(T_{\mathrm{WS}}\right)$ & & $36 \mathrm{~K}$ \\
\hline
\end{tabular}


The calibrations resulting from the processes described in this document are derived in principle from a complete realization of the radiance temperature scale, and therefore are not dependent upon the maintenance of in-house standards. In practice, the realization often omits the GPBB comparison and relies upon the spectral radiance that is maintained on the stable working standard lamp. The calibration history of the lamp compared to the GPBB is monitored to confirm the stability of the lamp (see fig. 9). The working standard lamp is compared to the gold point blackbody at least twice a year. Lamp and radiation thermometer check standards are periodically measured to ensure the accuracy of the measurements. The calibration history of the ribbon filament lamp check standards (Serial numbers P51 and P74) are shown in figure 20, while the calibration history of the radiation thermometer check standard (Minolta Cyclops 52) is shown in figure 21. The calibration process is further monitored by using control limits in the data acquisition and data reduction programs. A check-list is used to track the status of the test unit throughout the calibration process. A calibration summary sheet is created for each calibrated item to record customer information, measurements performed, test unit information, environmental conditions, filenames, and computer programs used for data acquisition and reduction. The calibration report is carefully reviewed by a party who was not involved in producing the values.

Audits are performed annually by the Division's quality control team. This calibration service participates in bilateral and multilateral laboratory comparisons of radiance temperature with various national laboratories usually involving guest scientists $[20,21]$.

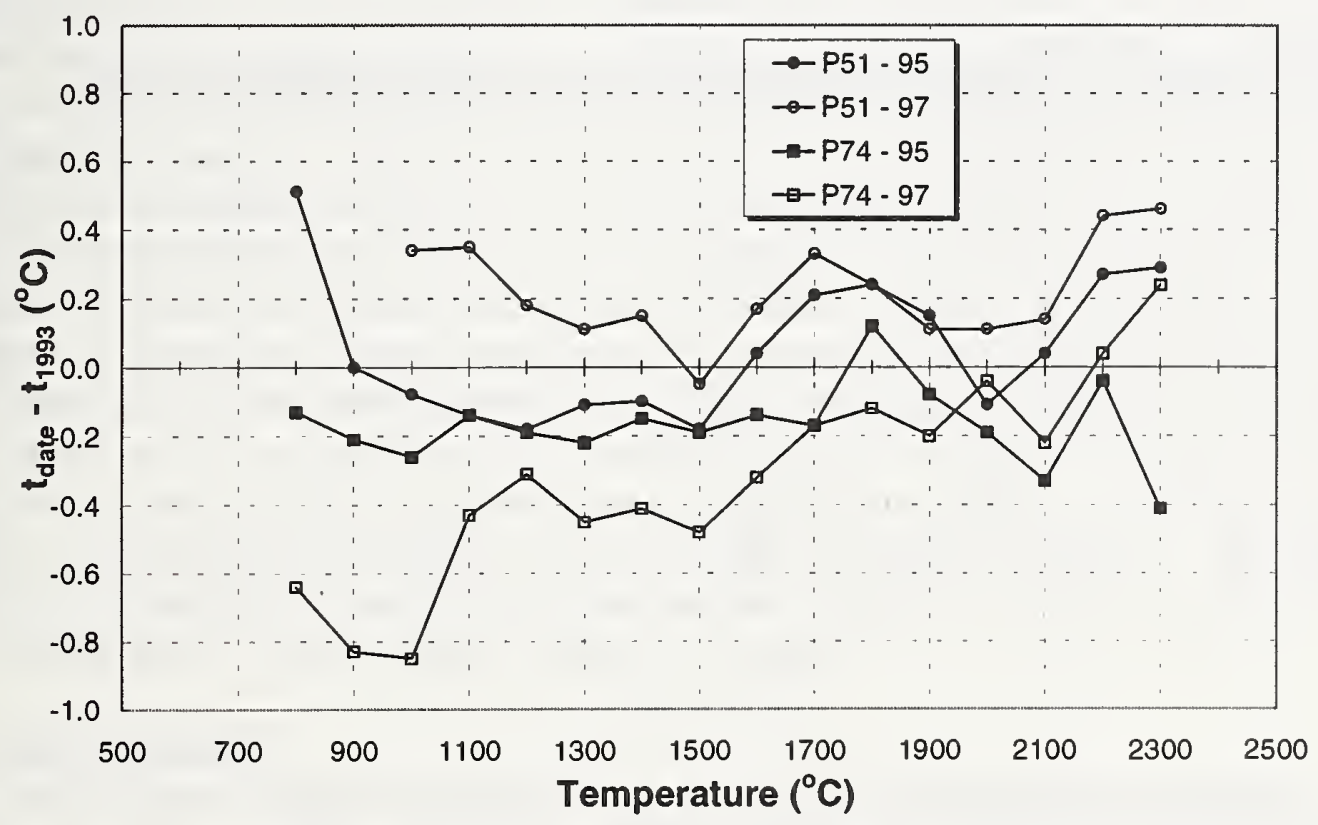

Figure 20. Calibration history of the ribbon filament lamp check standards. 


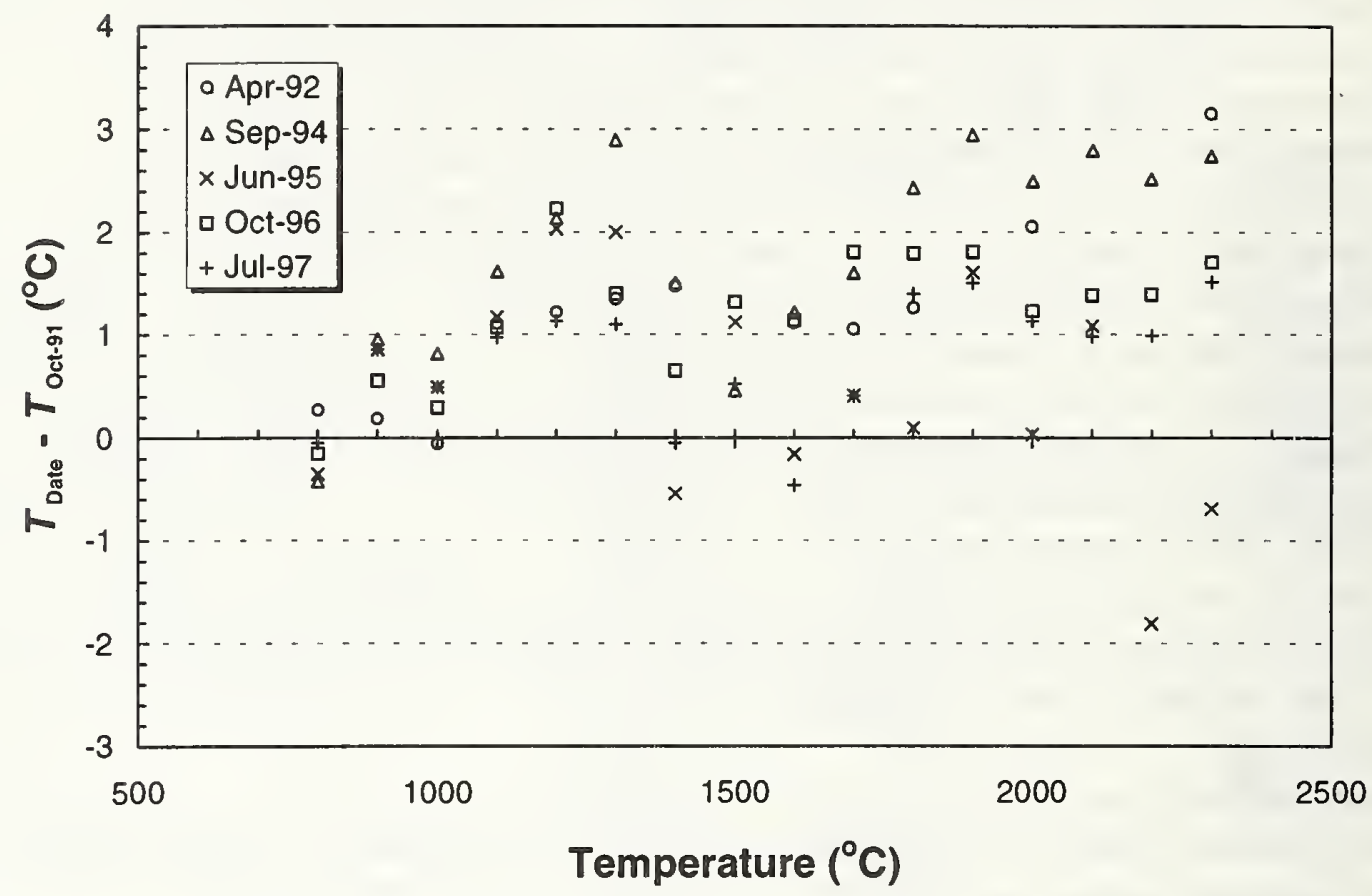

Figure 21. Calibration history of the radiation thermometer check standard (Minolta Cyclops 52). 


\section{Tungsten Ribbon Filament Lamp Calibrations}

\subsection{Lamp preparation}

Tungsten ribbon filament lamps are calibrated by NIST for the temperature range $800{ }^{\circ} \mathrm{C}$ to $2300{ }^{\circ} \mathrm{C}$ in terms of the 1990 NIST Radiance Temperature Scale by spectral comparison to a standard temperature lamp calibrated at $655.3 \mathrm{~nm}$. New lamps are inspected for filament continuity, envelope and window clarity, and filament flatness and centering. A digital multimeter is used to check the filament continuity. The envelope or window is checked for defects and striations in the optical path. The filament is checked to determine that it is flat, parallel to the envelope walls, and within $2 \mathrm{~mm}$ of being centered in the envelope or window. The lamps are cleaned with water and laboratory glassware detergent.

Test lamps (TL) are operated base down on direct current with the center contact (longer filament support for a bipost base lamp) at the positive potential. The test lamps are tested for air leaks by turning the lamp on, then off, and then on again after $15 \mathrm{~min}$. If air has leaked into the lamp envelope because of bad or broken seals, then the lamp will fail when it is turned on. Lamps that pass the leak test are annealed to improve lamp stability. New gas lamps are annealed at a radiance temperature of $2350{ }^{\circ} \mathrm{C}$ at $655.3 \mathrm{~nm}$ for $2 \mathrm{~h}$ on direct current and vacuum lamps are annealed at $1450^{\circ} \mathrm{C}$ for about $14 \mathrm{~h}$. The gas lamps are aged for an additional $50 \mathrm{~h}$ at $2300{ }^{\circ} \mathrm{C}$.

The lamp orientation chosen for the calibration of a new lamp minimizes the variation in lamp output while maintaining the optical axis of the measuring instrument approximately normal to the lamp filament. This orientation is determined with the lamp operating at approximately $1700{ }^{\circ} \mathrm{C}$ for a gas lamp, or $1200{ }^{\circ} \mathrm{C}$ for a vacuum lamp. An arrow is etched onto the rear surface of the lamp envelope to allow reproducible alignment of this orientation. The alignment is performed with the lamp operating base down, the filament vertical, and the optical axis of the PEP passing through the lamp envelope and intersecting the center of the filament at the height of the notch. The sides of the target area, area $0.6 \mathrm{~mm}$ wide by $0.8 \mathrm{~mm}$ high, are approximately parallel to the sides of the lamp filament. The center of the target area is located at the intersection of two orthogonal lines on the filament surface. One line bisects the filament lengthwise, and the other passes through the point centered at the mouth of the notch. The lamp is positioned so that the etched arrow on the lamp envelope is to the rear, as viewed from the PEP. The center of the target area is viewed along the horizontal optical axis of the PEP. A plumb line is used to make the notch side of the filament vertical. The image of the lamp filament is focused onto the field stop of the PEP to within $\pm 2.5 \mathrm{~mm}$. The lamp is then successively rotated about the horizontal and vertical centerlines through the target area until the tip of the arrowhead is centered at the mouth of the notch.

\subsection{Lamp calibration}

The values of radiance temperature apply when the lamp has been aligned to a specified orientation while operating at a designated radiance temperature and after the lamp has reached thermal stability at each specified operating current. The WS and TL are aligned as described in Section 4.1 at one temperature. At all other temperatures, the TL is translated vertically and/or horizontally so that the target area viewed by the PEP is always centered on the lamp filament at the height of the notch. No additional rotational alignments are performed 
The initial lamp current that corresponds to $1700^{\circ} \mathrm{C}$ is selected from previous data for the lamp type. The TL is turned on and set to approximately $1700^{\circ} \mathrm{C}$ and aligned after $30 \mathrm{~min}$. The spectral radiance ratio of the TL to the WS, $r_{2}$, is calculated, the WS signal, $S_{\mathrm{WS} 2}$, is measured, and the TL signal, $S_{\mathrm{TL}}$, that corresponds to $1700^{\circ} \mathrm{C}$ is calculated. The lamp current is adjusted until the measured signal is equal to $S_{\mathrm{TL}}$. After waiting $10 \mathrm{~min}$, the final alignment of the TL and the WS is performed and the TL is spectrally compared to the WS to determine its radiance temperature. The spectral radiance ratio of the TL to the WS is measured three times by alternately translating the WS and the TL to the PEP. If the percent standard deviation of the ratio is less then the control limit, then the next calibration point is measured; otherwise, the point is repeated. The control limits are equal to the relative standard uncertainty $(k=1)$ of the ratio and were determined from previous calibration data. The control limits are the expected uncertainties for the spectral radiance ratio measurement. Next, the TL is aligned and measured at $2300{ }^{\circ} \mathrm{C}$ after waiting $20 \mathrm{~min}$. The additional calibration temperatures are aligned and measured in decreasing order after waiting $10 \mathrm{~min}$. A typical calibration interval is $100{ }^{\circ} \mathrm{C}$. The following temperatures are repeated at the previously determined lamp currents to estimate the lamps stability: $1700{ }^{\circ} \mathrm{C}, 2300{ }^{\circ} \mathrm{C}, 1900^{\circ} \mathrm{C}, 1500{ }^{\circ} \mathrm{C}, 1100{ }^{\circ} \mathrm{C}$, and $800{ }^{\circ} \mathrm{C}$. The following data is stored in a computer file: nominal temperature, measured temperature, lamp current, and spectral radiance ratio. See the "Ribbon Filament Lamp Calibration Procedure" in Appendix D for a more details on lamp calibrations in the RTLC.

\subsection{Lamp data analysis}

The repeated calibration temperatures are averaged and the standard error of the mean is calculated and compared to the absolute control limits. These results are used to determine the expanded uncertainties listed in the calibration report.

Calibration data is reported at the nominal temperatures $800^{\circ} \mathrm{C}, 900{ }^{\circ} \mathrm{C}, 1000{ }^{\circ} \mathrm{C}, \ldots$ $2300{ }^{\circ} \mathrm{C}$. One method to determine the nominal temperatures is to measure it directly. Through an iterative process, the TL is repeatedly measured and the lamp current is adjusted until the nominal temperature is actually measured. However, the RTCL calculates the lamp current that corresponds to the nominal temperature from measurements of the measured temperature $\left(T_{\mathrm{m}}\right)$ near the nominal temperature $\left(T_{n}\right)$.

For a small $\Delta T$, where $\Delta T=T_{\mathrm{n}}-T_{\mathrm{m}}$, the small change in lamp current is approximated by the slope of the tangent at $T$ and given by

$$
\frac{\mathrm{d} I(T)}{\mathrm{d} T}=\lim _{\Delta T \rightarrow 0} \frac{\Delta I}{\Delta T}=\lim _{\Delta T \rightarrow 0} \frac{I(T+\Delta T)-I(T)}{\Delta T} .
$$

This limit simplifies to a working equation of the form

$$
I(T+\Delta T)=I(T)+\frac{\mathrm{d} I}{\mathrm{~d} T} \cdot \Delta T,
$$

where $\mathrm{I}(\mathrm{T})$ is the measured lamp current $I_{\mathrm{m}}$ at $T_{\mathrm{m}}$ and $\mathrm{I}(\mathrm{T}+\Delta T)$ is the measured lamp current $I_{\text {corr }}$. The derivative $\mathrm{d} I / \mathrm{d} T$ can be approximated by $\Delta I / \Delta T$, which can be modeled as 


$$
\frac{\Delta I}{\Delta T}=\sum_{j=0}^{5} a_{j} T_{\operatorname{mean}}^{j}
$$

The coefficients $a_{j}$ are calculated from a least squares fit of two other parameters, $T_{\text {mean }}$ and $\Delta I / \Delta T$. The first parameter is defined by

$$
T_{\text {mean }}=\frac{T_{\mathrm{m}, k}+T_{\mathrm{m}, k+1}}{2}
$$

and the slope of the line between the calibration points $P_{k}$ and $P_{k+1}$ in figure 22 is given by

$$
\frac{\Delta I}{\Delta T}=\frac{I_{\mathrm{m}, k}-I_{\mathrm{m}, k+1}}{T_{\mathrm{m}, k}-T_{\mathrm{m}, k+1}} .
$$

Figure 22 shows the shape of the curve for $T_{\mathrm{m}}$ versus $I_{\mathrm{m}} \cdot \Delta I / \Delta T\left(T_{\text {mean }}\right)$ is fit to a fifth degree polynomial giving the coefficients $a_{j}$. Figure 23 shows the shape of the curve with of $T_{\text {mean }}$ and $\Delta V / \Delta T$ used to calculate the coefficients $a_{j}$. From eq (36), the corrected lamp current is

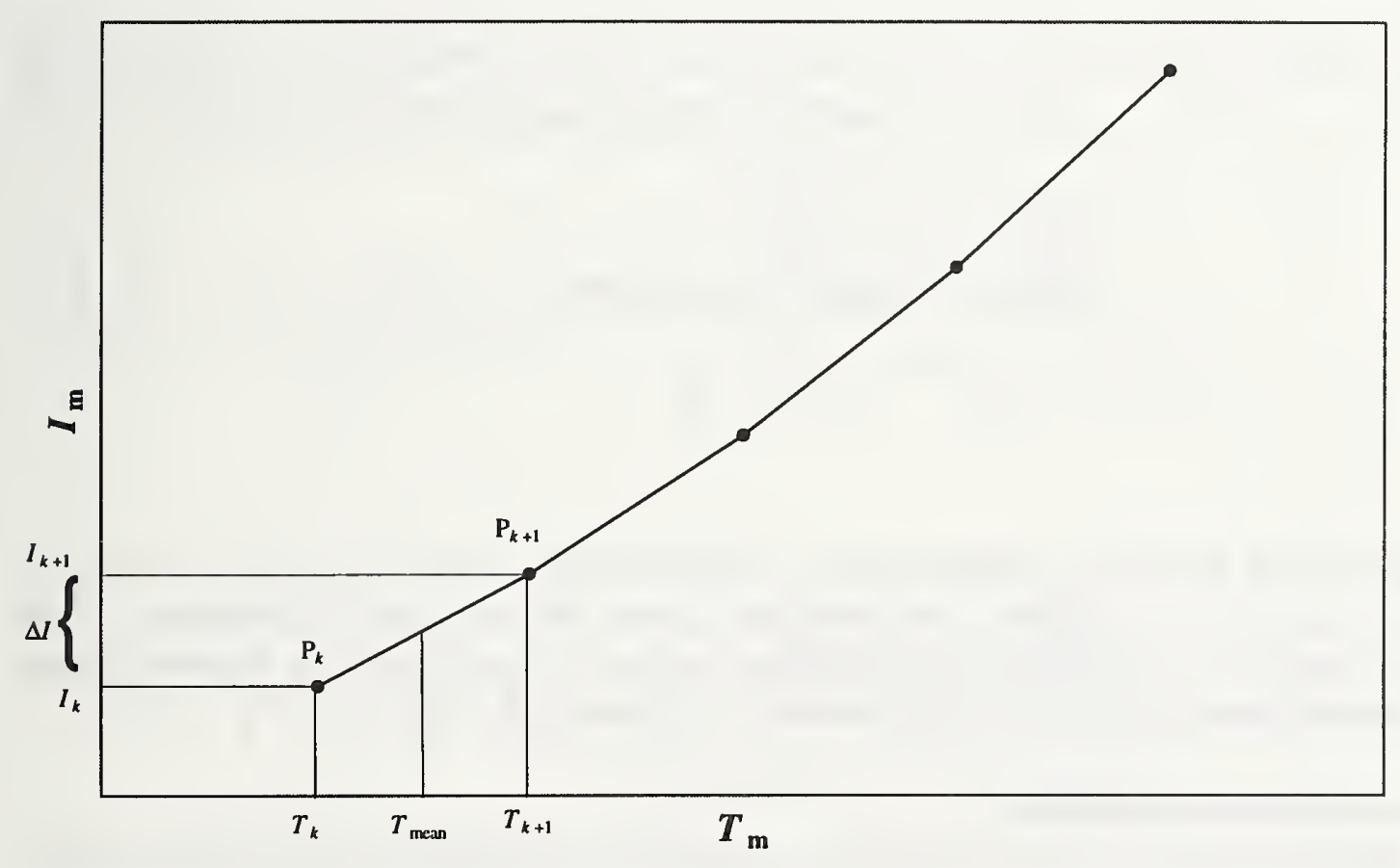

Figure 22. Calculation of $I_{\text {corr }}$ from $T_{\text {mean }}$ and $\Delta I / \Delta T$. 
determined to be

$$
I_{\text {corr }}=I_{\mathrm{m}}+\frac{\mathrm{d} I}{\mathrm{~d} T}\left(T_{\mathrm{n}}-T_{\mathrm{m}}\right) .
$$

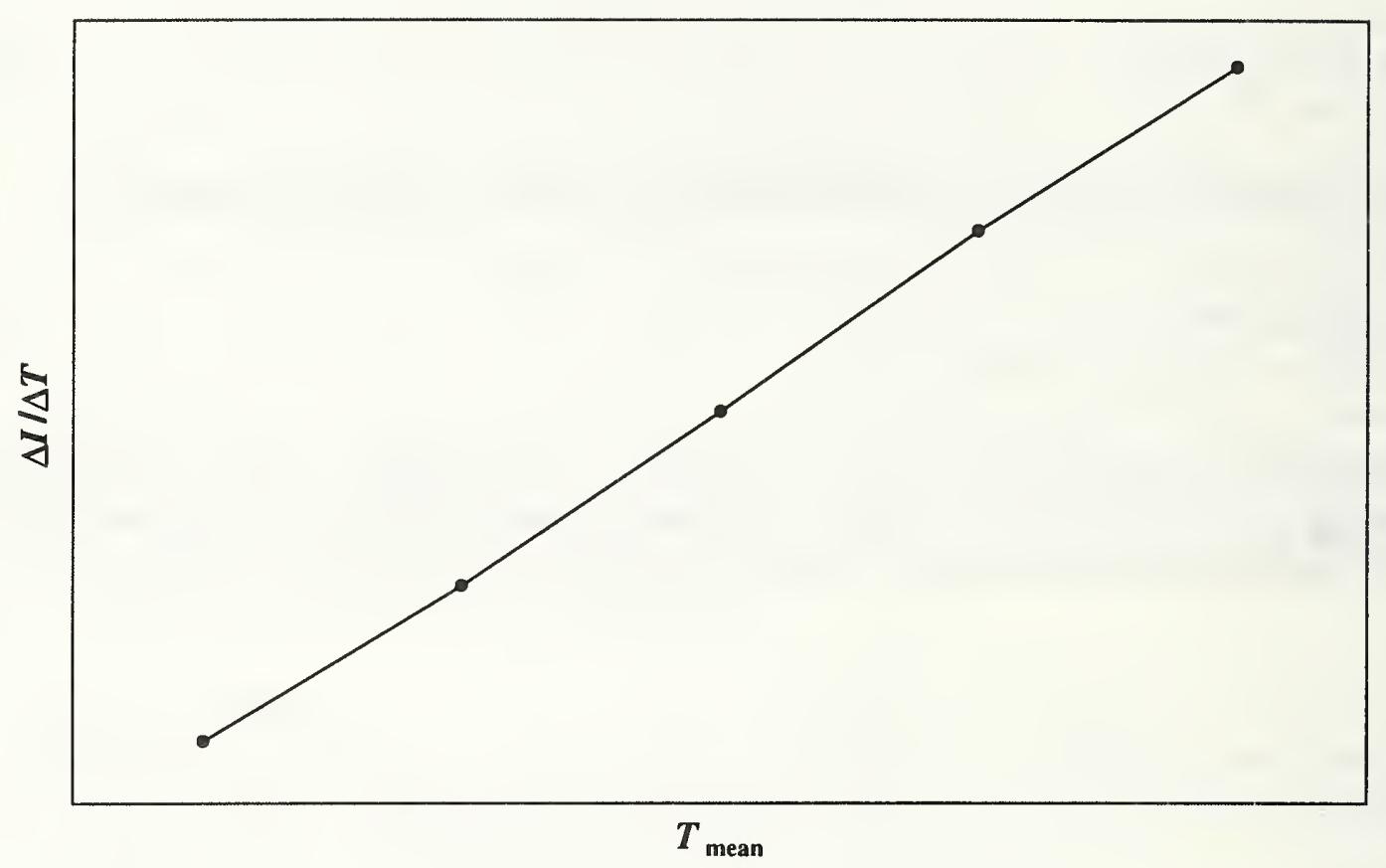

Figure 23. Graph of $T_{\text {mean }}$ and $\Delta l / \Delta T$.

A least squares fit of the entire calibration data sets finds the best curve for the data set but not necessarily for each data point. This method ensures that the direction of the correction is right and has been verified by comparison to the iterative method. Sample data can be found in the "Ribbon Filament Lamp Data Reduction Procedure" in Appendix D.

\subsection{Lamp calibration uncertainty}

To calibrate test lamps (TL), the ratio $\left(r_{2}\right)$ of the spectral radiance of the WS lamp to that of the TL,

$$
r_{2}=\frac{L_{\lambda}\left(T_{\mathrm{TL}}\right)}{L_{\lambda}\left(T_{\mathrm{wS} 2}\right)}=\frac{S_{\mathrm{TL}}}{S_{\mathrm{wS} 2}},
$$


is first measured. Taking into account the correction factors for the signals, the overall measurement equation for the 1990 NIST Scale of Radiance Temperature for calibration of the TL temperature is

$$
T_{\mathrm{TL}}=\frac{c_{2}}{n_{\lambda} \cdot \lambda \cdot \ln \left[1+\frac{\varepsilon_{\lambda, \mathrm{TL}} \cdot c_{1 L}}{n_{\lambda}^{2} \cdot \lambda^{5} \cdot L_{\mathrm{wS} 2} \cdot r_{2}} \frac{\left(C_{\mathrm{A}} \cdot C_{\mathrm{L}} \cdot C_{\mathrm{S}} \cdot G\right)_{\mathrm{WS}}}{\left(C_{\mathrm{A}} \cdot C_{\mathrm{L}} \cdot C_{\mathrm{S}} \cdot G\right)_{\mathrm{TL}}}\right]} .
$$

In a manner similar to eq (28), the uncertainty in the spectral radiance of the WS can be represented by the RSS of products of partial derivatives,

$$
\begin{aligned}
u_{0}\left(T_{\mathrm{TL}}\right) & =\left[\left(\frac{\partial T_{\mathrm{TL}}}{\partial n_{\lambda}} \cdot u\left(n_{\lambda}\right)\right)^{2}+\left(\frac{\partial T_{\mathrm{TL}}}{\partial \lambda} \cdot u(\lambda)\right)^{2}+\left(\frac{\partial T_{\mathrm{TL}}}{\partial c_{2}} \cdot u\left(c_{2}\right)\right)^{2}\right. \\
& \left.+\sum_{i=1}^{12}\left(\frac{\partial T_{\mathrm{TL}}}{\partial x_{i}} \cdot u\left(x_{i}\right)\right)^{2}\right]^{1 / 2},
\end{aligned}
$$

where $x_{\mathrm{i}}$ is one of the variables: $\varepsilon_{\mathrm{TL}}, c_{1 L}, L_{\mathrm{WS}}, r_{2}, C_{\mathrm{A}, \mathrm{WS}}, C_{\mathrm{L}, \mathrm{WS}}, C_{\mathrm{S}, \mathrm{WS}}, G_{\mathrm{WS}}, C_{\mathrm{A}, \mathrm{TL}}, C_{\mathrm{L}, \mathrm{TL}}, C_{\mathrm{S}, \mathrm{TL}}$, or $G_{\mathrm{TL}}$. The partial derivatives of $T_{\mathrm{TL}}$ with respect to $n_{\lambda}, \lambda$, and $c_{2}$ are

$$
\begin{gathered}
\frac{\partial T_{\mathrm{TL}}}{\partial n_{\lambda}}=\frac{T_{\mathrm{TL}}}{n_{\lambda}} \cdot\left[\frac{\varepsilon_{\lambda, \mathrm{TL}} \cdot c_{1 L}}{n_{\lambda}^{2} \cdot \lambda^{5} \cdot L_{\mathrm{WS} 2}} \cdot \frac{2 \cdot \frac{\left(C_{\mathrm{A}} \cdot C_{\mathrm{L}} \cdot C_{\mathrm{S}} \cdot G\right)_{\mathrm{WS}}}{\left(C_{\mathrm{A}} \cdot C_{\mathrm{L}} \cdot C_{\mathrm{S}} \cdot G\right)_{\mathrm{TL}}}}{r_{2} \cdot \frac{c_{2}}{n_{\lambda} \cdot \lambda \cdot T_{\mathrm{TL}}} \cdot \exp \left(\frac{c_{2}}{n_{\lambda} \cdot \lambda \cdot T_{\mathrm{TL}}}\right)}-1\right], \\
\frac{\partial T_{\mathrm{TL}}}{\partial \lambda}=\frac{T_{\mathrm{TL}}}{\lambda} \cdot\left[\frac{\varepsilon_{\lambda, \mathrm{TL}} \cdot c_{1 L}}{n_{\lambda}^{2} \cdot \lambda^{5} \cdot L_{\mathrm{WS} 2}} \cdot \frac{5 \cdot \frac{\left(C_{\mathrm{A}} \cdot C_{\mathrm{L}} \cdot C_{\mathrm{S}} \cdot G\right)_{\mathrm{WS}}}{\left(C_{\mathrm{A}} \cdot C_{\mathrm{L}} \cdot C_{\mathrm{S}} \cdot G\right)_{\mathrm{TL}}}}{r_{2} \cdot \frac{c_{2}}{n_{\lambda} \cdot \lambda \cdot T_{\mathrm{TL}}} \cdot \exp \left(\frac{c_{2}}{n_{\lambda} \cdot \lambda \cdot T_{\mathrm{TL}}}\right)}-1\right] \text {, and }
\end{gathered}
$$

$$
\frac{\partial T_{\mathrm{TL}}}{\partial c_{2}}=\frac{T_{\mathrm{TL}}}{c_{2}} .
$$


The partial derivatives of $T_{\mathrm{TL}}$ with respect to $x$ are

$$
\left|\frac{\partial T_{\mathrm{TL}}}{\partial x}\right|=\frac{T_{\mathrm{TL}}}{x} \cdot \frac{\varepsilon_{\lambda, \mathrm{TL}} \cdot c_{1 L}}{n_{\lambda}^{2} \cdot \lambda^{5} \cdot L_{\mathrm{WS} 2}} \cdot \frac{\frac{\left(C_{\mathrm{A}} \cdot C_{\mathrm{L}} \cdot C_{\mathrm{S}} \cdot G\right)_{\mathrm{WS}}}{\left(C_{\mathrm{A}} \cdot C_{\mathrm{L}} \cdot C_{\mathrm{S}} \cdot G\right)_{\mathrm{TL}}}}{r_{2} \cdot \frac{c_{2}}{n_{\lambda} \cdot \lambda \cdot T_{\mathrm{TL}}} \cdot \exp \left(\frac{c_{2}}{n_{\lambda} \cdot \lambda \cdot T_{\mathrm{TL}}}\right)},
$$

where $x$ is one of the variables labeled $x_{\mathrm{i}}$ in eq (43).

Typical values of the variables in eq (42) are shown in table 9, and the uncertainties of eq (43) are displayed in table 10. The total expanded relative uncertainty $u\left(T_{\mathrm{TL}}\right) / T_{\mathrm{TL}}$ in the TL temperature has contributions from $u_{0}\left(T_{\mathrm{TL}}\right)$ in eq (43), from the uncertainty $u(\mathrm{TLC})$ in the TL current, and from the uncertainty $u(\mathrm{AL})$ in alignment. These contributions are shown in table 10 and are summed by the RSS technique as follows,

$$
\frac{u\left(T_{\mathrm{TL}}\right)}{T_{\mathrm{TL}}}=\left[\left(\frac{u_{0}\left(T_{\mathrm{TL}}\right)}{T_{\mathrm{TL}}}\right)^{2}+\left(\frac{u(\mathrm{TLC})}{T_{\mathrm{TL}}}\right)^{2}+\left(\frac{u(\mathrm{AL})}{T_{\mathrm{TL}}}\right)^{2}\right]^{1 / 2} .
$$

From tables 9 and 10, a typical relative expanded uncertainty in the TL temperature realization is $1.10 \mathrm{~K} / 1973.52 \mathrm{~K}$, or about $0.059 \%$. For other nominal TL temperatures besides $1700^{\circ} \mathrm{C}$, the user is referred to table 2 .

Table 9. Typical values of TL variables and parameters

\begin{tabular}{lcc}
\hline \multicolumn{1}{c}{ Variable } & Symbol & Value \\
\hline Refractive index & $n_{\lambda}$ & 1.00028 \\
Wavelength & $\lambda$ & $655.3 \mathrm{~nm}$ \\
Second radiation constant & $c_{2}$ & $14387.69 \mu \mathrm{m} \cdot \mathrm{K}$ \\
Emissivity of TL & $\varepsilon_{\mathrm{TL}}$ & 1 \\
First radiation constant & $c_{1 L}$ & $1.191 \times 10^{8} \mathrm{~W} \cdot \mu \mathrm{m}^{4} \cdot \mathrm{m}^{-2}$ \\
WS spectral radiance & $L_{\mathrm{WS}}$ & $569.9 \mathrm{~W} \cdot \mathrm{m}^{-2} \cdot \mu \mathrm{m}^{-1} \cdot \mathrm{sr}^{-1}$ \\
Ratio of TL signal to WS signal & $r_{2}$ & 2.551 \\
WS amplifier calibration correction & $C_{\mathrm{A}, \mathrm{WS}}$ & 0.09986 \\
WS linearity correction & $C_{\mathrm{L}, \mathrm{WS}}$ & 1 \\
WS size of source correction & $C_{\mathrm{S}, \mathrm{WS}}$ & 1 \\
WS amplifier gain & $G_{\mathrm{WS}}$ & $1 \times 10^{9} \mathrm{~V} \cdot \mathrm{A}^{-1}$ \\
TL amplifier calibration correction & $C_{\mathrm{A}, \mathrm{TL}}$ & 1 \\
TL linearity correction & $C_{\mathrm{L}, \mathrm{TL}}$ & 1 \\
TL size of source correction & $C_{\mathrm{S}, \mathrm{TL}}$ & 1 \\
TL amplifier gain & $G_{\mathrm{TL}}$ & $1 \times 10^{8} \mathrm{~V} \cdot \mathrm{A}^{-1}$ \\
TL temperature & $T_{\mathrm{TL}}$ & $1973.52 \mathrm{~K}$ \\
\hline
\end{tabular}


Table 10. Uncertainty budget for the TL temperature calibration

\begin{tabular}{|c|c|c|c|}
\hline \multirow{2}{*}{ Uncertainty component } & \multirow{2}{*}{ Symbol } & \multicolumn{2}{|c|}{$\begin{array}{c}\text { Expanded } \\
\text { Uncertainty }(k=2)\end{array}$} \\
\hline & & Type A & Type B \\
\hline Refractive index & $u\left(n_{\lambda}\right)$ & & 0.00002 \\
\hline Wavelength & $u(\lambda)$ & & $0.2 \mathrm{~nm}$ \\
\hline Second radiation constant & $u\left(c_{2}\right)$ & & $0.24 \mu \mathrm{m} \cdot \mathrm{K}$ \\
\hline Emissivity of TL & $u\left(\varepsilon_{\mathrm{TL}}\right)$ & & 0.0002 \\
\hline First radiation constant & $u\left(c_{\mathrm{IL}}\right)$ & & $440 \mathrm{~W} \cdot \mu \mathrm{m}^{4} \cdot \mathrm{m}^{-2}$ \\
\hline WS spectral radiance & $u_{0}\left(L_{\mathrm{WS}}\right)$ & & $2.998 \mathrm{~W} \cdot \mathrm{m}^{-2} \cdot \mu \mathrm{m}^{-1} \cdot \mathrm{sr}^{-1}$ \\
\hline Ratio of TL signal to WS signal & $u\left(r_{2}\right)$ & 0.0051 & \\
\hline WS amplifier calibration correction & $u\left(C_{\mathrm{A}, \mathrm{Ws}}\right)$ & 0.00001 & \\
\hline WS linearity correction & $u\left(C_{\mathrm{L}, \mathrm{WS}}\right)$ & 0.001 & \\
\hline WS size of source correction & $u\left(C_{\mathrm{S}, \mathrm{WS}}\right)$ & 0.0002 & \\
\hline WS amplifier gain & $u\left(G_{\mathrm{ws}}\right)$ & & $0 \mathrm{~V} \cdot \mathrm{A}^{-1}$ \\
\hline TL amplifier calibration correction & $u\left(C_{\mathrm{A}, \mathrm{TL}}\right)$ & 0.0001 & \\
\hline TL linearity correction & $u\left(C_{\mathrm{L}, \mathrm{TL}}\right)$ & 0.001 & \\
\hline TL size of source correction & $u\left(C_{\mathrm{S}, \mathrm{TL}}\right)$ & 0.0002 & \\
\hline TL amplifier gain & $u\left(G_{\mathrm{TL}}\right)$ & & $0 \mathrm{~V} \cdot \mathrm{A}^{-1}$ \\
\hline TL temperature & $u_{0}\left(T_{\mathrm{TL}}\right)$ & & $1.10 \mathrm{~K}$ \\
\hline TL current & $u(\mathrm{TLC})$ & $0.09 \mathrm{~K}$ & \\
\hline Alignment & $u(\mathrm{AL})$ & $0.30 \mathrm{~K}$ & \\
\hline TL temperature calibration & $u\left(\mathrm{~T}_{\mathrm{TL}}\right)$ & & $1.10 \mathrm{~K}$ \\
\hline
\end{tabular}




\section{Disappearing fillament optical pyrometer calibrations}

\subsection{Optical pyrometer preparation}

Disappearing filament optical pyrometers (DFP) are calibrated from $800^{\circ} \mathrm{C}$ to $4200^{\circ} \mathrm{C}$ by comparison to the VTBB. When the test unit arrives, the batteries are checked, the objective lens and eyepiece are cleaned, and the eyepiece is focused onto the DFP lamp filament. The lamp is checked to ensure that it is operating and that matching is possible. If an operating manual is not on file, then one is requested from the customer because test pyrometers are operated according to the manufacturer's instructions unless other instructions are given. The pyrometers and associated electronics are initialized according to manufacturer's specifications.

\subsection{Optical pyrometer calibration}

The DFP is aligned onto the geometric center of the VTBB opening. The DFP is measured at an appropriate distance from the front surface of the objective lens holder to the blackbody cavity partition and is focussed on the center of the partition. After the VTBB is turned on, the pyrometer centering is checked and adjusted as necessary.

For the $800^{\circ} \mathrm{C}$ to $2700{ }^{\circ} \mathrm{C}$ temperature range, the PEP is used to spectrally compare the VTBB to the WS to determine the radiance temperature of the blackbody at each calibration temperature. The VTBB and the WS are compared three times and the mean is used. Once the temperature of the blackbody has been determined, the test DFP lamp filament is matched in brightness to that of the blackbody, and the DFP lamp current is measured using a standard resistor and a digital voltmeter. The matching is performed from bright to disappearance and from dark to disappearance twice and the mean of the four readings is used. The indicated temperature is recorded for pyrometers with either a temperature scale or a digital panel indicator. The output voltage is measured for pyrometers with internal current measuring resistors. The DFP measurements are not bracketed by VTBB measurements because the VTBB has been shown to be stable to within $\pm 0.1{ }^{\circ} \mathrm{C}$ during the time required to complete the measurements.

For temperatures above $2700{ }^{\circ} \mathrm{C}$, the method used to extrapolate the calibration to $4200{ }^{\circ} \mathrm{C}$ involves measuring temperatures below $2700^{\circ} \mathrm{C}$ on two or more ranges. For a three-range DFP with a low range (L) from $1100^{\circ} \mathrm{C}$ to $1700^{\circ} \mathrm{C}$, a medium range (M) from $1700^{\circ} \mathrm{C}$ to $2800^{\circ} \mathrm{C}$, and a high range $(\mathrm{H})$ from $2900^{\circ} \mathrm{C}$ to $4200^{\circ} \mathrm{C}$, the following measurements are performed. The DFP lamp currents are measured for VTBB temperatures from $1100^{\circ} \mathrm{C}$ to $1700^{\circ} \mathrm{C}$ on the $\mathrm{L}$ range, from $1600^{\circ} \mathrm{C}$ to $2700^{\circ} \mathrm{C}$ on the $\mathrm{M}$ range, and from $1700^{\circ} \mathrm{C}$ to $2700^{\circ} \mathrm{C}$ on the $\mathrm{H}$ range.

\subsection{Optical pyrometer data analysis}

The various data reduction methods used are determined by how the DFP indicates temperature. In all cases, the data is sorted by range and averaged and the standard deviation is calculated. For DFPs with ranges below $2700^{\circ} \mathrm{C}$, the data is analyzed and the blackbody temperature versus the scale or panel reading, output current, or output voltage is reported. The pyrometer correction, blackbody temperature minus DFP reading, that is added to the pyrometer reading is reported for scale and panel indicator DFPs.

For the three-range DFP case when temperatures are determined above $2700{ }^{\circ} \mathrm{C}$, more calculations are required before the data is reported. The current measurement averages are fit to 
the curve $I(T)=a_{0}+a_{1} \cdot T+a_{2} \cdot T^{2}+a_{3} \cdot T^{3}$ calculating a least squares approximation for each DFP range. For the $\mathrm{L}$ range the blackbody temperatures are calculated at the nominal temperatures $1100^{\circ} \mathrm{C}, 1200^{\circ} \mathrm{C}, \ldots, 1700^{\circ} \mathrm{C}$ and reported versus the pyrometer lamp currents. For the $\mathrm{M}$ range, the blackbody temperatures are calculated at the nominal temperatures $1700^{\circ} \mathrm{C}$, $1800^{\circ} \mathrm{C}, \ldots, 2700^{\circ} \mathrm{C}$ and reported versus the pyrometer lamp currents. The $2800{ }^{\circ} \mathrm{C}$ calibration point is determined in two steps. The first step is to calculate $A_{\mathrm{M}}$, the " $A$ " value [22] for the M range, which is defined be the relationship,

$$
A=\frac{1}{T_{\mathrm{APP}}}-\frac{1}{T_{\mathrm{BB}}}=\frac{\lambda}{c_{2}} \cdot \ln \tau,
$$

where $T_{\mathrm{APP}}$ is the apparent temperature $[\mathrm{K}], T_{\mathrm{BB}}$ is the blackbody temperature $[\mathrm{K}], \tau$ is the filter transmittance, and $A$ is the " $A$ " value $\left[\mathrm{K}^{-1}\right]$. From eq (44), it becomes apparent that $\ln \tau$ must be approximately equal to $1 / \lambda$ in order for $A$ to be constant. Typically, the value of $A$ is on the order of $173 \times 10^{-6} \mathrm{~K}^{-1} . T_{\mathrm{BB}}$, is determined during the $\mathrm{M}$ range measurements. $T_{\mathrm{APP}}$ is the temperature on the $\mathrm{L}$ range that corresponds to the current measured on the $M$ range which is determined through iteration of the $\mathrm{L}$ range function $I(t)$. The second step is to use the " $A$ " value to calculate the pyrometer lamp current that corresponds to the extrapolated blackbody temperature at $2800{ }^{\circ} \mathrm{C}$. Use eq (44) to calculate $T_{\mathrm{APP} 2}$ when $T_{\mathrm{BB} 2}=3073.15 \mathrm{~K}$ and $A=A_{\mathrm{M}}$. Next calculate the pyrometer lamp current using the $\mathrm{L}$ range function $I(t)$.

This procedure is repeated to determine the extrapolated blackbody temperatures for the $\mathrm{H}$ range. The $\mathrm{H}$ range " $A$-value", $A_{\mathrm{H}}$, is determined where $T_{\mathrm{APP}}$ is the temperature on the $\mathrm{L}$ range that corresponds to the current measured on the $\mathrm{H}$ range and $T_{\mathrm{BB}}$ is the blackbody temperature during the $\mathrm{H}$ range measurements. $A_{\mathrm{H}}$ is then used to calculate the apparent temperature $T_{\mathrm{APP} 2}$ for each extrapolated blackbody temperature from $2900{ }^{\circ} \mathrm{C}$ to $4200{ }^{\circ} \mathrm{C}$. The pyrometer lamp currents are calculated from the $\mathrm{L}$ range function $I(t)$. The extrapolated blackbody temperatures for the $\mathrm{M}$ and $\mathrm{H}$ ranges are reported versus the pyrometer lamp currents.

\subsection{Optical pyrometer calibration uncertainty}

To calibrate disappearing filament optical pyrometers (DFP), the ratio $\left(r_{3}\right)$ of the spectral radiance of the WS lamp to that of the variable-temperature blackbody (BB),

$$
r_{3}=\frac{L_{\lambda}\left(T_{\mathrm{BB}}\right)}{L_{\lambda}\left(T_{\mathrm{wS} 3}\right)}=\frac{S_{\mathrm{BB}}}{S_{\mathrm{wS} 3}},
$$

is first measured to determine the radiance temperature of the $\mathrm{BB}, T\left(\lambda, L_{\lambda, \mathrm{BB}}\right)$, at each disappearing filament optical pyrometer temperature by the equation,

$$
T_{\mathrm{BB}}=\frac{c_{2}}{n_{\lambda} \cdot \lambda \cdot \ln \left[1+\frac{\varepsilon_{\lambda, \mathrm{BB}} \cdot c_{1 L}}{n_{\lambda}^{2} \cdot \lambda^{5} \cdot L_{\mathrm{wS} 3} \cdot r_{3}} \cdot \frac{\left(C_{\mathrm{A}} \cdot C_{\mathrm{L}} \cdot C_{S} \cdot G\right)_{\mathrm{WS}}}{\left(C_{\mathrm{A}} \cdot C_{\mathrm{L}} \cdot C_{\mathrm{S}} \cdot G\right)_{\mathrm{BB}}}\right]} .
$$


The uncertainty in the spectral radiance of the BB can be calculated by the RSS of products of partial derivatives of eq (46) with their respective uncertainties as follows,

$$
\begin{aligned}
u_{0}\left(T_{\mathrm{BB}}\right)= & {\left[\left(\frac{\partial T_{\mathrm{BB}}}{\partial n_{\lambda}} \cdot u\left(n_{\lambda}\right)\right)^{2}+\left(\frac{\partial T_{\mathrm{BB}}}{\partial \lambda} \cdot u(\lambda)\right)^{2}+\left(\frac{\partial T_{\mathrm{BB}}}{\partial c_{2}} \cdot u\left(c_{2}\right)\right)^{2}\right.} \\
& \left.+\sum_{i=1}^{12}\left(\frac{\partial T_{\mathrm{BB}}}{\partial x_{i}} \cdot u\left(x_{i}\right)\right)^{2}\right]^{1 / 2},
\end{aligned}
$$

where $x_{\mathrm{i}}$ is one of the following variables: $\varepsilon_{\mathrm{BB}}, c_{1 L}, r_{3}, C_{\mathrm{A}, \mathrm{ws}}, C_{\mathrm{L}, \mathrm{ws}}, C_{\mathrm{S}, \mathrm{ws}}, G_{\mathrm{WS}}, C_{\mathrm{A}, \mathrm{BB}}, C_{\mathrm{L}, \mathrm{BB}}$, $C_{\mathrm{S}, \mathrm{BB}}$, or $G_{\mathrm{BB}}$. The partial derivatives of $n_{\lambda}, \lambda$, and $c_{2}$ can be derived from eq (46) as

$$
\begin{aligned}
& \frac{\partial T_{\mathrm{BB}}}{\partial n_{\lambda}}=\frac{T_{\mathrm{BB}}}{n_{\lambda}} \cdot\left[\frac{\varepsilon_{\lambda, \mathrm{BB}} \cdot c_{1 L}}{n_{\lambda}^{2} \cdot \lambda^{5} \cdot L_{\mathrm{WS} 3}} \cdot \frac{2 \cdot \frac{\left(C_{\mathrm{A}} \cdot C_{\mathrm{L}} \cdot C_{\mathrm{S}} \cdot G\right)_{\mathrm{WS}}}{\left(C_{\mathrm{A}} \cdot C_{\mathrm{L}} \cdot C_{\mathrm{S}} \cdot G\right)_{\mathrm{BB}}}}{r_{3} \cdot \frac{c_{2}}{n_{\lambda} \cdot \lambda \cdot T_{\mathrm{BB}}} \cdot \exp \left(\frac{c_{2}}{n_{\lambda} \cdot \lambda \cdot T_{\mathrm{BB}}}\right)}-1\right], \\
& \frac{\partial T_{\mathrm{BB}}}{\partial \lambda}=\frac{T_{\mathrm{BB}}}{\lambda} \cdot\left[\frac{\varepsilon_{\lambda, \mathrm{BB}} \cdot c_{1 L}}{n_{\lambda}^{2} \cdot \lambda^{5} \cdot L_{\mathrm{WS} 3}} \cdot \frac{5 \cdot \frac{\left(C_{\mathrm{A}} \cdot C_{\mathrm{L}} \cdot C_{\mathrm{S}} \cdot G\right)_{\mathrm{WS}}}{\left(C_{\mathrm{A}} \cdot C_{\mathrm{L}} \cdot C_{\mathrm{S}} \cdot G\right)_{\mathrm{BB}}}}{r_{3} \cdot \frac{c_{2}}{n_{\lambda} \cdot \lambda \cdot T_{\mathrm{BB}}} \cdot \exp \left(\frac{c_{2}}{n_{\lambda} \cdot \lambda \cdot T_{\mathrm{BB}}}\right)}-1\right] \text {, and } \\
& \frac{\partial T_{\mathrm{BB}}}{\partial c_{2}}=\frac{T_{\mathrm{BB}}}{c_{2}} .
\end{aligned}
$$

The expression,

$$
\left|\frac{\partial T_{\mathrm{BB}}}{\partial x}\right|=\frac{T_{\mathrm{BB}}}{x} \cdot \frac{\varepsilon_{\lambda, \mathrm{BB}} \cdot c_{1 L}}{n_{\lambda}^{2} \cdot \lambda^{5} \cdot L_{\mathrm{WS} 3}} \cdot \frac{\frac{\left(C_{\mathrm{A}} \cdot C_{\mathrm{L}} \cdot C_{\mathrm{S}} \cdot G\right)_{\mathrm{WS}}}{\left(C_{\mathrm{A}} \cdot C_{\mathrm{L}} \cdot C_{\mathrm{S}} \cdot G\right)_{\mathrm{BB}}}}{r_{3} \cdot \frac{c_{2}}{n_{\lambda} \cdot \lambda \cdot T_{\mathrm{BB}}} \cdot \exp \left(\frac{c_{2}}{n_{\lambda} \cdot \lambda \cdot T_{\mathrm{BB}}}\right)},
$$


represents the partial derivatives of $T_{\mathrm{BB}}$ with respect to $x$, where $x$ is one of the variables, $\varepsilon_{\mathrm{BB}}, c_{\mathrm{IL}}$, $r_{3}, C_{\mathrm{A}, \mathrm{ws}}, C_{\mathrm{L}, \mathrm{wS}}, C_{\mathrm{S}, \mathrm{ws}}, G_{\mathrm{WS}}, C_{\mathrm{A}, \mathrm{BB}}, C_{\mathrm{L}, \mathrm{BB}}, C_{\mathrm{S}, \mathrm{BB}}$, or $G_{\mathrm{BB}}$.

A summary of the DFP variable values in eq (46) in table 11 . Uncertainty values from eq (47) are given in table 12 . Table 12 also shows the standard uncertainties leading up to the total standard uncertainty in the DFP temperature,

$$
\frac{u\left(T_{\mathrm{BB}}\right)}{T_{\mathrm{BB}}}=\left[\left(\frac{u_{0}\left(T_{\mathrm{BB}}\right)}{T_{\mathrm{BB}}}\right)^{2}+\left(\frac{u(\mathrm{DMM})}{T_{\mathrm{BB}}}\right)^{2}\right]^{1 / 2} .
$$

The uncertainty in the pyrometer temperature is related to the uncertainty in the variabletemperature blackbody temperature by the following relationship,

$$
\frac{u\left(T_{\mathrm{DFP}}\right)}{T_{\mathrm{DFP}}}=\left[\frac{u^{2}\left(T_{\mathrm{BB}}\right)}{T_{\mathrm{BB}}^{2}}+\left(\frac{u(\mathrm{BU})}{T_{\mathrm{DFP}}}\right)^{2}+\left(\frac{u(\mathrm{PR})}{T_{\mathrm{DFP}}}\right)^{2}\right]^{1 / 2},
$$

where $u(\mathrm{BU})$ is the blackbody uniformity uncertainty and $u(\mathrm{PR})$ is the pyrometer reading uncertainty. The relative expanded uncertainty in the DFP temperature from tables 11 and 12 is $7.57 \mathrm{~K} / 2579.07 \mathrm{~K}$, or $0.29 \%$. The uncertainty values for other DFP temperatures are listed in table 2.

Table 11. Typical values of DFP variables and parameters

\begin{tabular}{lcc}
\hline \multicolumn{1}{c}{ Variable } & Symbol & Value \\
\hline Refractive index & $n_{\lambda}$ & 1.00028 \\
Wavelength & $\lambda$ & $655.3 \mathrm{~nm}$ \\
Second radiation constant & $c_{2}$ & $14387.69 \mu \mathrm{m} \cdot \mathrm{K}$ \\
Emissivity of BB & $\varepsilon_{\mathrm{BB}}$ & 0.99 \\
First radiation constant & $c_{1 \mathrm{~L}}$ & $1.191 \times 10^{8} \mathrm{~W} \cdot \mu \mathrm{m}^{4} \cdot \mathrm{m}^{-2}$ \\
WS spectral radiance & $L_{\mathrm{WS}}$ & $569.9 \mathrm{~W} \cdot \mathrm{m}^{-2} \cdot \mu \mathrm{m}^{-1} \cdot \mathrm{sr}^{-1}$ \\
Ratio of BB signal to WS signal & $r_{3}$ & 3.445 \\
WS amplifier calibration correction & $C_{\mathrm{A}, \mathrm{WS}}$ & 0.09986 \\
WS linearity correction & $C_{\mathrm{L}, \mathrm{WS}}$ & 1 \\
WS size of source correction & $C_{\mathrm{S}, \mathrm{WS}}$ & 1 \\
WS amplifier gain & $G_{\mathrm{WS}}$ & $1 \times 10^{9} \mathrm{~V} \cdot \mathrm{A}^{-1}$ \\
BB amplifier calibration correction & $C_{\mathrm{A}, \mathrm{BB}}$ & 9.978 \\
BB linearity correction & $C_{\mathrm{L}, \mathrm{BB}}$ & 0.9997 \\
BB size of source correction & $C_{\mathrm{S}, \mathrm{BB}}$ & 0.9987 \\
BB amplifier gain & $G_{\mathrm{BB}}$ & $1 \times 10^{7} \mathrm{~V} \cdot \mathrm{A}^{-1}$ \\
BB temperature & $T_{\mathrm{BB}}$ & $2579.07 \mathrm{~K}$ \\
\hline
\end{tabular}


Table 12. Uncertainty budget for the DFP pyrometer temperature calibration

\begin{tabular}{|c|c|c|c|}
\hline \multirow{2}{*}{ Uncertainty factor } & \multirow[t]{2}{*}{ Symbol } & \multicolumn{2}{|c|}{$\begin{array}{c}\text { Expanded } \\
\text { Uncertainty }(k=2)\end{array}$} \\
\hline & & Type A & Type B \\
\hline Refractive index & $u\left(n_{\lambda}\right)$ & & 0.00002 \\
\hline Wavelength & $u(\lambda)$ & & $0.2 \mathrm{~nm}$ \\
\hline Second radiation constant & $u\left(c_{2}\right)$ & & $0.24 \mu \mathrm{m} \cdot \mathrm{K}$ \\
\hline Emissivity of BB & $u\left(\varepsilon_{\mathrm{BB}}\right)$ & & 0.0002 \\
\hline First radiation constant & $u\left(c_{1 \mathrm{~L}}\right)$ & & $440 \mathrm{~W} \cdot \mu \mathrm{m}^{4} \cdot \mathrm{m}^{-2}$ \\
\hline WS spectral radiance & $u\left(L_{\mathrm{Ws}}\right)$ & & $2.998 \mathrm{~W} \cdot \mathrm{m}^{-2} \cdot \mu \mathrm{m}^{-1} \cdot \mathrm{sr}^{-1}$ \\
\hline Ratio of BB signal to WS signal & $u\left(r_{3}\right)$ & 0.00682 & \\
\hline WS amplifier calibration correction & $u\left(C_{\mathrm{A}, \mathrm{ws}}\right)$ & 0.00001 & \\
\hline WS linearity correction & $u\left(C_{\mathrm{L}, \mathrm{WS}}\right)$ & 0.001 & \\
\hline WS size of source correction & $u\left(C_{\mathrm{S}, \mathrm{WS}}\right)$ & 0.0002 & \\
\hline WS amplifier gain & $u\left(G_{\mathrm{WS}}\right)$ & & $0 \mathrm{~V} \cdot \mathrm{A}^{-1}$ \\
\hline $\mathrm{BB}$ amplifier calibration correction & $u\left(C_{\mathrm{A}, \mathrm{BB}}\right)$ & 0.001 & \\
\hline BB linearity correction & $u\left(C_{\mathrm{L}, \mathrm{BB}}\right)$ & 0.001 & \\
\hline $\mathrm{BB}$ size of source correction & $u\left(C_{\mathrm{S}, \mathrm{BB}}\right)$ & 0.0002 & \\
\hline BB amplifier gain & $u\left(G_{\mathrm{BB}}\right)$ & & $0 \mathrm{~V} \cdot \mathrm{A}^{-1}$ \\
\hline Digital voltmeter & $u(\mathrm{DMM})$ & $0 \mathrm{~K}$ & \\
\hline $\mathrm{BB}$ temperature & $u\left(T_{\mathrm{BB}}\right)$ & & $2.34 \mathrm{~K}$ \\
\hline Blackbody uniformity & $u(\mathrm{BU})$ & $0.20 \mathrm{~K}$ & \\
\hline DFP reading & $u(\mathrm{PR})$ & $7.20 \mathrm{~K}$ & \\
\hline DFP temperature calibration & $u\left(\mathrm{~T}_{\mathrm{DFP}}\right)$ & & $7.57 \mathrm{~K}$ \\
\hline
\end{tabular}




\section{Infrared thermometer calibrations}

\subsection{Radiation pyrometer preparation}

Radiation thermometers (RT) are measured for the temperature range from $800{ }^{\circ} \mathrm{C}$ to $2700{ }^{\circ} \mathrm{C}$. The RTs are operated according to the manufacturer's operating instructions unless special instructions are given. First, the lens, eyepiece, and filters are cleaned; then the emissivity control is set to unity. The RT is aligned so that its optical axis, when viewing the VTBB, coincides with the geometrical center of the blackbody.

\subsection{Radiation pyrometer calibration}

The VTBB is turned on and set to the highest temperature measured. After waiting $30 \mathrm{~min}$, the PEP is used to determine the radiance temperature of the VTBB by spectrally comparing it to the WS lamp at each calibration temperature from $2700^{\circ} \mathrm{C}$ to $800^{\circ} \mathrm{C}$ in $100{ }^{\circ} \mathrm{C}$ steps. The measurements are repeated at $2300^{\circ} \mathrm{C}, 1900^{\circ} \mathrm{C}, 1500^{\circ} \mathrm{C}, 1100^{\circ} \mathrm{C}$, and $800^{\circ} \mathrm{C}$ to determine the stability of the RT. The VTBB is compared to the WS three times, and the average of the measurements is used. After the temperature of the VTBB is determined, three RT measurements of the VTBB are made, and the output current, output voltage, or indicated temperature is recorded. The spectral radiance temperatures of the VTBB used in the calibration are determined at wavelengths of $655.3 \mathrm{~nm}, 900 \mathrm{~nm}$, and $1000 \mathrm{~nm}$. For $100{ }^{\circ} \mathrm{C}$ temperature changes, the VTBB is measured after waiting $5 \mathrm{~min}$ for the VTBB to stabilize.

\subsection{Radiation pyrometer data analysis}

For RTs with output currents or voltages, the nominal temperature, the VTBB temperature, and the output current or voltage are reported in the test report. For RT's with temperature indicators, the nominal temperature, the VTBB temperature, the temperature indicated by the RT, and the RT correction are reported in the test report. The RT correction is equal to the VTBB temperature minus the RT indicated temperature.

\subsection{Radiation pyrometer calibration uncertainty}

To calibrate radiation thermometers $(\mathrm{RT})$, the ratio $\left(r_{4}\right)$ of the spectral radiance of the WS lamp to that of the variable-temperature blackbody (BB),

$$
r_{4}=\frac{L_{\lambda}\left(T_{\mathrm{RT}}\right)}{L_{\lambda}\left(T_{\mathrm{WS} 4}\right)}=\frac{S_{\mathrm{RT}}}{S_{\mathrm{WS} 4}},
$$

is first measured to determine the radiance temperature of the $\mathrm{BB}, T\left(\lambda, L_{\lambda, \mathrm{BB}}\right)$, at each test temperature by the equation,

$$
T_{\mathrm{BB}}=\frac{c_{2}}{n_{\lambda} \cdot \lambda \cdot \ln \left[1+\frac{\varepsilon_{\lambda, \mathrm{RT}} \cdot c_{1 \mathrm{~L}}}{n_{\lambda}^{2} \cdot \lambda^{5} \cdot L_{\mathrm{wS} 4} \cdot r_{4}} \cdot \frac{\left(C_{\mathrm{A}} \cdot C_{\mathrm{L}} \cdot C_{\mathrm{S}} \cdot G\right)_{\mathrm{WS}}}{\left(C_{\mathrm{A}} \cdot C_{\mathrm{L}} \cdot C_{\mathrm{S}} \cdot G\right)_{\mathrm{BB}}}\right]} .
$$


The uncertainty in the spectral radiance of the BB can be calculated by the RSS of the products of the partial derivatives in eqs (57) through (60) with their respective uncertainties,

$$
\begin{aligned}
u_{0}\left(T_{\mathrm{BB}}\right) & =\left[\left(\frac{\partial T_{\mathrm{BB}}}{\partial n_{\lambda}} \cdot u\left(n_{\lambda}\right)\right)^{2}+\left(\frac{\partial T_{\mathrm{BB}}}{\partial \lambda} \cdot u(\lambda)\right)^{2}+\left(\frac{\partial T_{\mathrm{BB}}}{\partial c_{2}} \cdot u\left(c_{2}\right)\right)^{2}\right. \\
& \left.+\sum_{i=1}^{12}\left(\frac{\partial T_{\mathrm{BB}}}{\partial x_{i}} \cdot u\left(x_{i}\right)\right)^{2}\right]^{1 / 2},
\end{aligned}
$$

where $x_{\mathrm{i}}$ is one of the following variables: $\varepsilon_{\mathrm{RT}}, c_{1 L}, r_{4}, C_{\mathrm{A}, \mathrm{WS}}, C_{\mathrm{L}, \mathrm{wS}}, C_{\mathrm{S}, \mathrm{WS}}, G_{\mathrm{WS}}, C_{\mathrm{A}, \mathrm{BB}}, C_{\mathrm{L}, \mathrm{BB}}$, $C_{\mathrm{S}, \mathrm{BB}}$, or $G_{\mathrm{BB}}$. From eq (55), the partial derivatives of $n_{\lambda}, \lambda$, and $c_{2}$ are

$$
\begin{aligned}
& \frac{\partial T_{\mathrm{BB}}}{\partial n_{\lambda}}=\frac{T_{\mathrm{BB}}}{n_{\lambda}} \cdot\left[\frac{\varepsilon_{\lambda, \mathrm{RT}} \cdot c_{1 L}}{n_{\lambda}^{2} \cdot \lambda^{5} \cdot L_{\mathrm{WS} 4}} \cdot \frac{2 \cdot \frac{\left(C_{\mathrm{A}} \cdot C_{\mathrm{L}} \cdot C_{\mathrm{S}} \cdot G\right)_{\mathrm{WS}}}{\left(C_{\mathrm{A}} \cdot C_{\mathrm{L}} \cdot C_{\mathrm{S}} \cdot G\right)_{\mathrm{BB}}}}{r_{4} \cdot \frac{c_{2}}{n_{\lambda} \cdot \lambda \cdot T_{\mathrm{BB}}} \cdot \exp \left(\frac{c_{2}}{n_{\lambda} \cdot \lambda \cdot T_{\mathrm{BB}}}\right)}-1\right], \\
& \frac{\partial T_{\mathrm{BB}}}{\partial \lambda}=\frac{T_{\mathrm{BB}}}{\lambda} \cdot\left[\frac{\varepsilon_{\lambda, \mathrm{RT}} \cdot c_{1 L}}{n_{\lambda}^{2} \cdot \lambda^{5} \cdot L_{\mathrm{WS} 4}} \cdot \frac{5 \cdot \frac{\left(C_{\mathrm{A}} \cdot C_{\mathrm{L}} \cdot C_{\mathrm{S}} \cdot G\right)_{\mathrm{WS}}}{\left(C_{\mathrm{A}} \cdot C_{\mathrm{L}} \cdot C_{\mathrm{S}} \cdot G\right)_{\mathrm{BB}}}}{r_{4} \cdot \frac{c_{2}}{n_{\lambda} \cdot \lambda \cdot T_{\mathrm{BB}}} \cdot \exp \left(\frac{c_{2}}{n_{\lambda} \cdot \lambda \cdot T_{\mathrm{BB}}}\right)}-1\right] \text {, and } \\
& \frac{\partial T_{\mathrm{BB}}}{\partial c_{2}}=\frac{T_{\mathrm{BB}}}{c_{2}} .
\end{aligned}
$$

The expression,

$$
\left|\frac{\partial T_{\mathrm{BB}}}{\partial x}\right|=\frac{T_{\mathrm{BB}}}{x} \cdot \frac{\varepsilon_{\lambda, \mathrm{RT}} \cdot c_{1 L}}{n_{\lambda}^{2} \cdot \lambda^{5} \cdot L_{\mathrm{WS} 4}} \cdot \frac{\frac{\left(C_{\mathrm{A}} \cdot C_{\mathrm{L}} \cdot C_{\mathrm{S}} \cdot G\right)_{\mathrm{WS}}}{\left(C_{\mathrm{A}} \cdot C_{\mathrm{L}} \cdot C_{\mathrm{S}} \cdot G\right)_{\mathrm{BB}}}}{r_{4} \cdot \frac{c_{2}}{n_{\lambda} \cdot \lambda \cdot T_{\mathrm{BB}}} \cdot \exp \left(\frac{c_{2}}{n_{\lambda} \cdot \lambda \cdot T_{\mathrm{BB}}}\right)},
$$

represents the partial derivatives of $T_{\mathrm{BB}}$ with respect to $x$, where $x$ is one of the variables, $\varepsilon_{\mathrm{RT}}, c_{1 L}$, 
$r_{4}, C_{\mathrm{A}, \mathrm{ws}}, C_{\mathrm{L}, \mathrm{ws}}, C_{\mathrm{S}, \mathrm{ws}}, G_{\mathrm{WS}}, C_{\mathrm{A}, \mathrm{BB}}, C_{\mathrm{L}, \mathrm{BB}}, C_{\mathrm{S}, \mathrm{BB}}$, or $G_{\mathrm{BB}}$.

Table 13 shows the typical values of the variables in eq (55). The uncertainties of eq (56) are displayed in table 14. Finally, the total expanded uncertainty shown in table 14 is

$$
\frac{u\left(T_{\mathrm{BB}}\right)}{T_{\mathrm{BB}}}=\left[\left(\frac{u_{0}\left(T_{\mathrm{BB}}\right)}{T_{\mathrm{BB}}}\right)^{2}+\left(\frac{u(\mathrm{DMM})}{T_{\mathrm{BB}}}\right)^{2}\right]^{1 / 2} .
$$

The uncertainty in the RT temperature is related to the uncertainty in the variable-temperature blackbody temperature by the following relationship,

$$
\frac{u\left(T_{\mathrm{RT}}\right)}{T_{\mathrm{RT}}}=\left[\frac{u^{2}\left(T_{\mathrm{BB}}\right)}{T_{\mathrm{BB}}^{2}}+\left(\frac{u(\mathrm{BU})}{T_{\mathrm{RT}}}\right)^{2}+\left(\frac{u(\mathrm{RTR})}{T_{\mathrm{RT}}}\right)^{2}\right]^{1 / 2} .
$$

From tables 13 and 14 , the relative expanded uncertainty in the $T_{\mathrm{RT}}$ is $3.05 \mathrm{~K} / 2579.07 \mathrm{~K}$, or $0.12 \%$. For other RT temperatures, table 2 can be used to approximate the uncertainties.

Table 13. Typical values of RT variables and parameters

\begin{tabular}{lcc}
\multicolumn{1}{c}{ Variable } & Symbol & Value \\
\hline Refractive index & $n_{\lambda}$ & 1.00028 \\
Wavelength & $\lambda$ & $655.3 \mathrm{~nm}$ \\
Second radiation constant & $c_{2}$ & $14387.69 \mu \mathrm{m} \cdot \mathrm{K}$ \\
Emissivity of BB & $\varepsilon_{\mathrm{BB}}$ & 0.99 \\
First radiation constant & $c_{1 L}$ & $1.191 \times 10^{8} \mathrm{~W} \cdot \mu \mathrm{m}^{4} \cdot \mathrm{m}^{-2}$ \\
WS spectral radiance & $L_{\mathrm{WS}}$ & $569.9 \mathrm{~W} \cdot \mathrm{m}^{-2} \cdot \mu \mathrm{m}^{-1} \cdot \mathrm{sr}^{-1}$ \\
Ratio of BB signal to WS signal & $r_{4}$ & 3.445 \\
WS amplifier calibration correction & $C_{\mathrm{A}, \mathrm{Ws}}$ & 0.09986 \\
WS linearity correction & $C_{\mathrm{L}, \mathrm{WS}}$ & 1 \\
WS size of source correction & $C_{\mathrm{S}, \mathrm{WS}}$ & 1 \\
WS amplifier gain & $G_{\mathrm{WS}}$ & $1 \times 10^{9} \mathrm{~V} \cdot \mathrm{A}^{-1}$ \\
BB amplifier calibration correction & $C_{\mathrm{A}, \mathrm{BB}}$ & 9.978 \\
BB linearity correction & $C_{\mathrm{L}, \mathrm{BB}}$ & 0.9997 \\
BB size of source correction & $C_{\mathrm{S}, \mathrm{BB}}$ & 0.9987 \\
BB amplifier gain & $G_{\mathrm{BB}}$ & $1 \times 10^{7} \mathrm{~V} \cdot \mathrm{A}^{-1}$ \\
BB temperature & $T_{\mathrm{BB}}$ & $2579.07 \mathrm{~K}$ \\
\hline
\end{tabular}


Table 14. Uncertainty budget for the RT temperature calibration

\begin{tabular}{|c|c|c|c|}
\hline \multirow{2}{*}{ Uncertainty component } & \multirow{2}{*}{ Symbol } & \multicolumn{2}{|c|}{$\begin{array}{c}\text { Expanded } \\
\text { Uncertainty }(k=2)\end{array}$} \\
\hline & & Type A & Type B \\
\hline Refractive index & $u\left(n_{\lambda}\right)$ & & 0.00002 \\
\hline Wavelength & $u(\lambda)$ & & $0.2 \mathrm{~nm}$ \\
\hline Second radiation constant & $u\left(c_{2}\right)$ & & $0.24 \mu \mathrm{m} \cdot \mathrm{K}$ \\
\hline Emissivity of BB & $u\left(\varepsilon_{\mathrm{BB}}\right)$ & & 0.0002 \\
\hline First radiation constant & $u\left(c_{1 L}\right)$ & & $440 \mathrm{~W} \cdot \mu \mathrm{m}^{4} \cdot \mathrm{m}^{-2}$ \\
\hline WS spectral radiance & $u\left(L_{\mathrm{WS}}\right)$ & & $2.998 \mathrm{~W} \cdot \mathrm{m}^{-2} \cdot \mu \mathrm{m}^{-1} \cdot \mathrm{sr}^{-1}$ \\
\hline Ratio of BB signal to WS signal & $u\left(r_{4}\right)$ & 0.00579 & \\
\hline WS amplifier calibration correction & $u\left(C_{\mathrm{A}, \mathrm{WS}}\right)$ & 0.00001 & t \\
\hline WS linearity correction & $u\left(C_{\mathrm{L}, \mathrm{WS}}\right)$ & 0.001 & \\
\hline WS size of source correction & $u\left(C_{\mathrm{S}, \mathrm{WS}}\right)$ & 0.0002 & \\
\hline WS amplifier gain & $u\left(G_{\mathrm{WS}}\right)$ & & $0 \mathrm{~V} \cdot \mathrm{A}^{-1}$ \\
\hline BB amplifier calibration correction & $u\left(C_{\mathrm{A}, \mathrm{BB}}\right)$ & 0.001 & \\
\hline $\mathrm{BB}$ linearity correction & $u\left(C_{\mathrm{L}, \mathrm{BB}}\right)$ & 0.001 & \\
\hline $\mathrm{BB}$ size of source correction & $u\left(C_{\mathrm{S}, \mathrm{BB}}\right)$ & 0.0002 & \\
\hline BB amplifier gain & $u\left(G_{\mathrm{BB}}\right)$ & & $0 \mathrm{~V} \cdot \mathrm{A}^{-1}$ \\
\hline Digital voltmeter & $u(\mathrm{DMM})$ & & $0 \mathrm{~K}$ \\
\hline $\mathrm{BB}$ temperature & $u\left(T_{\mathrm{BB}}\right)$ & & $2.29 \mathrm{~K}$ \\
\hline Blackbody uniformity & $u(\mathrm{BU})$ & $0.20 \mathrm{~K}$ & \\
\hline $\mathrm{RT}$ reading & $u(\mathrm{RTR})$ & $2.00 \mathrm{~K}$ & \\
\hline RT temperature calibration & $u\left(T_{\mathrm{RT}}\right)$ & & $3.05 \mathrm{~K}$ \\
\hline
\end{tabular}




\section{Modifications to the NIST photoelectric pyrometer}

The radiance temperature calibrations described in this document are performed using the NIST PEP, which is a single wavelength instrument. The spectral radiance temperatures at $900 \mathrm{~nm}$ and $1000 \mathrm{~nm}$ are calculated from measurements made at $655.3 \mathrm{~nm}$. Modifications to the PEP are underway to allow direct measurements at $900 \mathrm{~nm}$ and $1000 \mathrm{~nm}$. The modified pyrometer also uses refractive optics, interference filters, and a photomultiplier tube. The modifications will include adding a filtered silicon detector and amplifier system, and a laser to simplify source alignments. A schematic of the modified PEP is shown in figure 24. The methods described in the report to realize the radiance temperature scale at $655.3 \mathrm{~nm}$ will be employed to realize the scale in the infrared.

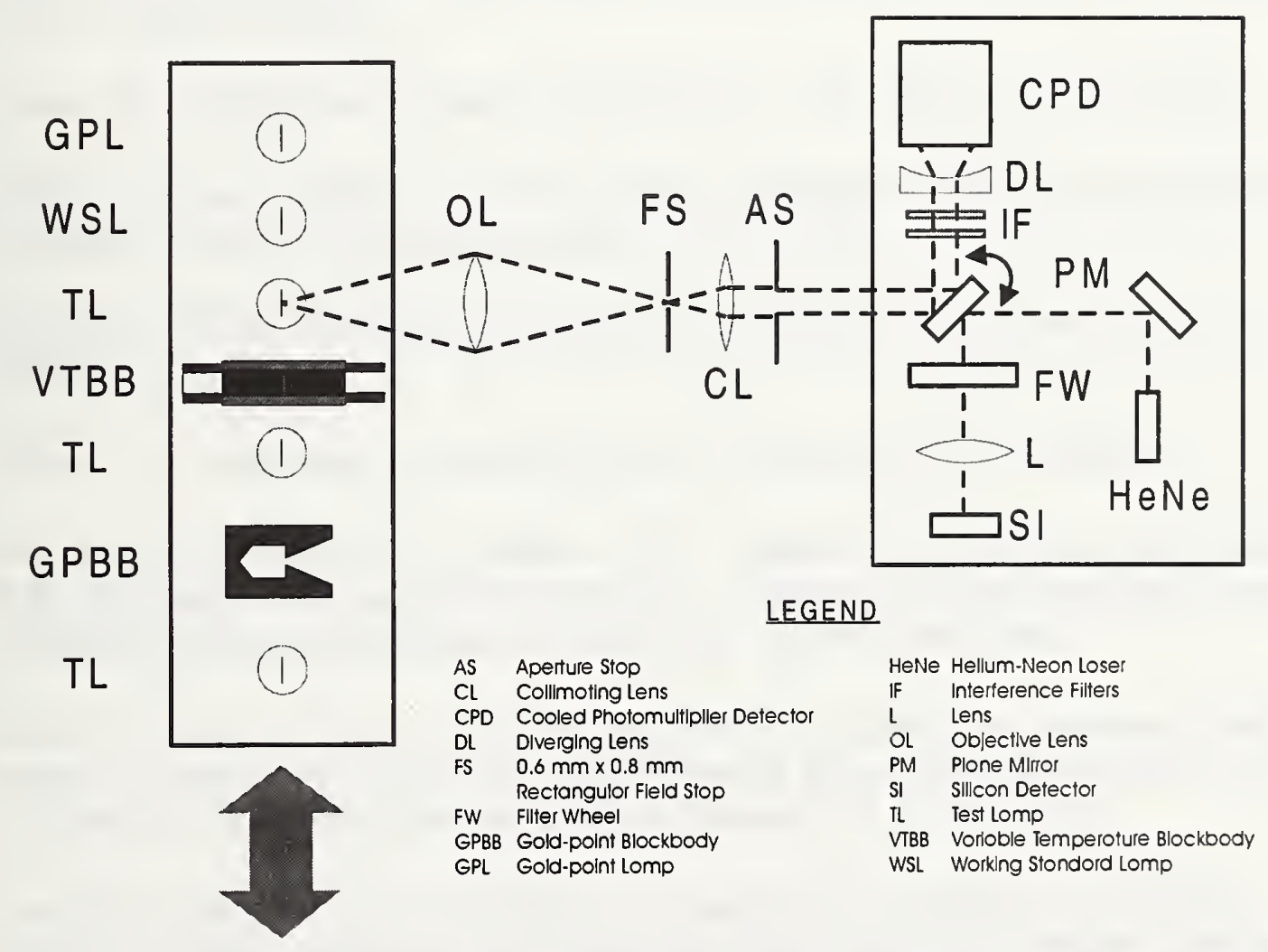

Figure 24. Modified NIST photoelectric pyrometer. 


\section{Acknowledgments}

The authors would like to thank Robert D. Saunders for his technical assistance in reading the manuscript and his constant encouragement. They also like to thank Frank Lovas, Dean Ripple, and Chris Kuyatt for useful suggestions and comments. 


\section{References}

[1] Mielenz, K.D., Saunders, R.D., Parr, A.C., and Hsia, J.J., "The 1990 NIST Scales of Thermal Radiometry," J. Res. NIST, 95, 621 (1990).

[2] Preston-Thomas, H., "The International Temperature Scale of 1990 (ITS-90)," Metrologia, 27, 3-10, 107 (1990).

[3] Taylor, B.N., and Kuyatt, C.E., "Guidelines for Evaluating and Expressing the Uncertainty of NIST Measurement Results," NIST TN 1297 (2nd ed., 1994).

[4] Simmons, J.D. Ed., "NIST Calibration Services Users Guide," NIST SP 250, 69 (1991).

[5] Kostkowski, H.J., and Nicodemus, F.E., "An Introduction to the Measurement Equation, Chapter 5 of Self-Study Manual on Optical Radiation Measurements: Part I - Concepts," NBS TN 910-2, 58 (1978).

[6] Planck, M., "Distribution of Energy in the Spectrum," Ann. Phys., 4, 3, 553 (1901).

[7] Cohen, E.R. and Taylor, B.N., "The 1986 Adjustment of the Fundamental Physical Constants," Review of Modern Physics, 59, 4, 1121 (1987).

[8] Lide, D.R., "CRC Handbook of Chemistry and Physics," CRC Press, 67th ed., E-373 (1986-1987).

[9] Quinn, T.J., "Temperature," Academic Press Inc., San Diego, CA, 380 (1990).

[10] Saunders, R.D., Gibson, C.E., Mielenz, K.D., Sapritsky, V.I., Sudarev, KA., Khlevnoy, B.B., Mekhontsev, S.N, and Harchenko, G.D. , "Results of a NIST/VNIIOFI Comparison of Spectral-Radiance Measurements," Metrologia, 32, 449 (1995/1996).

[11] Quinn, T.J. and Lee, R.D., "Vacuum Tungsten Strip Lamps with Improved Stability as Radiance Temperature Standards," Temperature, Its Measurement and Control in Science and Industry, Instrument Society of America, Pittsburgh, 4, 1, 395 (1972).

[12] Lee, R.D., Kostkowski, H.J., Quinn, T.J., Chandler, P.R., Jones, T.N., Tapping, J., and Kunz, H., "Intercomparison of the IPTS68 Above $1064^{\circ} \mathrm{C}$ by Four National Laboratories," Temperature, Its Measurement and Control in Science and Industry, Instrument Society of America, Pittsburgh, 4, 1, 377 (1972).

[13] Eckerle, K.L., Hsia, J.J., Mielenz, K.D., and Weidner, V.R., "Regular Spectral Transmittance," NBS SP 250-6 (1987). 
[14] Saunders, R.D. and Shumaker,J.B., "Automated Radiometric Linearity Tester," Appl. Opt., 23, 20, 3504, (1984).

[15] Larason, T.C., Bruce, S.S., and Cromer, C.L., "The NIST High Accuracy Scale for Absolute Spectral Response from $406 \mathrm{~nm}$ to $920 \mathrm{~nm}$," J. Res. NIST, 101, 2, 133 (1996).

[16] Mielenz, K.D., Saunders, R.D., and Shumaker, J. B., "Spectroradiometric Determination of the Freezing Temperature of Gold," J. Res. NIST, 95, 49 (1990).

[17] "American National Standard for Calibration - Calibration Laboratories and Measuring and Test Equipment - General Requirements," ANSI/NCSL Z540-1-1994.

[18] "ISO Guide 25 General requirements for the competence of calibration and testing laboratories," 3rd edition (1990).

[19] Bruce, S.S. and Larason, T.C., "Developing Quality System Documentation Based on ANSI/NCSL Z540-1-1994 : The Optical Technology Division's Effort," NISTIR 5866 (1996).

[20] Johnson, B.C., Gibson, C., Machin, G., and Rusby, R.L., "Intercomparison of the ITS-90 radiance temperature scales of the national physical laboratory and NIST," J. Res. NIST, 99, 731 (1994).

[21] Johnson, B.C., Sakuma, F., Sakate, H., Gibson, C., Machin, G., Ricolfi, T., Battuello, M., Fischer, J., and Jung, H.J., "International comparison of radiation temperature scales among five national metrological laboratories using a transfer standard radiation thermometer," Metrolgia, 33, 241 (1996).

[22] Kostkowski, H.J., and Lee, R.D. "Theory and Methods of Optical Pyrometry," NBS Monograph 41, (1962). 
In reply refer to: $\quad 844 / 123456-95$

Radiometric Systems Inc.

Attn: John Doe

123 Calibration Court

Measurement City, MD 00000-0000

Subject: Ribbon Filament Lamp Report of Calibration

Order No.: $\quad$ AB1234 dated January 1, 1995

Dear Mr. Doe:

Enclosed are results of the calibration you requested for Test Number 35050C Radiance Temperature Standard, Ribbon Filament Lamp. Please refer to the above file number in any further communication concerning this calibration.

Sincerely,

Albert C. Parr, Chief

Optical Technology Division

Physics Laboratory

Enclosures:

One Report of Calibration

ACP/jah 


\title{
REPORT OF CALIBRATION
}

\author{
35050C Radiance Temperature Standard, \\ Ribbon Filament Lamp
}

for

Model \# General Electric 30A/T24/6, Serial \# P000

\author{
Submitted by: \\ John Doe \\ Radiometric Systems Inc. \\ 123 Calibration Court \\ Measurement City, MD 00000-0000
}

(See your Purchase Order No. AB 1234 dated January 1, 1995)

\section{Description of Calibration Item}

A gas-filled tungsten ribbon filament lamp with a mogul screw base was calibrated by the National Institute of Standards and Technology (NIST) as a standard of radiance temperature from $1000^{\circ} \mathrm{C}$ to $2200^{\circ} \mathrm{C}$. The serial number is located on the rear of the lamp envelope opposite the side viewed by the pyrometer.

\section{Description of Calibration}

The lamp was calibrated in the NIST Radiance Temperature Calibration Facility using the equipment and procedures described in Ref. [1]. The NIST Photoelectric Pyrometer, which has a mean effective wavelength of $655.3 \mathrm{~nm}$, was used to spectrally compare the test lamp to working standard SL20 to determine its radiance temperature at each test lamp current. The NIST Photoelectric Pyrometer is described in the Ref. [1].

The orientation and operation of the test lamp is described in the enclosed NIST SP250-43 entitled, "Radiance Temperature Calibrations." The calibration was performed with the lamp operating on direct current and with the center contact of the lamp base at positive potential. The lamp was aligned base down while operating at a radiance temperature of $1700{ }^{\circ} \mathrm{C}$.

Laboratory Environment:

Temperature: $24^{\circ} \mathrm{C} \pm 1{ }^{\circ} \mathrm{C}$

Relative Humidity: $25 \% \pm 5 \%$ 


\section{REPORT OF CALIBRATION}

35050C Radiance Temperature Standard, Ribbon Filament Lamp

Radiometric Systems Inc.

\section{Results of Calibration}

Table 1 gives the radiance temperature of the test lamp at $655.3 \mathrm{~nm}$ versus the test lamp current.

Table 2 gives the calibration uncertainties in relative to the International System of Units (SI Units). The expanded uncertainties $U=k u_{c}(T)$ (coverage factor $k=2$ ) are two standard deviation estimates. Details on the estimation of these uncertainties are given in Ref. [1]. The NIST policy on uncertainty statements is described in Ref. [3].

\section{General Information}

The temperatures described in this report are radiance temperatures. The temperatures are stated with respect to the 1990 NIST Radiance Temperature Scale and correspond to temperatures when sighting on a Planckian radiator. See Ref. [2] for further details on the 1990 NIST Radiance Temperature Scale.

To maintain the highest accuracy, keep the lamp envelope clean and have the lamp recalibrated periodically. Appropriate calibration schedules vary with lamp and application and are best determined by the user.

The following was taken from Barber [4]. The radiance temperature below $1500{ }^{\circ} \mathrm{C}$ for gas-filled lamps and $900^{\circ} \mathrm{C}$ for vacuum lamps will change as the room or ambient temperature changes. Barber observed a change in radiance temperature for a gas-filled lamp of between $0.3^{\circ} \mathrm{C}$ and $0.4^{\circ} \mathrm{C}$ per $1{ }^{\circ} \mathrm{C}$ change in room temperature at $1000^{\circ} \mathrm{C}$ and $0.05^{\circ} \mathrm{C}$ per $1{ }^{\circ} \mathrm{C}$ change in room temperature at $1400^{\circ} \mathrm{C}$. Changes of the same magnitude were observed at $700{ }^{\circ} \mathrm{C}$ and $900{ }^{\circ} \mathrm{C}$ for a vacuum lamp.

The results of this calibration apply only to the lamp referenced in this report. This report shall not be reproduced, except in full, without the written approval of the Radiance Temperature Measurements Calibration Service.

Prepared by:

Approved by:

Charles E. Gibson

Optical Technology Division

Physics Laboratory

(301) 975-2329
Robert D. Saunders

For the Director,

National Institute of

Standards and Technology (301) 975-2355

Calibration Date: January 2, 1995

NIST Test No.: 844/123456-95 


\section{REPORT OF CALIBRATION}

35050C Radiance Temperature Standard, Ribbon Filament Lamp

Radiometric Systems Inc.

\section{References}

[1] C. E. Gibson, B. K. Tsai, and A. C. Parr, "Radiance Temperature Calibrations," NIST Special Publication 250-43 (1997).

[2] K. D. Mielenz, R. D. Saunders, A. C. Parr, and J. J. Hsia, "The 1990 NIST Scales of Thermal Radiometry," J. Res. Natl. Inst. Stand. Technol., 95, 621-629, (1990).

[3] B. N. Taylor and C. E. Kuyatt, "Guidelines for Evaluating and Expressing the Uncertainty of the NIST Measurement Results," NIST Technical Note 1297 (2nd ed., 1994).

[4] C. R. Barber, "Factors affecting the reproducibility of brightness of tungsten strip lamps for pyrometry standardization," J. Sci. Instr. 23, 238 (1946). 
35050C Radiance Temperature Standard, Ribbon Filament Lamp

Radiometric Systems Inc.
Model \#: GE 30A/T24/6

Serial \#: P000

TABLE 1

Radiance Temperature of Lamp P000 at $655.3 \mathrm{~nm}$

\begin{tabular}{|c|c|}
\hline $\begin{array}{c}\text { Radiance } \\
\text { Temperature } \\
(1990 \text { NIST }) \\
{\left[{ }^{\circ} \mathrm{C}\right]}\end{array}$ & $\begin{array}{c}\text { Lamp } \\
\text { Current } \\
{[\mathrm{A}]}\end{array}$ \\
\hline 1000 & 12.945 \\
\hline 1100 & 14.220 \\
\hline 1200 & 15.698 \\
\hline 1300 & 17.358 \\
\hline 1400 & 19.191 \\
\hline 1500 & 21.155 \\
\hline 1600 & 23.246 \\
\hline 1700 & 25.449 \\
\hline 1800 & 27.757 \\
\hline 1900 & 30.175 \\
\hline 2000 & 32.669 \\
\hline 2100 & 35.254 \\
\hline 2200 & 37.922 \\
\hline
\end{tabular}

Calibration Date: January 2, 1995

NIST Test No.: 844/123456-95 


\section{REPORT OF CALIBRATION}

35050C Radiance Temperature Standard, Ribbon Filament Lamp

Radiometric Systems Inc.

Model \#: GE 30A/T24/6

Serial \#: P000

TABLE 2

Radiance Temperature Calibration Uncertainties

\begin{tabular}{|c|c|c|c|c|c|c|}
\hline \multirow{2}{*}{ Source of Uncertainty } & \multirow{2}{*}{ Type } & \multicolumn{5}{|c|}{ Expanded Uncertainties $(k=2)\left[{ }^{\circ} \mathrm{C}\right]$} \\
\hline & & $800^{\circ} \mathrm{C}$ & $1100^{\circ} \mathrm{C}$ & $1500^{\circ} \mathrm{C}$ & $1900^{\circ} \mathrm{C}$ & $2300^{\circ} \mathrm{C}$ \\
\hline $\begin{array}{l}\text { 1. Calibration of the reference } \\
\text { radiance temperature lamp } \\
\text { relative to the } 1990 \text { NIST } \\
\text { Radiance Temperature Scale }\end{array}$ & B & 0.12 & 0.19 & 0.32 & 0.48 & 0.67 \\
\hline $\begin{array}{l}\text { 2. Test lamp temperature } \\
\text { determination }\end{array}$ & A & 0.42 & 0.17 & 0.29 & 0.43 & 0.60 \\
\hline 3. Current measurement & B & 0.29 & 0.19 & 0.15 & 0.14 & 0.14 \\
\hline $\begin{array}{l}\text { 4. Mean effective wavelength } \\
\text { measurement for the NIST } \\
\text { Photoelectric Pyrometer }\end{array}$ & B & 0.10 & 0.04 & 0.09 & 0.28 & 0.54 \\
\hline 5. Test lamp alignment & B & 0.09 & 0.14 & 0.24 & 0.36 & 0.51 \\
\hline $\begin{array}{l}\text { 6. } 1990 \text { NIST Radiance } \\
\text { Temperature Scale relative to } \\
\text { the Thermodynamic } \\
\text { Temperature Scale }\end{array}$ & B & 0.15 & 0.24 & 0.40 & 0.61 & 0.85 \\
\hline $\begin{array}{l}\text { Overall uncertainty of test le } \\
\text { calibration with respect to SI }\end{array}$ & nits & 0.6 & 0.4 & 0.7 & 1.0 & 1.5 \\
\hline
\end{tabular}


Appendix B: Optical pyrometer sample calibration report

In reply refer to: $\quad 844 / 123456-95$

Radiometric Systems Inc.

Attn: John Doe

123 Calibration Court

Measurement City, MD 00000-0000

Subject: Optical Pyrometer Report of Calibration

Order No.: $\quad$ AB1234 dated January 1, 1995

Dear Mr. Doe:

Enclosed are results of the calibration you requested for Test Number 35040C Radiance Temperature Standard, Disappearing Filament Optical Pyrometer. Please refer to the above file number in any further communication concerning this calibration.

Sincerely,

Albert C. Parr, Chief

Optical Technology Division

Physics Laboratory

Enclosure:

One Report of Calibration

ACP/jah 


\section{REPORT OF CALIBRATION}

35040C Radiance Temperature Standard,

Disappearing Filament Optical Pyrometer

for

Model \# Leeds and Northrup 8631-F, Serial \# 0000000

Submitted by:

John Doe

Radiometric Systems Inc.

123 Calibration Court

Measurement City, MD 00000-0000

(See your Purchase Order No. AB1234 dated January 1, 1995)

\section{Description of Calibration Item}

An optical pyrometer was tested by the National Institute of Standards and Technology (NIST) as a standard of radiance temperature from $1149^{\circ} \mathrm{C}\left(2100^{\circ} \mathrm{F}\right)$ to $1482{ }^{\circ} \mathrm{C}\left(2700^{\circ} \mathrm{F}\right)$.

\section{Description of Calibration}

The test pyrometer was measured in the NIST Radiance Temperature Calibration Facility using the equipment and procedures described in Ref. [1]. The NIST Photoelectric Pyrometer, which has a mean effective wavelength of $655.3 \mathrm{~nm}$, was used to spectrally compare the variabletemperature blackbody to working standard SL20 to determine the radiance temperature of the blackbody at each calibration temperature. The portion of the test pyrometer lamp filament below the wire marker was matched in brightness to that of the blackbody and the test pyrometer scale reading was recorded at each calibration temperature. The NIST Photoelectric Pyrometer is described in the Ref. [1]

The variable-temperature blackbody has an estimated emissivity of 0.99 . The blackbody cavity is a single piece of graphite, specially tapered for temperature uniformity. This graphite tube is cylindrically hollow on both ends to form two $2.54 \mathrm{~cm}$ diameter cavities with a common partition in the center. One cavity is used for temperature control and the other as a blackbody source.

Laboratory Environment:

Temperature: $23{ }^{\circ} \mathrm{C} \pm 1{ }^{\circ} \mathrm{C}$

Relative Humidity: $46 \% \pm 5 \%$ 


\section{REPORT OF CALIBRATION}

35040C Radiance Temperature Standard, Optical Pyrometer

Radiometric Systems Inc.

The test pyrometer was operated according to the manufacturer's operating instructions. The pyrometer was calibrated from $1149^{\circ} \mathrm{C}\left(2100^{\circ} \mathrm{F}\right)$ to $1482^{\circ} \mathrm{C}\left(2700^{\circ} \mathrm{F}\right)$ on the high range $(\mathrm{H})$. The pyrometer was aligned so that its optical axis, when viewing the variable-temperature blackbody, coincided with the geometrical center of the blackbody. The pyrometer was measured at a distance of $81.7 \mathrm{~cm}$ from the front surface of the objective lens holder to the blackbody cavity partition and was focussed on the center of the partition.

\section{Results of Calibration}

Table 1 gives the radiance temperature at $655.3 \mathrm{~nm}$ versus the test pyrometer scale reading.

Table 2 gives the calibration uncertainties relative to the International System of Units (SI Units). The expanded uncertainties $U=k u_{\mathrm{c}}(T)$ (coverage factor $k=2$ ) are two standard deviation estimates. Details on the estimation of these uncertainties are given in Ref. [1]. The NIST policy on uncertainty statements is described in Ref. [3].

\section{General Information}

The temperatures described in this report are radiance temperatures. The temperatures are stated with respect to the 1990 NIST Radiance Temperature Scale and correspond to temperatures when sighting on a Planckian radiator. See Ref. [2] for further details on the 1990 NIST Radiance Temperature Scale.

To maintain the highest accuracy, keep the optical components clean and have the pyrometer recalibrated periodically. Appropriate calibration schedules vary with instrument and application and are best determined by the user.

The results of this calibration apply only to the pyrometer referenced in this report. This report shall not be reproduced, except in full, without the written approval of the Radiance Temperature Measurements Calibration Service.

Prepared by:

Charles E. Gibson

Optical Technology Division

Physics Laboratory

(301) 975-2329
Approved by:

Robert D. Saunders

For the Director,

National Institute of

Standards and Technology

(301) 975-2355 


\section{REPORT OF CALIBRATION}

35040C Radiance Temperature Standard, Optical Pyrometer

Radiometric Systems Inc.

\section{References}

[1] C. E. Gibson, B. K. Tsai, and A. C. Parr, "Radiance Temperature Calibrations," NIST Special Publication 250-43 (1997).

[2] K. D. Mielenz, R. D. Saunders, A. C. Parr, and J. J. Hsia, "The 1990 NIST Scales of Thermal Radiometry," J. Res. Natl. Inst. Stand. Technol., 95, 621-629, (1990).

[3] B. N. Taylor and C. E. Kuyatt, "Guidelines for Evaluating and Expressing the Uncertainty of the NIST Measurement Results," NIST Technical Note 1297 (2nd ed., 1994). 


\section{REPORT OF CALIBRATION}

35040C Radiance Temperature Standard, Optical Pyrometer

Radiometric Systems Inc.

TABLE 1

Radiance Temperature at $655.3 \mathrm{~nm}$

\begin{tabular}{|c|c|c|c|c|}
\hline $\begin{array}{c}\text { Nominal } \\
\begin{array}{c}\text { Temperature } \\
{\left[{ }^{\circ} \mathrm{C}\right]}\end{array}\end{array}$ & $\begin{array}{c}\text { Blackbody } \\
\text { Temperature } \\
(1990 \mathrm{NIST}) \\
{\left[{ }^{\circ} \mathrm{C}\right]}\end{array}$ & $\begin{array}{c}\text { Blackbody } \\
\text { Temperature } \\
{\left[{ }^{\circ} \mathrm{F}\right]}\end{array}$ & $\begin{array}{c}\text { Pyrometer } \\
\text { Scale Reading } \\
\text { Value }\left[{ }^{\circ} \mathrm{F}\right]\end{array}$ & $\begin{array}{c}\text { Pyrometer } \\
\text { Correction } \\
{\left[{ }^{\circ} \mathrm{F}\right]}\end{array}$ \\
\hline 1148.9 & 1149.2 & 2100.6 & 2098 & 3 \\
\hline 1315.6 & 1316.5 & 2401.7 & 2401 & 1 \\
\hline 1482.2 & 1482.9 & 2701.2 & 2700 & 1 \\
\hline
\end{tabular}

This equation was used to convert the blackbody temperature $T$ from ${ }^{\circ} \mathrm{C}$ to ${ }^{\circ} \mathrm{F}$ :

$$
T /{ }^{\circ} \mathrm{F}=\left(1.8 \times T /{ }^{\circ} \mathrm{C}\right)+32
$$




\section{REPORT OF CALIBRATION}

35040C Radiance Temperature Standard, Optical Pyrometer

Radiometric Systems Inc.

TABLE 2

Radiance Temperature Calibration Uncertainties

\begin{tabular}{|c|c|c|c|c|}
\hline \multirow{2}{*}{ Source of Uncertainty } & \multirow{2}{*}{ Type } & \multicolumn{3}{|c|}{$\begin{array}{l}\text { Expanded Uncertainties }(k=2) \\
{\left[{ }^{\circ} \mathrm{C}\left({ }^{\circ} \mathrm{F}\right)\right]}\end{array}$} \\
\hline & & $\begin{array}{l}1148.9^{\circ} \mathrm{C} \\
\left(2100^{\circ} \mathrm{F}\right)\end{array}$ & $\begin{array}{l}1315.6^{\circ} \mathrm{C} \\
\left(2400^{\circ} \mathrm{F}\right)\end{array}$ & $\begin{array}{l}1482.2^{\circ} \mathrm{C} \\
\left(2700^{\circ} \mathrm{F}\right)\end{array}$ \\
\hline $\begin{array}{l}\text { 1. Calibration of the variable temperature } \\
\text { blackbody relative to the } 1990 \text { NIST } \\
\text { Radiance Temperature Scale }\end{array}$ & B & $\begin{array}{c}0.3 \\
(0.6)\end{array}$ & $\begin{array}{c}0.4 \\
(0.7)\end{array}$ & $\begin{array}{c}0.4 \\
(0.7)\end{array}$ \\
\hline $\begin{array}{l}\text { 2. Mean effective wavelength measurement for } \\
\text { the NIST Photoelectric Pyrometer }\end{array}$ & B & $\begin{array}{c}0.0 \\
(0.0)\end{array}$ & $\begin{array}{c}0.0 \\
(0.0)\end{array}$ & $\begin{array}{c}0.1 \\
(0.2)\end{array}$ \\
\hline 3. Blackbody uniformity & B & $\begin{array}{c}0.2 \\
(0.4)\end{array}$ & $\begin{array}{c}0.2 \\
(0.4)\end{array}$ & $\begin{array}{c}0.2 \\
(0.4)\end{array}$ \\
\hline 4. Test pyrometer temperature determination & A & $\begin{array}{c}1.1 \\
(2.0)\end{array}$ & $\begin{array}{c}1.1 \\
(2.0)\end{array}$ & $\begin{array}{c}2.2 \\
(4.0)\end{array}$ \\
\hline $\begin{array}{l}\text { 5. } 1990 \text { NIST Radiance Temperature Scale } \\
\text { relative to the Thermodynamic Temperature } \\
\text { Scale }\end{array}$ & B & $\begin{array}{c}0.3 \\
(0.5)\end{array}$ & $\begin{array}{c}0.3 \\
(0.6)\end{array}$ & $\begin{array}{c}0.4 \\
(0.7)\end{array}$ \\
\hline $\begin{array}{l}\text { Overall uncertainty of test lamp calibration } \\
\text { respect to SI units }\end{array}$ & with & $\begin{array}{c}1.2 \\
(2.2)\end{array}$ & $\begin{array}{c}1.2 \\
(2.2)\end{array}$ & $\begin{array}{c}2.3 \\
(4.1)\end{array}$ \\
\hline
\end{tabular}

Note: The expanded uncertainties in parentheses are in ${ }^{\circ} \mathrm{F}$. The following equation was used to convert the blackbody temperature $T$ from ${ }^{\circ} \mathrm{C}$ to ${ }^{\circ} \mathrm{F}: T /{ }^{\circ} \mathrm{F}=\left(1.8 \times T /{ }^{\circ} \mathrm{C}\right)+32$ 
Appendix C: Radiation thermometer sample calibration report

In reply refer to: $\quad 844 / 123456-95$

Radiometric Systems Inc.

Attn: John Doe

123 Calibration Court

Measurement City, MD 00000-0000

Subject: $\quad$ Radiation Thermometer Report of Test

Order No.: $\quad$ AB1234 dated January 1, 1995

Dear Mr. Doe:

Enclosed are results of the test you requested for Test Number 35070S Special Test of Radiation Thermometer. Please refer to the above file number in any further communication concerning this test.

Sincerely,

Albert C. Parr, Chief

Optical Technology Division

Physics Laboratory

Enclosure:

One Report of Test

ACP/jah 


\section{REPORT OF TEST}

35070S Special Test of Radiation Thermometer

for

Model \# Minolta-Land Cyclops 52, Serial \# 00000000

Submitted by:

John Doe

Radiometric Systems Inc.

123 Calibration Court

Measurement City, MD 00000-0000

(See your Purchase Order No. AB1234 dated January 1, 1995)

\section{Description of Test Item}

A radiation thermometer was tested by the National Institute of Standards and Technology (NIST) as a standard of radiance temperature from $800^{\circ} \mathrm{C}$ to $2300{ }^{\circ} \mathrm{C}$. The test unit was measured with clear filter (Serial Number 0) and dark filter (Serial Number 0).

\section{Description of Test}

The test thermometer was measured in the NIST Radiance Temperature Calibration Facility using the equipment and procedures described in Ref. [1]. The NIST Photoelectric Pyrometer, which has a mean effective wavelength of $655.3 \mathrm{~nm}$, was used to spectrally compare the variabletemperature blackbody to working standard SL20 to determine the radiance temperature of the blackbody at each calibration temperature. The test thermometer display panel value was recorded at each calibration temperature. The NIST Photoelectric Pyrometer is described in the Ref. [1]

The variable-temperature blackbody has an estimated emissivity of 0.99 . The blackbody cavity is a single piece of graphite, specially tapered for temperature uniformity. This graphite tube is cylindrically hollow on both ends to form two $2.54 \mathrm{~cm}$ diameter cavities with a common partition in the center. One cavity is used for temperature control and the other as a blackbody source.

Laboratory Environment:

Temperature: $23^{\circ} \mathrm{C} \pm 1{ }^{\circ} \mathrm{C}$

Relative Humidity: $46 \% \pm 5 \%$ 
The thermometer was aligned so that its optical axis, when viewing the variable-temperature blackbody, coincided with the geometrical center of the blackbody. The test thermometer was operated according to the manufacturer's operating instructions and measured with the following conditions.

Temperatures measured: $\quad 800{ }^{\circ} \mathrm{C}$ to $1200^{\circ} \mathrm{C}$ with the clear filter $1200{ }^{\circ} \mathrm{C}$ to $2300{ }^{\circ} \mathrm{C}$ with the dark filter

Distance: $100 \mathrm{~cm}$ from the thermometer alignment mark to the blackbody cavity partition

Operating mode: continuous mode

Calculated target size: $5.6 \mathrm{~mm}$ diameter focused on the center of the blackbody cavity partition

Emissivity setting: 1

\section{Results of Test}

Table 1 gives the radiance temperature at $1000 \mathrm{~nm}$ versus the test thermometer display panel value.

Table 2 gives the test uncertainties relative to the International System of Units (SI Units). The expanded uncertainties $U=k u_{\mathrm{c}}(T)$ (coverage factor $k=2$ ) are two standard deviation estimates. Details on the estimation of these uncertainties are given in Ref. [1]. The NIST policy on uncertainty statements is described in Ref. [3].

\section{General Information}

The temperatures described in this report are radiance temperatures. The temperatures are stated with respect to the 1990 NIST Radiance Temperature Scale and correspond to temperatures when sighting on a Planckian radiator. See Ref. [2] for further details on the 1990 NIST Radiance Temperature Scale.

To maintain the highest accuracy, keep the optical components clean and have the thermometer recalibrated periodically. Appropriate calibration schedules vary with instrument and application and are best determined by the user.

The results of this test apply only to the thermometer referenced in this report. This report shall not be reproduced, except in full, without the written approval of the Radiance Temperature Measurements Calibration Service. 


\section{REPORT OF TEST}

35070S Special Test of Radiation Thermometer

Radiometric Systems Inc.

Prepared by:

Charles E. Gibson

Optical Technology Division

Physics Laboratory

(301) 975-2329
Model \#: Minolta-Land Cyclops 52

Serial \#: 00000000

Approved by:

Robert D. Saunders

For the Director,

National Institute of

Standards and Technology

(301) $975-2355$

\section{References}

[1] C. E. Gibson, B. K. Tsai, and A. C. Parr, "Radiance Temperature Calibrations," NIST Special Publication 250-43 (1997).

[2] K. D. Mielenz, R. D. Saunders, A. C. Parr, and J. J. Hsia, "The 1990 NIST Scales of Thermal Radiometry," J. Res. Natl. Inst. Stand. Technol., 95, 621-629, (1990).

[3] B. N. Taylor and C. E. Kuyatt, "Guidelines for Evaluating and Expressing the Uncertainty of the NIST Measurement Results," NIST Technical Note 1297 (2nd ed., 1994). 
TABLE 1

Radiance Temperature at $1000 \mathrm{~nm}$

\begin{tabular}{|c|c|c|c|}
\hline $\begin{array}{c}\text { Nominal } \\
\text { Temperature } \\
{\left[{ }^{\circ} \mathbf{C}\right]}\end{array}$ & $\begin{array}{c}\text { Blackbody } \\
\text { Temperature } \\
(\mathbf{1 9 9 0} \text { NIST }) \\
{\left[{ }^{\circ} \mathbf{C}\right]}\end{array}$ & $\begin{array}{c}\text { Thermometer } \\
\text { Display Panel } \\
\text { Value } \\
{\left[{ }^{\circ} \mathbf{C}\right]}\end{array}$ & $\begin{array}{c}\text { Thermometer } \\
\text { Correction } \\
{\left[{ }^{\circ} \mathbf{C}\right]}\end{array}$ \\
\hline 800 & 798.7 & 801 & -2.3 \\
\hline 900 & 899.1 & 900 & -0.9 \\
\hline 1000 & 1000.2 & 1000.5 & -0.3 \\
\hline 1100 & 1100.6 & 1100.5 & 0.1 \\
\hline 1200 & 1200.5 & 1199.5 & 1.0 \\
\hline \multicolumn{4}{|c|}{ Clear Filter } \\
\hline 1200 & 1200.4 & 1200 & 0.4 \\
\hline 1300 & 1299.4 & 1298 & 1.4 \\
\hline 1400 & 1399.6 & 1396.5 & 3.1 \\
\hline 1500 & 1500.3 & 1497 & 3.3 \\
\hline 1600 & 1600.6 & 1597 & 3.6 \\
\hline 1700 & 1700.5 & 1696.5 & 4.0 \\
\hline 1800 & 1801.7 & 1797 & 4.7 \\
\hline 1900 & 1899.5 & 1894 & 5.5 \\
\hline 2000 & 1999.9 & 1992 & 7.9 \\
\hline 2100 & 2099.9 & 2091.5 & 8.4 \\
\hline 2200 & 2200.7 & 2191 & 9.7 \\
\hline 2300 & 2301.2 & 2290 & 11.2 \\
\hline
\end{tabular}

Test Date: January 2, 1995 
$35070 S$ Special Test of Radiation Thermometer

Radiometric Systems Inc.

Model \#: Minolta-Land Cyclops 52

Serial \#: 00000000

TABLE 2

Radiance Temperature Test Uncertainties

\begin{tabular}{|c|c|c|c|c|c|c|}
\hline \multirow{2}{*}{ Source of Uncertainty } & \multirow{2}{*}{ Type } & \multicolumn{5}{|c|}{ Expanded Uncertainties $(k=2)\left[{ }^{\circ} \mathrm{C}\right]$} \\
\hline & & $800^{\circ} \mathrm{C}$ & $1100^{\circ} \mathrm{C}$ & $1500^{\circ} \mathrm{C}$ & $1900^{\circ} \mathrm{C}$ & $2300^{\circ} \mathrm{C}$ \\
\hline $\begin{array}{l}\text { 1. Calibration of the variable } \\
\text { temperature blackbody } \\
\text { relative to the } 1990 \text { NIST } \\
\text { Radiance Temperature Scale }\end{array}$ & B & 0.3 & 0.3 & 0.4 & 0.6 & 0.9 \\
\hline $\begin{array}{l}\text { 2. Mean effective wavelength } \\
\text { measurement for the NIST } \\
\text { Photoelectric Pyrometer }\end{array}$ & B & 0.1 & 0.0 & 0.1 & 0.3 & 0.5 \\
\hline $\begin{array}{l}\text { 3. Blackbody temperature } \\
\text { correction }\end{array}$ & B & 0.1 & 0.2 & 0.4 & 0.6 & 0.8 \\
\hline 4. Blackbody uniformity & B & 0.2 & 0.2 & 0.2 & 0.2 & 0.2 \\
\hline $\begin{array}{l}\text { 5. Test thermometer temperature } \\
\text { determination }\end{array}$ & A & 2.0 & 2.0 & 2.0 & 2.0 & 2.0 \\
\hline $\begin{array}{l}\text { 6. } 1990 \text { NIST Radiance } \\
\text { Temperature Scale relative to } \\
\text { the Thermodynamic } \\
\text { Temperature Scale }\end{array}$ & B & 0.1 & 0.2 & 0.4 & 0.6 & 0.9 \\
\hline $\begin{array}{l}\text { Overall uncertainty of test Is } \\
\text { calibration with respect to SI }\end{array}$ & & 2.0 & 2.1 & 2.1 & 2.3 & 2.5 \\
\hline
\end{tabular}


Radiance Temperature Measurements Laboratory Procedures Manual

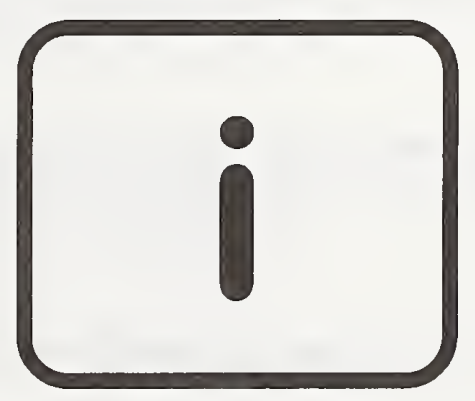




\section{Safety Issues}

Safety glasses are required in lab at all times.

The following hazards have been identified in this lab. Safety measures are in place to reduce risk of injury from hazards below.

\section{BRIGHT SOURCE}

Staring at source is to be avoided because staring can cause severe eye damage. Using correct neutral density filter when viewing is required

\section{BURN}

To avoid burns, it is wise to keep body and clothes away from lamps and blackbodies.

\section{COLLISION}

The boxcar path should be kept clear of collision with any objects, and cables should not be hung from boxcar at any time.

\section{ELECTROCUTION}

Since high voltage cornections are present, electrical parts should not be touched at all.

\section{LASER}

As with other bright sources, staring into laser is to be avoided because staring can cause severe eye damage. When lasers are not in use, block laser with opaque object and turn off laser when it is not in use.

Symbols, similar to one below, are used throughout this document to alert operator to potential hazards.

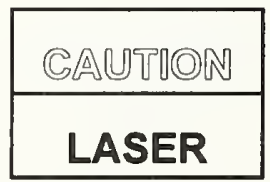




\section{Table of Contents}

i. Safety Issues

1. Running General Data Taking Program (RTMLP1)

2. NIST Photoelectric Pyrometer (PEP) Operation (RTMLP2)

3. Gold-point Blackbody (GPBB) Alignment (RTMLP3)

4. Gold-point Blackbody Operation (RTMLP4)

5. Ribbon Filament Lamp Preparation (RTMLP5)

6. Ribbon Filament Lamp Alignment (RTMLP6)

7. Ribbon Filament Lamp Operation (RTMLP7)

8. Ribbon Filament Lamp Calibration Procedure (RTMLP8)

9. Ribbon Filament Lamp Data Reduction (RTMLP9)

10. Variable Temperature Blackbody (BB) Alignment (RTMLP10)

11. Variable Temperature Blackbody Operation (RTMLP11)

12. Disappearing Filament Optical Pyrometer Alignment (RTMLP12)

13. Radiation Thermometer (RT) Ailignment (RTMLP13)

14. Radiation Thermometer (Optical Pyrometer) Calibration Procedure (RTMLP14)

15. Radiation Thermometer Data Reduction (RTMLP15) 


\section{Optical Technology Division (844) \\ Radiance Temperature Measurements Laboratory Procedure \\ Running General Data Taking Program}

Written by: Charles Gibson

Approved by:

Revised by:
Procedure: RTMLP1

Date:

Date:

Running the General Data Taking Program

1. Turn on computer

2. Enter password to work online or click on Cancel button to work offline

3. Load Visual Basic program: c:|programs|datatakn|pyro.mak (do one of following)

a. Click on Pyro.mak shortcut icon

b. Double click on folder c:|programs|datatakn|pyro.mak using Windows Explorer

4. Run program (do one of following)

a. Press F5

b. Click on tool bar icon

c. Click on menu item "Run" then "Start"

5. Run Hardware.frm to set up equipment with settings used by other programs

6. Run Software.frm to input data used by other programs

7. Run all other programs from these forms 
Optical Technology Division (844)

Radiance Temperature Measurements Laboratory Procedure

NIST Photoelectric Pyrometer (PEP) Operation

Written by: Charles Gibson

Procedure: RTMLP2

Approved by:

Date:

Revised by:

Date:

NIST Photoelectric Pyrometer (PEP) Operation

1. Turn on equipment

a. PMT thermoelectric cooler

b. Digital multimeters

c. Motor controller

d. High voltage power supply

e. Current amplifier

f. Environment monitor

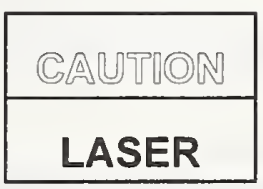

2. Check alignment of optics

a. Align laser on source table so that beam goes through center of pin hole aperture and field stop

b. Check that collimating lens is centered on and normal to optical axis (retroreflection checked at field stop)

c. Check that aperture stop is centered on and normal to optical axis (place microscope slide against aperture stop to check retroreflection at field stop)

d. $\quad$ Check scope alignment (see step 3)

e. Check that lamp beam is centered on aperture stop

f. Record aperture stop micrometer position in lab notebook

\begin{tabular}{|c|}
\hline CAUUTION \\
\hline BRIGHT SOURCE \\
\hline BURN \\
\hline COLLISION \\
\hline ELECTROCUTION \\
\hline
\end{tabular}


3. Check scope alignment (scope is used to define optical axis of PEP)

a. Turn on SL20 or other lamp in focal plane of PEP (see RTMLP7)

b. Move lamp to PEP

c. Close PMT shutter

d. Open enclosure doors

e. Open scope door

f. Place $3 / 4$ " aperture on objective lens

g. Put in field stop

h. Put in prism

i. Focus reticle to operator's eye

j. $\quad$ Focus scope on field stop

k. Rotate reticle so that \#5 vertical scale line is parallel to side of field stop opening

1. Position reticle center (intersection of \#5 vertical scale line and horizontal scale line) on field stop opening

m. Remove prism

n. Remove field stop

o. Put in prism

4. Set up PEP for measurements

a. Remove aperture from objective lens

b. Remove prism

c. Close scope door

d. Put in field stop

e. Close all enclosure doors

f. Position baffles at front of PEP

g. Open PMT shutter

h. Begin calibration (see (RTMLP8) for lamps or (RTMLP14) for radiation thermometers) 
Written by: Charles Gibson

Approved by:

Revised by:
Procedure: RTMLP3

Date:

Date:

Gold-point Blackbody (GPBB) Alignment

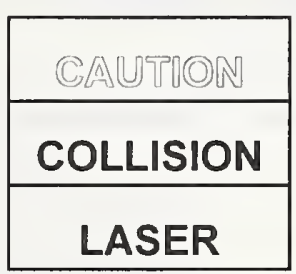

1. Align laser on source table so that beam goes through center of pin hole aperture and field stop

2. Move first laser to laser on PEP table

3. Align second laser so that it coincides with first laser

4. Remove outer most graphite ring

5. Put in alignment jig

6. Translate GPBB to center jig on laser

7. Rotate GPBB to make jig normal to laser (retroreflect laser beam)

8. Turn on GPBB (see RTMLP4)

9. Radiometrically center GPBB

a. Center $\mathrm{X}$ along horizontal axis

b. Center $\mathrm{Y}$ along vertical axis

c. $\quad$ Center $<\mathrm{X}$ about horizontal axis

d. $\quad$ Center $<\mathrm{Y}$ about vertical axis

e. Make \pm 8 turns along optical axis

f. Repeat steps a and b until centered

g. Check centering

i. Monitor BB signal on graph logger

ii. Hold card in front of BB opening

iii. Check for equal signal drop-offs when blocking top, bottom, left, and right portions of $\mathrm{BB}$ opening 


\section{Optical Technology Division (844) \\ Radiance Temperature Measurements Laboratory Procedure \\ Gold-point Blackbody Operation}

Written by: Charles Gibson

Procedure: RTMLP4

Approved by:

Date:

Revised by:

Date:

Gold-point Blackbody (GPBB) Operation

\begin{tabular}{|c|}
\hline CAUTION \\
\hline BRIGHT SOURCE \\
\hline BURN \\
\hline ELECTROCUTION \\
\hline
\end{tabular}

1. Close GPBB door

2. Turn on cold water at flow rate of $10 \mathrm{GPH}$

3. Set argon at flow rate of $54 \mathrm{~mL} / \mathrm{min}$ (set black ball to 50 )

4. Go to rack of power supplies

5. Turn on digital multimeter

6. Check that correct cable is connected to GPBB power supply connector

7. Switch on power supply (labeled HPPS)

8. Run lamp current monitoring program

a. Turn on computer

b. $\quad$ Type 2 and press [Enter] at DOS prompt to load and run lamp monitoring program

c. Prepare GPBB

i. $\quad$ Ramp up GPBB

(1) Ramp up GPBB to about $1040{ }^{\circ} \mathrm{C}$

(2) Set current at $2 \mathrm{~A}$

(3) Wait $3 \mathrm{~h}$

(4) Ramp up to $8 \mathrm{~A}$ in $4 \mathrm{~h}$ (ramping rate $1.5 \mathrm{~A} / \mathrm{h}$ )

(5) Set GPBB temperature to about $1040{ }^{\circ} \mathrm{C}$ in $8 \mathrm{~h}$ to $10 \mathrm{~h}$

ii. $\quad$ Press 8 to ramp up GPBB

iii. Type (start time) and press [Enter]

iv. program will start ramping up GPBB at start time 
Optical Technology Division (844)

Radiance Temperature Measurements Laboratory Procedure

Procedure RTMLP4: Gold-point Blackbody Operation

d. Cycle GPBB through melt and freeze cycles

i. $\quad$ Press 3 to monitor lamps and read GPBB temperature

ii. Press [Esc] to return to main menu

iii. Set current to $8.5 \mathrm{~A}$ and begin GPBB melt cycle when set point falls below $1050{ }^{\circ} \mathrm{C}$

iv. Set current to $7.95 \mathrm{~A}$ and begin GPBB freeze cycle when set point rises above $1071{ }^{\circ} \mathrm{C}$

9. Set argon at flow rate of $235 \mathrm{~mL} / \mathrm{min}$ (set black ball to 120)

10. Open GPBB door

11. Turn off GPBB
a. Close GPBB door
b. Set argon at flow rate of $54 \mathrm{~mL} / \mathrm{min}$ (set black ball to 50)
c. Turn of power to GPBB
d. Leave water and argon on overnight until GPBB is cool 
Date:

Ribbon Filament Lamp Preparation

\begin{tabular}{|c|}
\hline CAUTION \\
\hline BRIGHT SOURCE \\
\hline BURN \\
\hline ELECTROCUTION \\
\hline
\end{tabular}

1. Lamp inspection

a. Check filament continuity

b. Check clarity of envelope (and window)

c. Check flatness of filament

d. Check that filament is within $2 \mathrm{~mm}$ of being centered in envelope (or window)

2. Clean lamp envelope

3. Anneal lamp

a. Anneal gas lamp

i. Leak test lamp

(1) Set lamp to $1700{ }^{\circ} \mathrm{C}$ (PMT signal $=2.5 \mathrm{~V}$ on 8 range, high voltage $=449 \mathrm{~V})($ About $25 \mathrm{~A} \mathrm{dc})$

(2) Turn off lamp

(3) Wait $15 \mathrm{~min}$ to allow air to enter any leaks

(4) Set lamp to $2350{ }^{\circ} \mathrm{C}$ (PMT signal $=1.2 \mathrm{~V}$ on 7 range, high voltage $=394 \mathrm{~V})($ About $45 \mathrm{~A} \mathrm{dc})$

(5) Wait $15 \mathrm{~min}$

ii. Anneal lamp for $2 \mathrm{~h}$

iii. Age lamp for $50 \mathrm{~h}$ at $2300{ }^{\circ} \mathrm{C}$ (About $42 \mathrm{~A} \mathrm{dc}$ ) 


\section{Optical Technology Division (844) \\ Radiance Temperature Measurements Laboratory Procedure \\ Procedure RTMLP5: Ribbon Filament Lamp Preparation}

b. Anneal vacuum lamp

i. Leak test lamp

(1) Set lamp to $1000{ }^{\circ} \mathrm{C}(\mathrm{PMT}$ signal $=5.3 \mathrm{~V}$ on 9 range, high voltage $=730 \mathrm{~V}$ )

(2) Turn off lamp

(3) Wait $15 \mathrm{~min}$ to allow air to enter any leaks

(4) Set lamp to $1450{ }^{\circ} \mathrm{C}$ (PMT signal $=5.1 \mathrm{~V}$ on 9 range, high voltage $=449 \mathrm{~V}$ )

(5) Wait $15 \mathrm{~min}$

ii. Anneal lamp for $14 \mathrm{~h}$

4. Locate arrow on lamp

a. Set lamp to $1700{ }^{\circ} \mathrm{C}$ for gas lamps or $1200{ }^{\circ} \mathrm{C}$ for vacuum lamps (for $1200{ }^{\circ} \mathrm{C}$,

PMT signal $=5.5 \mathrm{~V}$ on 8 range, high voltage $=730 \mathrm{~V}$ )

b. Use plumb line to make notch side of filament vertical

c. Translate lamp horizontally so that reticle center bisects filament lengthwise

d. Translate lamp vertically so that reticle center is positioned at center of notch opening

e. Translate lamp along optical axis until filament is in focus

f. Rotate lamp about vertical axis so that both edges of filament are in focus

g. Use graph logger to locate angular settings with smallest change in radiance with respect to rotation about horizontal and vertical axes

h. First person looks through alignment scope and guides second person to notch

i. Second person makes dot on lamp envelope at notch

j. Draw picture of notch in lab notebook showing its relationship to dot

k. Draw arrow showing relationship of alignment arrow to dot

1. Repeat steps for each lamp 


\section{Ribbon Filament Lamp Alignment}

Written by: Charles Gibson

Procedure: RTMLP6

Approved by:

Date:

Revised by:

Date:

Ribbon Filament Lamp Alignment

\begin{tabular}{|c|}
\hline CAUTION \\
\hline BRIGHT SOURCE \\
\hline BURN \\
\hline COLLISION \\
\hline ELECTROCUTION \\
\hline
\end{tabular}

1. Check PEP scope alignment (see RTMLP2)

2. Place $3 / 4$ " aperture on objective lens

3. Turn on lamp (see RTMLP7)

4. Move lamp to PEP optical axis

5. Use plumb line to make notch side of filament vertical

6. Translate lamp horizontally so that reticle center bisects filament lengthwise

7. Translate lamp vertically so that reticle center is positioned at height of notch opening

8. Translate lamp along optical axis until filament is in focus

9. Rotate lamp about vertical axis so that both edges of filament are in focus

10. Translate lamp horizontally and vertically to reticle center

11. Place $1 / 4$ " aperture on objective lens

12. Place mirror behind lamp alignment arrow

13. Rotate lamp about horizontal axis so that tip of arrowhead is positioned at height of notch opening

14. Rotate lamp about vertical axis so that tip of arrowhead is positioned at notch opening

15. Repeat steps 13 and 14 until tip of arrowhead is centered at notch opening

16. Translate lamp horizontally and vertically to reticle center at height of notch

17. Repeat steps 3 to 16 for standard and test lamps

18. Set up PEP for measurements (see RTMLP2) 


\section{Optical Technology Division (844) \\ Radiance Temperature Measurements Laboratory Procedure \\ Ribbon Filament Lamp Operation}

Written by: Charles Gibson

Procedure: RTMLP7

Approved by:

Date:

Revised by:

Date:

Ribbon Filament Lamp Operation

\begin{tabular}{|c|}
\hline CAUTION \\
\hline BRIGHT SOURCE \\
\hline BURN \\
\hline ELECTROCUTION \\
\hline
\end{tabular}

1. Use Kimwipe to avoid touching lamp envelope

2. Place lamp in socket

a. Check lamp polarity (center contact for screw base, longer filament support for mogal base at positive potential)

b. Set alignment arrow or mark away from PEP

3. Go to rack of power supplies

4. Turn on digital multimeter

5. Turn on GP-IB Programmer(s) for supply(s) to be used

a. cables and programmers are numbered with corresponding power supply number

b. programmers are two channel 12 bit D/A converters

6. Check that correct cable is connected to power supply

7. Switch on power supply

8. Run lamp current monitoring program

a. Turn on computer

b. Type 2 and press [Enter] at DOS prompt to load and run lamp monitoring program

c. Set lamp current

i. Press 1 to set power supply current

ii. Type (supply \#) and press [Enter]

iii. Type (lamp current) and press [Enter]

d. Monitor lamp currents

i. Press 3

ii. Press [Esc] to return to main menu 
e. Turn off supply

i. $\quad$ Press 2

ii. Type (supply \#) and press [Enter]

f. Change lamp current

i. $\quad$ same as (1)

g. Set multiple lamp currents

i. $\quad$ Press A to select power supplies to turn on

ii. Type (lamp current) and press [Enter] to select supplies to turn on

iii. Type 0 and press [Enter] to skip supply

h. Turn off all supplies

i. $\quad$ Press B to turn off all lamps

ii. Type OFF and press [Enter] to turn off all lamps

i. Trouble-shoot

i. $\quad$ Check program locking

(1) Type Ctrl [Break]

(2) Type GOTO 20, press [Enter] to return to main menu

9. Align lamps (see RTMLP6)

10. Use EMERGENCY TURN OFF procedure when necessary
a. Go to supply
b. Turn CURRENT knob counter clockwise to turn down lamp current
c. Turn off supply
d. Turn off GP-IB Programmer for supply 
Optical Technology Division (844)

Radiance Temperature Measurements Laboratory Procedure

Ribbon Filament Lamp Procedure

Written by: Charles Gibson

Approved by:

Revised by:
Procedure: RTMLP8

Date:

Date:

\section{Ribbon Filament Lamp Calibration Procedure}

1. Review calibration summary

a. Align and measure test lamp at $1700{ }^{\circ} \mathrm{C}$

b. Measure $2300{ }^{\circ} \mathrm{C}$ to $800{ }^{\circ} \mathrm{C}$ in $100{ }^{\circ} \mathrm{C}$ steps

c. Repeat $1700{ }^{\circ} \mathrm{C}, 2300{ }^{\circ} \mathrm{C}, 1900{ }^{\circ} \mathrm{C}, 1500{ }^{\circ} \mathrm{C}, 1100{ }^{\circ} \mathrm{C}$, and $800{ }^{\circ} \mathrm{C}$

2. Run general data taking program (see RTMLP1)

3. Align standard and test lamps (see RTMLP6))

4. Run calibration program

a. $\quad$ Click on "Calibrations" from Hardware.frm menu to load Rtcal.frm

b. $\quad$ Select "Lamps and blackbodies" button

c. Enter data filename

d. Enter test filename suffix $\$$

i. Create test filenames from names on Software. frm

e. Select Yes and use suggested ranges (PMT high voltage and amplifier ranges are part of Rtcal.frm program)

f. Click on "Start" button

g. Enter data on Software. frm

i. Enter lamp and blackbody data

(1) Enter data for reference and test lamps

(2) Select "Use" button

(3) Enter lamp position

(4) Enter lamp name

(5) Select "Reference" button

(6) Enter lamp current (no necessary, lamp current automatically read from lamp monitoring computer)

(7) Enter power supply number

ii. Select temperature scale

iii. Select measurement wavelength [nm]

iv. Enter number of repeats (number of test/standard measurements) 
v. Enter number of readings (number of readings per DMM trigger)

vi. Select lamp type

vii. Select detector channel

h. Click on "Save Configuration" button

i. $\quad$ Select "Continue" button to return to Rtcal.frm

j. $\quad$ Enter Standard temperature in ${ }^{\circ} \mathrm{C}$ in input box

k. Enter Nominal radiance temperature in input box

1. Read lamp currents automatically

m. Adjust test lamp current so that test lamp signal matches that indicated on Suggest.frm

n. Wait for lamp to stabilize (5 min, $10 \mathrm{~min}, 15 \mathrm{~min}$, or $20 \mathrm{~min}$ depending on measurement temperature)

o. Check lamp alignment

p. Move source table to reference source and measure full scale signal

q. Move source table to dark signal position and measure dark signal

r. Move source table to test source and measure full scale signal

s. Move source table to dark signal position and measure dark signal on test source amplifier range, if reference and test source amplifier ranges are different

t. Repeat steps $r$ to $s$ for each test source

u. Repeat steps $\mathrm{p}$ to $\mathrm{s}$ "number of repeats" times

v. Select next action and then select "Continue" button

i. Repeat measurement with no changes

ii. Measure with new temperature

iii. Measure with new software changes

iv. Stop measurements

w. Repeat steps $\mathrm{k}$ to $\mathrm{v}$ for each measurement point 
Optical Technology Division (844)

Radiance Temperature Measurements Laboratory Procedure

Procedure RTMLP8: Ribbon Filament Lamp Procedure

5. Store calibration data in log file "CALMMDD.YY"

6. Use sample log file below:

\begin{tabular}{|c|c|c|c|}
\hline \multicolumn{4}{|c|}{ Date 08-15-1995 Time 12:49:14 PM } \\
\hline \multicolumn{4}{|c|}{ File Name $=$ CAL0815.95 } \\
\hline PMT Detector & PMT HV $=449$ & $\mathrm{NRDS}=5$ Integration & $8.35 \mathrm{~s}$ \\
\hline \multicolumn{4}{|c|}{ Wavelength $=655.3 \mathrm{~nm} \quad$ Nominal Rad Temp $=1700^{\circ} \mathrm{C}$} \\
\hline Name & SL20 & P51 & \\
\hline Rad. Temp & $1255.07^{\circ} \mathrm{C}$ & $1700.37^{\circ} \mathrm{C}$ & \\
\hline Current & $7.7788 \mathrm{~A}$ & $26.960 \mathrm{~A}$ & \\
\hline Sp. Rad. & $5.696 \mathrm{E}+02$ & $1.456 \mathrm{E}+04$ & \\
\hline Ratio & $1.000 \mathrm{E}+00$ & $2.556 \mathrm{E}+01$ & \\
\hline Std. Ratio & $0.01 \%$ & $0.04 \%$ & \\
\hline Amp Range & 9 & 8 & \\
\hline \multirow[t]{3}{*}{ Full Scale } & $1.052 \mathrm{E}+00 \pm 0.00 \%$ & $2.685 \mathrm{E}+00 \pm 0.00 \%$ & \\
\hline & $1.052 \mathrm{E}+00 \pm 0.00 \%$ & $2.683 \mathrm{E}+00 \pm 0.00 \%$ & \\
\hline & $1.052 \mathrm{E}+00 \pm 0.00 \%$ & $2.684 \mathrm{E}+00 \pm 0.00 \%$ & \\
\hline Dark Sig. & $1.501 \mathrm{E}-04$ & $-8.035 \mathrm{E}-05$ & \\
\hline Mean & $1.052 \mathrm{E}+00$ & $2.684 \mathrm{E}+00$ & \\
\hline Std(Mean) & $0.01 \%$ & $0.04 \%$ & \\
\hline Range Cf. & 9.9858E-02 & $1.0000 \mathrm{E}+00$ & \\
\hline SS Cf. & $1.000 \mathrm{E}+00$ & $1.000 \mathrm{E}+00$ & \\
\hline Corr. Mean & $1.050 \mathrm{E}-01$ & $2.684 \mathrm{E}+00$ & \\
\hline Position \# & 1 & 6 & \\
\hline Table Pos. & 37500 & 246000 & \\
\hline
\end{tabular}


Optical Technology Division (844)

Radiance Temperature Measurements Laboratory Procedure Procedure RTMLP8: Ribbon Filament Lamp Procedure

7. Store lamp data in test file "XXXXMMDD.YY"

8. Use sample test file below:

\begin{tabular}{|c|c|c|c|}
\hline \multicolumn{4}{|l|}{ P510815.95 } \\
\hline 08-15-1995 & 12:49:14 PM & & \\
\hline Tnom ${ }^{\circ} \mathrm{C}$ & Tmeas ${ }^{\circ} \mathrm{C}$ & Imeas ${ }^{\circ} \mathrm{C}$ & Test/Standard \\
\hline 1700 & 1700.37 & 26.960 & $2.5558 \mathrm{E}+01$ \\
\hline 2300 & 2300.22 & 43.340 & $3.4164 \mathrm{E}+02$ \\
\hline 2200 & 2200.29 & 40.330 & $2.4203 \mathrm{E}+02$ \\
\hline 2100 & 2100.04 & 37.440 & $1.6636 \mathrm{E}+02$ \\
\hline 2000 & 2000.04 & 34.670 & $1.1075 E+02$ \\
\hline 1900 & 1900.16 & 31.990 & $7.1053 E+01$ \\
\hline 1800 & 1800.13 & 29.420 & $4.3646 \mathrm{E}+01$ \\
\hline
\end{tabular}

9. Reduce data (see RTMLP9) 
Optical Technology Division (844)

Radiance Temperature Measurements Laboratory Procedure

\section{Ribbon Filament Lamp Data Reduction}

Written by: Charles Gibson

Procedure: RTMLP9

Approved by:

Date:

Revised by:

Date:

Ribbon Filament Lamp Data Reduction

1. Print out test file

2. Look in lab notebook and make changes on printout and then edit file

3. Load Visual Basic program: $c$ :|programs $\mid$ mpredn|Rtred.mak (do one of following)

a. Click on Rtred.mak shortcut icon

b. Double click on folder $c$ : Iprograms $\mid$ mpredn|Rtred mak using Windows Explorer

4. Run program (do one of following)

a. Press F5

b. Click on tool bar icon

c. Click on menu item "Run" then on "Start"

5. Select number of lamps to reduce

6. Enter 4 character serial number for each lamp

7. Enter data file suffix

8. Select directory that contains data file

9. Select degrees of freedom for curve fit

10. Click on "Run" button

11. Print data in list box

12. Calculate mean $\left(\mathrm{T}_{\text {meas }}\right)$ and standard deviation are calculated

13. Compare standard deviation to control limit

14. Correct lamp current to nominal temperature using following method, because measured temperatures are different from nominal temperatures $\left(\mathrm{T}_{\text {nom }}\right)$

a. $\quad$ Fit data to fifth degree polynomial using least squares approximation

b. $\quad$ Define independent variable: $T_{\text {mean }}=\left(T_{\text {meas }}(n-1)+T_{\text {meas }}(n)\right) / 2$

c. $\quad$ Define dependent variable: $\Delta I / \Delta T=\left(I_{\text {meas }}(n-1)-I_{\text {meas }}(n)\right) /\left(T_{\text {meas }}(n-1)-T_{\text {meas }}(n)\right)$

d. Calculate $\mathrm{dI} / \mathrm{dT}$ from fit

e. $\quad$ Define corrected lamp current: $I_{\text {corr }}=I_{\text {meas }}+\mathrm{d} I / \mathrm{d} T *\left(T_{\text {nom }}-T_{\text {meas }}\right)$

15. Store reduced data in log file "REDMMDD.YY"

16. Use sample log file on next page: 


\begin{tabular}{|c|c|c|c|c|c|c|c|c|}
\hline Reducing & ${ }^{6} \mathrm{C} \backslash \mathrm{P}$ & YRO\P51 & 10815.95 & $08-17-19$ & $\begin{array}{ll}995 & 11\end{array}$ & $11: 26: 56$ & $\mathrm{AM}$ & \\
\hline P510815.9 & & & & & & & & \\
\hline 08-15-199 & 51 & $2: 49: 14 \mathrm{H}$ & PM & & & & & \\
\hline Tnom ${ }^{\circ} \mathrm{C}$ & Tme & eas ${ }^{\circ} \mathrm{C}$ In & meas $\mathrm{A}$ & Test/Standar & & & & \\
\hline 1700 & 170 & $0.37 \quad 26$ & 26.96 & $2.5558 \mathrm{E}+01$ & & & & \\
\hline 2300 & 230 & 0.22 & +3.34 & $3.4164 \mathrm{E}+02$ & & & & \\
\hline 2200 & 220 & 0.29 & 40.33 & $2.4203 \mathrm{E}+02$ & & & & \\
\hline 2100 & 210 & 0.04 & 37.44 & $1.6636 \mathrm{E}+02$ & & & & \\
\hline 2000 & 200 & 0.04 & 34.67 & $1.1075 E+02$ & & & & \\
\hline 1900 & 190 & 0.16 & 1.99 & $7.1053 \mathrm{E}+01$ & & & & \\
\hline 1800 & 180 & 0.13 & 29.42 & $4.3646 \mathrm{E}+01$ & & & & 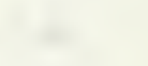 \\
\hline Tnom ${ }^{\circ} \mathrm{C}$ & Tme & ean ${ }^{\circ} \mathrm{C}$ In & meas A & Std Error & Limit $F$ & Flag & & Nrpt \\
\hline 800 & 800 & & 1.850 & 0.09 & 0.21 & & & 3 \\
\hline 900 & 899. & & 2.720 & 0.00 & 0.19 & & & 1 \\
\hline 1000 & 100 & 0.04 & 3.800 & 0.00 & 0.15 & & & 1 \\
\hline 1100 & 110 & 0.02 & 5.100 & 0.00 & 0.09 & & & 1 \\
\hline 1200 & 119 & 9.63 & 6.620 & 0.00 & 0.10 & & & 1 \\
\hline $\begin{array}{c}\text { Tnom Ime } \\
{ }^{\circ} \mathrm{C}\end{array}$ & & $\begin{array}{l}\text { Tmeas } \\
{ }^{\circ} \mathrm{C}\end{array}$ & $\begin{array}{l}\text { Tmean } \\
{ }^{\circ} \mathrm{C}\end{array}$ & Dell/DelT & T $\mathrm{dI} / \mathrm{dT}$ & DelT & & $\begin{array}{c}\text { Icorr } \\
\mathrm{A}\end{array}$ \\
\hline $\begin{array}{ll}0800 & 11.8\end{array}$ & & 0800.82 & 0850.20 & 0.0088 & 0.0079 & -0.82 & -0.007 & 11.843 \\
\hline $\begin{array}{ll}0900 & 12.7\end{array}$ & & 0899.58 & 0949.81 & 0.0108 & 0.0097 & $7 \quad 0.42$ & 0.004 & 12.724 \\
\hline $\begin{array}{ll}1000 & 13.8\end{array}$ & & 1000.04 & 1050.03 & 0.0130 & 0.0119 & -0.04 & 0.000 & 13.800 \\
\hline $1100 \quad 15.1$ & & 1100.02 & 1149.83 & 0.0153 & 0.0141 & -0.02 & 0.000 & 15.100 \\
\hline $1200 \quad 16.6$ & & 1199.63 & 1249.74 & 0.0174 & 0.0163 & 0.37 & 0.006 & 16.626 \\
\hline
\end{tabular}




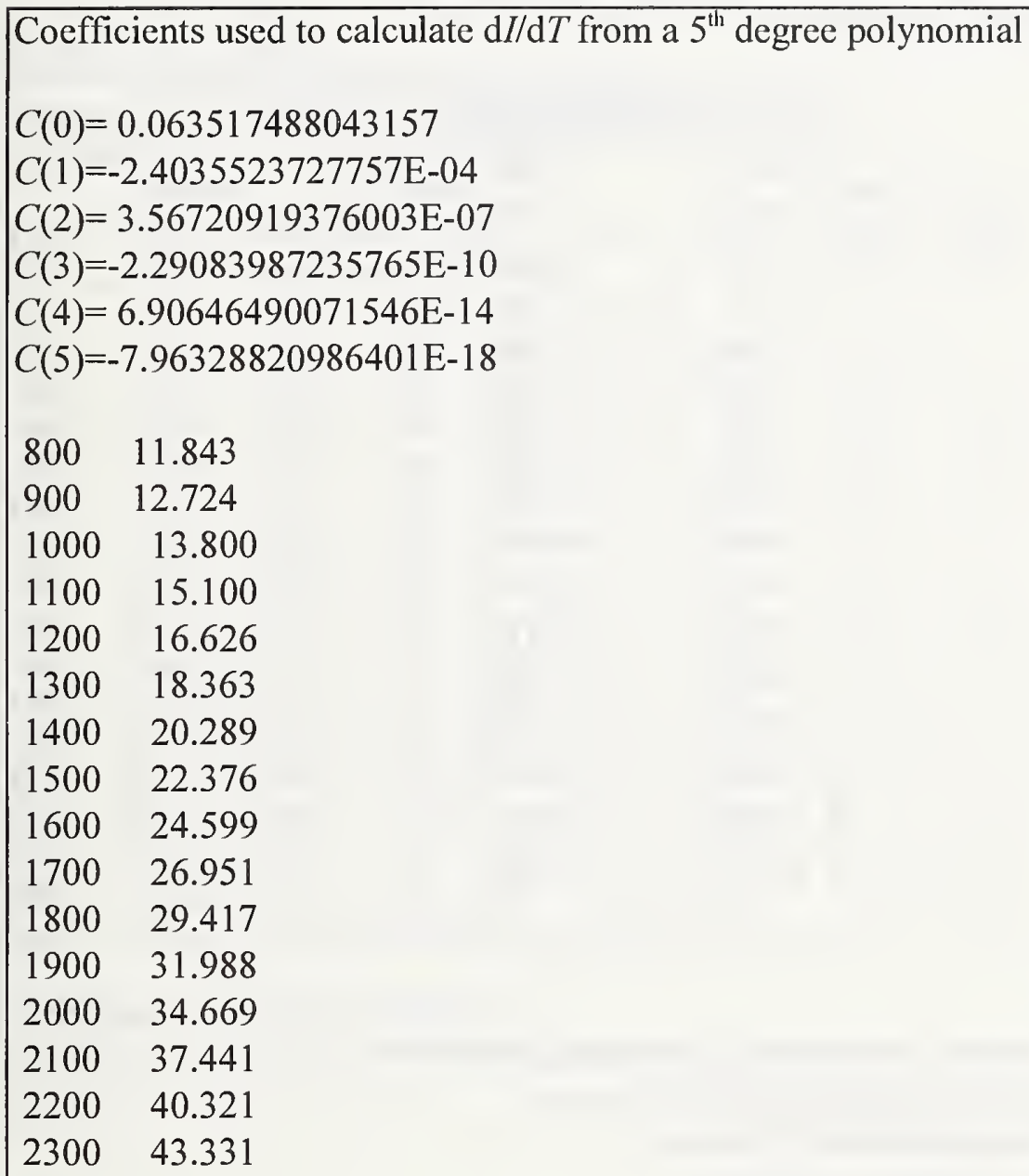

Data is stored in 'C:IPYROLP510895.TXT'

Reduction of file 'C:IPYROIP510815.95' is complete 


\section{Optical Technology Division (844) \\ Radiance Temperature Measurements Laboratory Procedure Procedure RTMLP9: Ribbon Filament Lamp Data Reduction}

17. Save $T_{\text {nom }}$ and $I_{\text {corr }}$ in data file "XXXXMMYY.TXT"

18. Use sample test data file below:

\begin{tabular}{|lc|}
\hline C:IPYRO\P510895.TXT \\
800 & 11.843 \\
900 & 12.724 \\
1000 & 13.800 \\
1100 & 15.100 \\
1200 & 16.626 \\
1300 & 18.363 \\
1400 & 20.289 \\
1500 & 22.376 \\
1600 & 24.599 \\
1700 & 26.951 \\
1800 & 29.417 \\
1900 & 31.988 \\
2000 & 34.669 \\
2100 & 37.441 \\
2200 & 40.321 \\
2300 & 43.331 \\
& \\
\hline
\end{tabular}

19. Compare current calibration to previous calibration

20. Click on "Compare calibrations" from menu

21. Select previous calibration filename

22. Select current calibration filename

23. Select temperature scale $\left({ }^{\circ} \mathrm{C},{ }^{\circ} \mathrm{F}\right.$, or $\left.\mathrm{K}\right)$

24. Select international temperature scale (ITS-48, ITS-68, ITS-90)

25. Enter wavelength (nm) for previous data file

26. Enter wavelength (nm) for current data file

27. Click on "Run" button

28. Enter data file name "XXXXmyy.MYY"

a. Define myy: month and year of previous calibration

b. Define MYY: month and year of current calibration

29. Store comparison data in log file "CMPMMDD.YY"

30. Use sample log file on next page: 


\begin{tabular}{|c|c|c|c|c|c|c|c|c|c|c|}
\hline \multicolumn{11}{|c|}{$\begin{array}{l}\text { 08-17-1995 11:50:32 } \\
\text { Previous calibration data file = 'c: }: \mid \text { files } \backslash p 510393 . t x t ' \\
\text { Current calibration data file = 'c: } \mid \text { files } \backslash \text { ' 510895.txt' } \\
\text { Comparing previous to current calibration }\end{array}$} \\
\hline & $655.3 \mathrm{nr}$ & & $655.3 \mathrm{nt}$ & & & WL & Change & Total & $\%$ Change & Scale \\
\hline Temp & Old [I] & New [I] & New [I] & $\mathrm{dI}$ & $\mathrm{DI} / \mathrm{DT}$ & Corr. & Temp. & Change & Rad. & Corr. \\
\hline$\left[{ }^{\circ} \mathrm{C}\right]$ & $\begin{array}{c}\text { ITS-90 } \\
{[\mathrm{A}]}\end{array}$ & $\begin{array}{c}\text { ITS }-90 \\
\text { [A] }\end{array}$ & $\begin{array}{c}\text { ITS-90 } \\
{[\mathrm{A}]}\end{array}$ & $\begin{array}{l}\text { ITS-90 } \\
{[\mathrm{A}]}\end{array}$ & {$\left[\mathrm{A} /{ }^{\circ} \mathrm{C}\right]$} & & ITS-90 & ITS-90 & & {$\left[{ }^{\circ} \mathrm{C}\right]$} \\
\hline 800 & 11.847 & 11.843 & 11.843 & 0.004 & 0.0078 & 0.00 & 0.51 & 0.51 & $0.98 \%$ & 0.00 \\
\hline 900 & 12.724 & 12.724 & 12.724 & 0.000 & 0.0096 & 0.00 & 0.00 & 0.00 & $0.00 \%$ & 0.00 \\
\hline 1000 & 13.799 & 13.800 & 13.800 & -0.001 & 0.0119 & 0.00 & -0.08 & -0.08 & $-0.11 \%$ & 0.00 \\
\hline 1100 & 15.098 & 15.100 & 15.100 & -0.002 & 0.0142 & 0.00 & -0.14 & -0.14 & $-0.16 \%$ & 0.00 \\
\hline 1200 & 16.623 & 16.626 & 16.626 & -0.003 & 0.0164 & 0.00 & -0.18 & -0.18 & $-0.18 \%$ & 0.00 \\
\hline 1300 & 18.361 & 18.363 & 18.363 & -0.002 & 0.0185 & 0.00 & -0.11 & -0.11 & $-0.10 \%$ & 0.00 \\
\hline 1400 & 20.287 & 20.289 & 20.289 & -0.002 & 0.0201 & 0.00 & -0.10 & -0.10 & $-0.08 \%$ & 0.00 \\
\hline 1500 & 22.372 & 22.376 & 22.376 & -0.004 & 0.0216 & 0.00 & -0.18 & -0.18 & $-0.13 \%$ & 0.00 \\
\hline 1600 & 24.600 & 24.599 & 24.599 & 0.001 & 0.0230 & 0.00 & 0.04 & 0.04 & $0.03 \%$ & 0.00 \\
\hline 1700 & 26.956 & 26.951 & 26.951 & 0.005 & 0.0242 & 0.00 & 0.21 & 0.21 & $0.12 \%$ & 0.00 \\
\hline 1800 & 29.423 & 29.417 & 29.417 & 0.006 & 0.0252 & 0.00 & 0.24 & 0.24 & $0.12 \%$ & 0.00 \\
\hline 1900 & 31.992 & 31.988 & 31.988 & 0.004 & 0.0262 & 0.00 & 0.15 & 0.15 & $0.07 \%$ & 0.00 \\
\hline 2000 & 34.666 & 34.669 & 34.669 & -0.003 & 0.0272 & 0.00 & -0.11 & -0.11 & $-0.05 \%$ & 0.00 \\
\hline 2100 & 37.442 & 37.441 & 37.441 & 0.001 & 0.0283 & 0.00 & 0.04 & 0.04 & $0.01 \%$ & 0.00 \\
\hline 2200 & 40.329 & 40.321 & 40.321 & 0.008 & 0.0295 & 0.00 & 0.27 & 0.27 & $0.10 \%$ & 0.00 \\
\hline 2300 & 43.340 & 43.331 & 43.331 & 0.009 & 0.0307 & 0.00 & 0.29 & 0.29 & $0.10 \%$ & 0.00 \\
\hline
\end{tabular}


31. Use sample comparison data file below:

\begin{tabular}{|lll|}
\hline P51_393.895 & $08-17-1995$ & $11: 50: 49 \mathrm{AM}$ \\
$\mathrm{Temp}\left[{ }^{\circ} \mathrm{C}\right]$ & $\mathrm{dT}\left[{ }^{\circ} \mathrm{C}\right]$ & $\% d \mathrm{dL}$ \\
800 & 0.51 & $0.98 \%$ \\
900 & 0.00 & $0.00 \%$ \\
1000 & -0.08 & $-0.11 \%$ \\
1100 & -0.14 & $-0.16 \%$ \\
1200 & -0.18 & $-0.18 \%$ \\
1300 & -0.11 & $-0.10 \%$ \\
1400 & -0.10 & $-0.08 \%$ \\
1500 & -0.18 & $-0.13 \%$ \\
1600 & 0.04 & $0.03 \%$ \\
1700 & 0.21 & $0.12 \%$ \\
1800 & 0.24 & $0.12 \%$ \\
1900 & 0.15 & $0.07 \%$ \\
2000 & -0.11 & $-0.05 \%$ \\
2100 & 0.04 & $0.01 \%$ \\
2200 & 0.27 & $0.10 \%$ \\
2300 & 0.29 & $0.10 \%$ \\
& & \\
\hline
\end{tabular}




\section{Optical Technology Division (844) \\ Radiance Temperature Measurements Laboratory Procedure \\ Procedure RTMLP9: Ribbon Filament Lamp Data Reduction}

32. Prepare calibration summary sheet

33. A sample calibration summary sheet is below:

\section{Radiance Temperature Lab \\ Calibration Summary Sheet}

Today's date: December 17, 1997

NIST Test No: 844/123456-95

Use sample report: 35050c.rfl

Company: Radiometric Systems Inc

Contact: John Doe

Phone: 301 123-4567

P.O.\#: AB1234 dated January 1, 1995

Test number: 35050C Radiance Temperature Standard, Ribbon Filament Lamp

Test item: One General Electric Tungsten Ribbon Filament Lamp, Model \# 30/T24/6, Serial \# P51

Temperatures measured: $800{ }^{\circ} \mathrm{C}$ to $2300{ }^{\circ} \mathrm{C}$ Aligned at $1700{ }^{\circ} \mathrm{C}$

Standard(s) used: SL20 (7.7788 A, $2.093 \mathrm{~V}),(\mathrm{P} \cos (2 \theta)=0.001107,12 / 92 \mathrm{TR} 2 \mathrm{p} 123)$

Temperature: $21{ }^{\circ} \mathrm{C} \pm 1{ }^{\circ} \mathrm{C} \quad$ Relative humidity: $38 \% \pm 5 \%$

Calibration date: $5 / 24 / 95$ Measurement date(s):5/24/95 TR3 p42

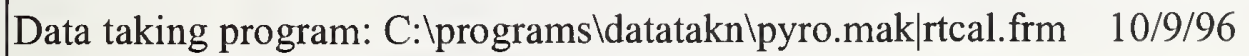
Calibration files: CAL0815.95, P510815.95

Data reduction program:C: programs $\backslash$ lampredn\rtred.mak|lmpred.frm $\quad 5 / 25 / 95$ Reduction summary: Red0525.95

Final data filename: P510895.TXT

Data analysis program:C: |programs $\backslash$ lampredn $\backslash$ rtred.mak|compare.frm $\quad 5 / 25 / 95$

Reduction summary: Cmp0817.95

Previous calibration filename: P510393.TXT

Comparison filename: P51_393.895 
Optical Technology Division (844)

Radiance Temperature Measurements Laboratory Procedure

Procedure RTMLP9: Ribbon Filament Lamp Data Reduction

34. Enter data file name "XXXXmyy.MYY"

a. Prepare history file consisting of Microsoft EXCEL spreadsheet with plots of temperature difference from first calibration versus nominal temperature 


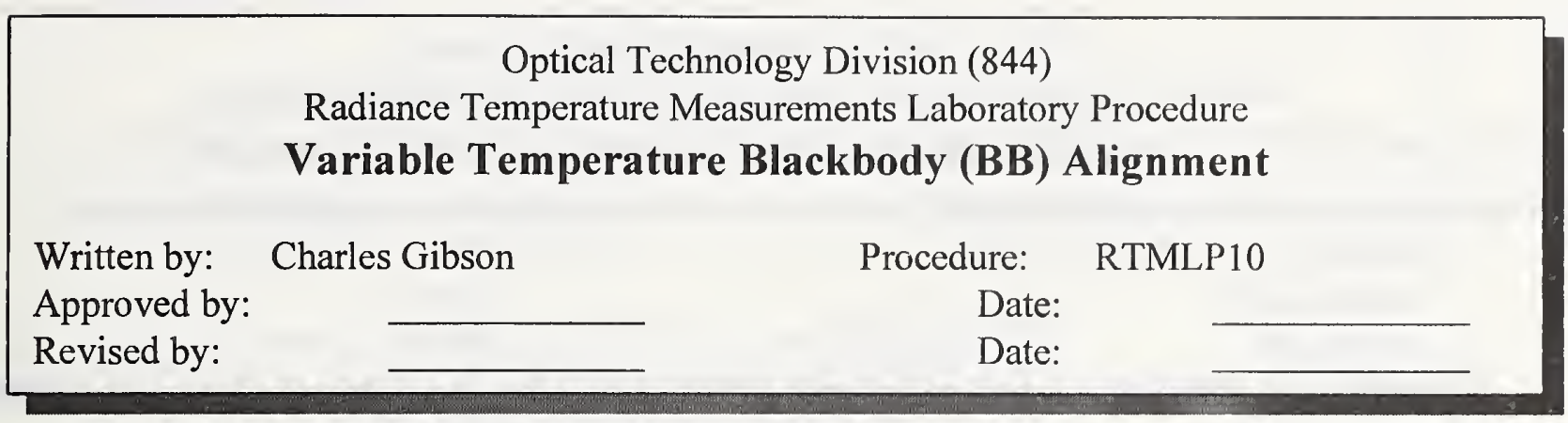

Variable Temperature Blackbody (BB) Alignment

\begin{tabular}{|c|}
\hline CAMUION \\
\hline COLLISION \\
\hline
\end{tabular}

1. Align PEP (see RTMLP2)

2. Remove field stop

3. Remove objective lens aperture, if any

4. Level aluminum plate $(<\mathrm{X})$

5. Use fiber optic light to illuminate $B B$

6. Translate $B B$ along optical axis until center partition is in focus $(Z)$

7. Center BB on optical axis (X and $\mathrm{Y}$ )

8. Turn on BB (see RTMLP11)

9. Radiometrically center BB

a. $\quad$ Center $<$ Y about vertical axis

b. Center $\mathrm{X}$ along horizontal axis

c. Repeat $\mathrm{i}$ and ii until centered

d. Check centering

i. Monitor BB signal on graph logger

ii. Hold card in front of BB opening

iii. Check for equal drop-offs when blocking top, bottom, left, and right portions of $\mathrm{BB}$ opening 
Written by: Charles Gibson

Approved by:

Revised by:
Procedure: RTMLP11

Date:

Date:

Variable Temperature Blackbody Operation

\begin{tabular}{|c|}
\hline CAAUTION \\
\hline BRIGHT SOURCE \\
\hline BURN \\
\hline ELECTROCUTION \\
\hline
\end{tabular}

1. Turn On BB

a. Open tap water valve $1 / 8$ turn

b. Check that blue box flow rate is about $2 \mathrm{gpm}$

c. Open chilled water valves

i. Open supply valve $1 / 4$ turn

ii. Open return valve fully

d. Press reset button on blue water switch box to select chilled water

e. Check that blue box flow rate is about $5 \mathrm{gpm}$

f. Open argon cylinder valve fully

g. Turn on argon alarm and check that it trips at $10 \mathrm{cfh}$

h. Purge BB using argon flow rate of $70 \mathrm{cfh}$

i. Cover both BB openings for $5 \mathrm{~s}$ with your hands

ii. Uncover one end and wait $5 \mathrm{~s}$

iii. Cover both BB openings for $5 \mathrm{~s}$ with your hands

iv. Uncover other end and wait $5 \mathrm{~s}$

i. Repeat step h 5 times

j. Reduce argon flow rate to $10 \mathrm{cfh}$

$\mathrm{k}$. Check that BB housing is cool and that argon is flowing

1. Insert correct detector filter for initial set point

i. Filter $0,700{ }^{\circ} \mathrm{C}$ to $1300{ }^{\circ} \mathrm{C}$, Low with insulation (LIN)

ii. Filter $1,1300{ }^{\circ} \mathrm{C}$ to $1800{ }^{\circ} \mathrm{C}$, Medium (MED)

iii. Filter $2,1800{ }^{\circ} \mathrm{C}$ to $2500{ }^{\circ} \mathrm{C}$, High (HI)

iv. Filter $3,2500{ }^{\circ} \mathrm{C}$ to $3100{ }^{\circ} \mathrm{C}$, Extra High(XH)

m. Switch control mode to [MANUAL]

n. Turn potentiometer to 0 


\section{Procedure RTMLP11: Variable Temperature Blackbody (BB) Operation}

o. $\quad$ Press [START], [WATER ON], and [RUN] buttons

i. Note that BB does not control chilled water flow, because automatic BB shutoff switch has been disabled

p. Turn potentiometer slowly until voltmeter reads between $150 \mathrm{VAC}$ and $200 \mathrm{VAC}$ (sets BB below $1300{ }^{\circ} \mathrm{C}$ )

2. Operate BB

a. Run BB control program

i. Program is BBPROG.PRG in BetterBasic

ii. Enter BB at DOS prompt

iii. Enter measurement direction

(1) ' 0 ' to run high to low

(2) '1' to run low to high

iv. Enter set point unit
(1) $\quad \mathrm{C}^{\prime}$ for ${ }^{\circ} \mathrm{C}$

(2) $\quad \mathrm{F}^{\prime}$ for ${ }^{\circ} \mathrm{F}$

v. Enter temperature range
(1) LOW
(2) LIN
(3) MED
(4) $\mathrm{HI}$
(5) $\mathrm{XH}$

vi. Insert correct filter and press [Enter]

b. Press [Shift S] to enter initial set point

c. Adjust potentiometer until temperature is $20^{\circ} \mathrm{C}$ above set point

d. Switch control mode to [PC] to maintain set point

WARNING! DO NOT INCREASE SET POINT BY STEPS LARGER THAN $20^{\circ} \mathrm{C}$ TO REDUCE DAMAGE TO BB

e. Select new set point (set point is in ${ }^{\circ} \mathrm{C}$ or ${ }^{\circ} \mathrm{F}$ depending on set point unit selected)

i. Press [Shift $\mathrm{S}]$ to enter set point

ii. Use numeric keypad to increment set point

(1) Press increment key
(a) Press 7 for $100{ }^{\circ} \mathrm{C}$
(b) Press 4 for $10^{\circ} \mathrm{C}$
(c) Press 1 for $1{ }^{\circ} \mathrm{C}$ 
(d) Press 0 for $0.1{ }^{\circ} \mathrm{C}$

(2) Press direction key to set new set point

(a) Press 8 to increase set point

(b) Press 2 to decrease set point

f. Pause program (suspending BB control) if new set point is not in current range

i. Use default set points depending on measurement direction

(1) Use high to low default set points

(a) Select $\mathrm{XH}$ for $2500{ }^{\circ} \mathrm{C}$

(b) Select $\mathrm{HI}$ for $2300{ }^{\circ} \mathrm{C}$

(c) Select MED for $1800{ }^{\circ} \mathrm{C}$

(d) Select LOW for $1300{ }^{\circ} \mathrm{C}$

(2) Use low to high default set points

(a) Select LOW for $800^{\circ} \mathrm{C}$

(b) Select MED for $1300{ }^{\circ} \mathrm{C}$

(c) Select $\mathrm{HI}$ for $1800^{\circ} \mathrm{C}$

(d) Select $\mathrm{XH}$ for $2500{ }^{\circ} \mathrm{C}$

ii. Switch control mode to [MANUAL] if new set point is not default value

iii. Loop program step 2.a.v. (see

3. Use EMERGENCY TURN OFF procedure when necessary

a. Press [EMERGENCY STOP] button on power supply (chilled water and argon will continue flowing)

b. $\quad$ Continue with steps 4.b. to 4.j.

4. Turn Off BB

a. Switch control mode to [MANUAL]

b. Turn to potentiometer to 0

c. Press [EMERGENCY STOP] button on power supply (chilled water and argon will continue flowing)

d. Switch off main breaker on wall

e. Wait until furnace has stopped glowing

f. Close chilled water supply valve

g. Close chilled water return valve

h. Close cold water supply valve

i. Close argon cylinder valve

j. Close argon flow meter valve 


\section{Optical Technology Division (844) \\ Radiance Temperature Measurements Laboratory Procedure \\ Disappearing Filament Optical Pyrometer Alignment}

Written by: Charles Gibson

Procedure: RTMLP12

Approved by:

Date:

Revised by:

Date:

Disappearing Filament Optical Pyrometer Alignment

1. Align BB (see RTMLP10)

2. Check that objective lens and eye piece are clean

3. Check batteries

4. Zero galvanometer

5. Use post with magnetic base, height adjustment, and angle bracket to mount pyrometer

6. Position post and level angle bracket mounting surface

7. Mount pyrometer to angle bracket

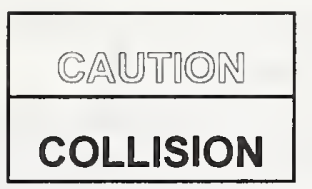

8. Use joystick to move BB to test pyrometer position

9. Use fiber optic light to illuminate BB

10. Set pyrometer at measuring distance from $\mathrm{BB}$ center partition

a. Use distance of $30.2 \mathrm{~cm}$ from center partition to end of graphite extension tube

b. Measure distance from front surface of objective lens holder to extension tube (for $1 \mathrm{~m}$, distance is $69.8 \mathrm{~cm}$ )

11. Adjust pyrometer eye piece to focus on illuminated lamp filament

12. Focus pyrometer on center partition

13. Adjust pyrometer and/or move BB so that pyrometer views down center of BB cavity

14. Check distance

15. Adjust pyrometer and/or move BB so that pyrometer views down center of BB cavity

16. Record table position

17. Repeat for other test pyrometers 
Written by: Charles Gibson

Approved by:

Revised by:
Procedure: RTMLP13

Date:

Date:

\section{Radiation Thermometer (RT) Alignment}

1. Align BB (see RTMLP10)

2. Check that objective lens and eye piece are clean

3. Use post with magnetic base, height adjustment, and angle bracket to mount RT

4. Position post and level angle bracket mounting surface

5. Mount RT to angle bracket

$$
\begin{array}{|l|}
\hline \text { CAUUTION } \\
\hline \text { COLLISION } \\
\hline
\end{array}
$$

6. Use joystick to move BB to test RT position

7. Use fiber optic light to illuminate $\mathrm{BB}$

8. Set RT at measuring distance from $\mathrm{BB}$ center partition

a. Use distance of $30.2 \mathrm{~cm}$ from center partition to end of graphite extension tube

b. Measure distance from front surface of objective lens holder to extension tube (for $1 \mathrm{~m}$, distance is $69.8 \mathrm{~cm}$ )

c. Measure distance from alignment mark to extension tube for Land Cyclops RT (for $1 \mathrm{~m}$, distance is $69.8 \mathrm{~cm}$ )

9. Adjust RT eye piece to operator's eye

10. Focus RT on center partition

11. Adjust RT and/or move BB so that RT views down center of BB cavity

12. Check distance

13. Adjust RT and/or move BB so that RT views down center of BB cavity

14. Record table position

15. Repeat steps 2 to 14 for each test RT

16. Turn on BB (see RTMLP11)

17. Check centering of each test RT

a. Monitor RT signal on graph logger or look at RT display panel

b. Hold card in front of BB opening

c. Check for equal drop-offs when blocking top, bottom, left, and right portions of $\mathrm{BB}$ opening 
Optical Technology Division (844)

Radiance Temperature Measurements Laboratory Procedure

\section{Radiation Thermometer (Optical Pyrometer)}

Calibration Procedure

Written by: Charles Gibson

Approved by:

Revised by:
Procedure: RTMLP14

Date:

Date:

Radiation Thermometer (Optical Pyrometer) Calibration Procedure

1. Review calibration summary

a. Align standard lamp, BB, and test RTS

b. Measure from $2700{ }^{\circ} \mathrm{C}$ to $800{ }^{\circ} \mathrm{C}$ in $100{ }^{\circ} \mathrm{C}$ steps

c. Repeat $2300{ }^{\circ} \mathrm{C}, 1900{ }^{\circ} \mathrm{C}, 1500{ }^{\circ} \mathrm{C}, 1300{ }^{\circ} \mathrm{C}, 1100{ }^{\circ} \mathrm{C}$, and $800{ }^{\circ} \mathrm{C}$

2. Run general data taking program (see RTMLP1)

3. Align standard lamp (see RTMLP6)

4. Align BB (see RTMLP10)

5. Align RTS (see RTMLP13)

6. Run calibration program

a. Click on "Calibrations" from Hardware.frm menu to load Rtcal.frm

b. Select "Radiation thermometer" button

c. Enter data filename

d. Enter test filename suffix $\$$

i. $\quad$ Create test filenames from names on Software.frm

e. Select Yes and use suggested ranges (PMT high voltage and amplifier ranges are part of Rtcal.frm program)

f. Click on "Start" button

g. Enter data on Software. frm

i. Enter lamp and blackbody data

(1) Enter data for reference and BB

(2) Select "Use" button

(3) Enter lamp position

(4) Enter lamp name

(5) Select "Reference" button

(6) Enter lamp current (not necessary because lamp currents are automatically read from lamp monitoring computer)

(7) Enter power supply number 
ii. Enter radiation thermometer data

(1) Enter data for check standard and test RTS

(2) Select "Use" button

(3) Enter RT name

(4) Enter source table position

(5) Enter digital multimeter channel to read signal

(6) Enter RT type ( $\mathrm{O}$ for optical pyrometers and $\mathrm{R}$ for radiation thermometers)

(7) Enter output type (P for panel or scale, D for digital, A for analog)

(8) Select instrument wavelength (nm)

iii. Select temperature scale

iv. Select measurement wavelength [nm]

v. Enter number of repeats (number of test/standard measurements)

vi. Enter number of readings (number of readings per DMM trigger)

vii. Select lamp type

viii. Select detector channel

h. Click on "Save Configuration" button

i. $\quad$ Select "Continue" button to return to Rtcal.frm

j. $\quad$ Enter Standard temperature in ${ }^{\circ} \mathrm{C}$ in input box

k. Enter Nominal radiance temperature in input box

1. Read lamp currents automatically

m. Enter BB set point

n. Wait $5 \mathrm{~min}$ for BB to stabilize

o. Move source table to reference source and measure full scale signal

p. Move source table to dark signal position and measure dark signal

q. Move source table to BB and measure full scale signal

r. Move source table to dark signal position and measure dark signal on BB amplifier range if reference and $\mathrm{BB}$ amplifier ranges are different

s. $\quad$ Repeat steps o to $r$ "number of repeats" times

t. Enter emissivity correction for test RT wavelength

i. $\quad$ Enter 0 for $655.3 \mathrm{~nm}$

ii. Enter 1 for $900 \mathrm{~nm}$

iii. Enter 2 for $1000 \mathrm{~nm}$

iv. Enter 3 for true temperature 
u. Move BB in front of each RT and take reading

i. $\quad$ Read RTs with digital outputs 3 times

ii. Read RTs with analog outputs 3 times

iii. Enter display value for RTs with digital display panels

iv. Read OPs matching from bright to dark and then from dark to bright

(1) Enter scale value or press [Enter] to read output signal

(2) Read 2 sets

v. Select next action and then select "Continue" button

i. Repeat measurement with no changes

ii. Measure with new temperature

iii. Measure with new software changes

iv. Stop measurements

w. Repeat xxii for each measurement point

7. Store calibration data in log file "CALMMDD.YY"

8. Use sample log file on next page: 


$$
\text { Optical Technology Division (844) }
$$

Radiance Temperature Measurements Laboratory Procedure

\section{Procedure RTMLP14: Radiation Thermometer (Optical Pyrometer)}

Calibration Procedure

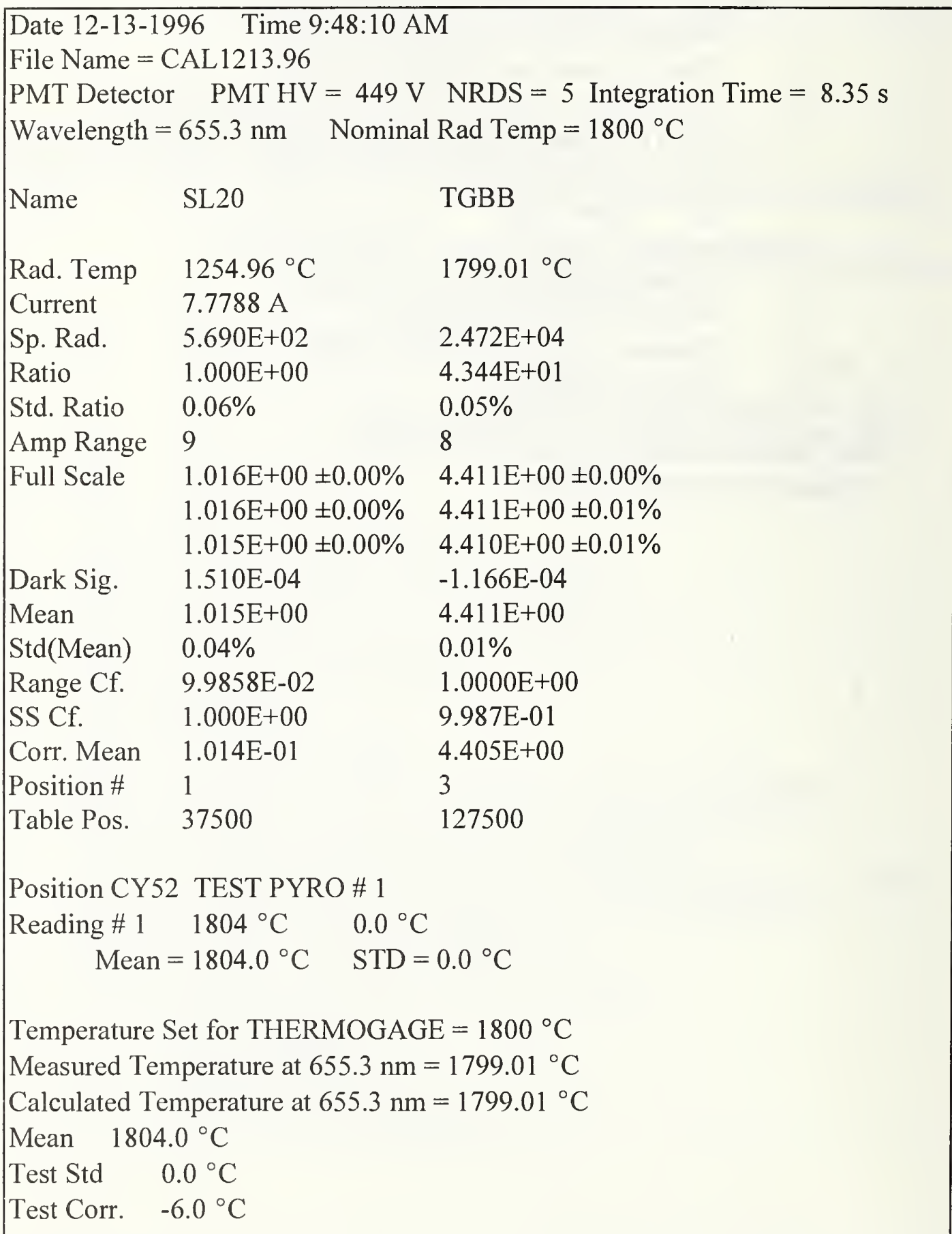


Optical Technology Division (844)

Radiance Temperature Measurements Laboratory Procedure

Procedure RTMLP14: Radiation Thermometer (Optical Pyrometer)

Calibration Procedure

9. Store RT data in test file "XXXXMMDD.YY"

10. Use sample test data file below:

\begin{tabular}{|c|c|c|c|c|c|}
\hline \multicolumn{6}{|c|}{ c:IPYROICY521213.96 } \\
\hline \multicolumn{6}{|c|}{$12-13-1996 \quad 9: 59: 06 \mathrm{AM}$} \\
\hline \multicolumn{6}{|c|}{ Standard used is SL20 at $1254.96{ }^{\circ} \mathrm{C}$} \\
\hline \multicolumn{6}{|c|}{ Temperature in ${ }^{\circ} \mathrm{C}$} \\
\hline \multicolumn{6}{|c|}{ Temperature measured at $655.3 \mathrm{~nm}$ Temperature calculated at $1000^{\circ} \mathrm{C}$} \\
\hline Tnom & Tbb & Tcorr & CY52 & Std & Corr \\
\hline 1800 & 1799.01 & 1797.98 & 1804.0 & 0.0 & -6.0 \\
\hline 1700 & 1699.18 & 1698.26 & 1704.5 & 0.0 & -6.2 \\
\hline 1600 & 1599.47 & 1598.64 & 1603.0 & 0.0 & -4.4 \\
\hline 1500 & 1499.31 & 1498.56 & 1502.0 & 0.0 & -3.4 \\
\hline 1400 & 1399.24 & 1398.57 & 1401.0 & 0.0 & -2.4 \\
\hline 1300 & 1299.30 & 1298.71 & 1302.0 & 0.0 & -3.3 \\
\hline 1200 & 1199.36 & 1198.85 & 1201.0 & 0.0 & -2.2 \\
\hline 1100 & 1099.34 & 1098.89 & 1100.5 & 0.0 & -1.6 \\
\hline 1100 & 1099.25 & 1098.80 & 1100.5 & 0.0 & -1.7 \\
\hline 1000 & 999.15 & 998.76 & 1000.0 & 0.0 & -1.2 \\
\hline
\end{tabular}

11. Reduce data (see RTMLP15) 


\section{Optical Technology Division (844) \\ Radiance Temperature Measurements Laboratory Procedure Radiation Thermometer (RT) Data Reduction}

Written by: Charles Gibson

Procedure: RTMLP15

Approved by:

Date:

Revised by:

Date:

Radiation Thermometer (RT) Data Reduction

1. Print out test file for RT check standard

a. Verify that RT check standard values are within uncertainty

2. Print out test file for BB RT check standard

a. Verify that BB RT check standard values are within uncertainty

3. Print out test files

4. Look in lab notebook and document any changes on print out and then edit file

5. Load EXCEL and open test file

6. Separate data by range or filter

7. Sort data

8. Calculate mean and standard deviation of repeats

9. Plot data

10. Save in data file "XXXXMMYY.XLS"

11. Use sample data file below:

\begin{tabular}{|c|c|c|c|c|c|c|c|c|}
\hline TEST1096. & & & $11 / 7 / 96$ & & & & & \\
\hline & & & & & & & & \\
\hline C:IPYROITE & $T 1007.96$ & & & & & & & \\
\hline Tnom & Tbb: & Tcorri & TEST & Std: & Corr: & Corr Mean & Corr Std & Filter: \\
\hline${ }^{\circ} \mathrm{C}$ & ${ }^{\circ} \mathrm{C}$ & ${ }^{\circ} \mathrm{C}$ & ${ }^{\circ} \mathrm{C}$ & ${ }^{\circ} \mathrm{C}$ & ${ }^{\circ} \mathrm{C}$ & ${ }^{\circ} \mathrm{C}$ & ${ }^{\circ} \mathrm{C}$ & \\
\hline 800 & 799.10 & 798.83 & 801 & 0 & -2.2 & -2.5 & 0.4 & Clear: \\
\hline 800 & 800.58 & 800.30 & 803 & 0 & -2.7 & & & \\
\hline 900 & 899.04 & 898.71 & 900.5 & 0 & -1.8 & & & \\
\hline 1000 & 999.13 & 998.74 & 1000 & 0 & -1.3 & & & \\
\hline 1100 & 1099.19 & 1098.74 & 1100 & 0 & -1.3 & -1.2 & 0.2 & \\
\hline 1100 & 1100.48 & 1100.03 & 1101 & 0 & -1.0 & & & \\
\hline 1200 & 1199.32 & 1198.80 & 1200 & 0 & -1.2 & & & \\
\hline
\end{tabular}

12. Use, for repeats, values of blackbody temperature ( $\left.T_{\text {corr }}\right)$, test RT reading (TEST), and test $\mathrm{RT}$ correction (Corr) that best represents mean of repeats so that actual reading is reported

13. Save data in text file (tab delimited) "XXXXMMYY.TXT" 
14. Use sample file below:

\begin{tabular}{|lllll|}
\hline \multicolumn{3}{|l}{ Test1096.TXT } & & $11 / 4 / 96$ \\
Tnom & Tcorr & TEST & Corr & Filter \\
{$\left[{ }^{\circ} \mathrm{C}\right]$} & {$\left[{ }^{\circ} \mathrm{C}\right]$} & {$\left[{ }^{\circ} \mathrm{C}\right]$} & {$\left[{ }^{\circ} \mathrm{C}\right]$} & Clear \\
800 & 800.3 & 803 & -2.7 & \\
900 & 898.7 & 900.5 & -1.8 & \\
1000 & 998.7 & 1000 & -1.3 & \\
1100 & 1098.7 & 1100 & -1.3 & \\
1200 & 1198.8 & 1200 & -1.2 & \\
\hline
\end{tabular}

15. Prepare calibration summary sheet

16. Use sample calibration summary sheet on next page: 


\section{Radiance Temperature Lab \\ Calibration Summary Sheet}

Today's date: December 17, 1997

NIST Test No: $844 / 123456-95$

Use sample report: 35070sdc.1 um

Company: Radiometric Systems Inc

Contact: Joe Calibration

Phone: 301 123-4567

P.O.\#: AB1234 dated January 1, 1995

Test number: 35070S Special Test of Radiation Thermometer

Test item: One Minolta-Land Infrared Thermometer, Model \# Cyclops 52, Serial \# 0000000

Wavelength $=1000 \mathrm{~nm} \quad$ Distance: $100 \mathrm{~cm}$ from alignment mark

Target size: $5.6 \mathrm{~mm}$

Focus: 1 meterClear and dark lenses (sn L1)

Temperatures measured: $800{ }^{\circ} \mathrm{C}$ to $2500{ }^{\circ} \mathrm{C}$

$800{ }^{\circ} \mathrm{C}$ to $1200{ }^{\circ} \mathrm{C}$ with clear filter

$1100{ }^{\circ} \mathrm{C}$ to $2500{ }^{\circ} \mathrm{C}$ with dark filter

Standard(s) used: SL20 (7.7788 A / 2.093 V ), $(P \cos (20)=0.001107,12 / 92$ TR2 p 123)

Land Cyclops 52 pyrometer, Serial no.: 202681

Thermogage 7000-1 pyrometer, Serial no.: 5127

Temperature: $21{ }^{\circ} \mathrm{C} \pm 1{ }^{\circ} \mathrm{C}$

Relative humidity: $38 \% \pm 5 \%$

Calibration date: $2 / 16 / 96$

Measurement date(s):2/15-16/96 TR3 p79

Data taking program: C: $\mid$ programs $\backslash$ Lmpredn $\backslash$ pyro.mak|rtcal.frm $\quad$ 10/9/96

Calibration files: Cal1007.96, Test1007.96 Tgbb1007.96

Data reduction program: Excel 7.0

Data reduction file: Test1096.xls

Final data file: Test1096.txt 
17. Print out test file for RT check standard

a. Prepare history file consisting of Microsoft EXCEL spreadsheet with plots of temperature difference from first calibration versus nominal temperature 



\section{Appendix E: How to Request Radiance Temperature Measurement Services}

1. Prepare a purchase order with the following:

a. Company name and address

b. Contact person's name and phone number.

c. Billing address

d. Service ID number requested (include range and points)

e. Test fee

f. Address to ship test item

g. Return shipping instructions (prepay and add, COD, charge to account with shipper)

i. the test fee does not include shipping costs

ii. customers are responsible for all shipping costs

iii. If no instructions are given, NIST will return the test item by common carrier, collect, and uninsured.

2. Send the purchase order to:

National Institute of Standards and Technology

Calibration Program

Building 820, Room 232

Gaithersburg, MD 20899-0001

Tel.: (301) 975-2002

FAX: (301) 869-3548

E-mail: calibrations@enh.nist.gov

3.Send the test item(s) to:

Charles Gibson

NIST

Building 221 / Room B208

Gaithersburg, MD 20899-0001

Tel.: (301) 975-2329

FAX: (301) 869-5700

E-mail: cgibson@nist.gov

WWW: http://physics.nist.gov/Divisions/Div844/staff/Gp3/gibson.html

Radiance temperature calibrations are performed in February, May, August, and November.

Requests for calibration services are scheduled after the receipt of a purchase order.

NIST policy requires prepayment of all calibration services performed for non-U.S. organizations. Please contact the Calibration Program office to arrange payment. 



SP 250-1 Spectral Radiance Calibrations PB87179883

SP 250-2 Far Ultraviolet Detector Standards PB87227609

SP 250-3 Radiometric Standards in the Vacuum Ultraviolet PB87227625

SP 250-4 Fricke Dosimetry in High-Energy Electron Beams PB88110374

SP 250-5 Alpha-Particle Calibrations PB88168620

SP 250-6 Regular Spectral Transmittance PB88108550

SP 250-7 Radiance Temperature Calibrations PB88123674

SP 250-8 Spectral Reflectance PB88109905

SP 250-9 Calibration of Beta-Particle-Emitting Ophthalmic Applicators PB88108535

SP 250-10 Radioactivity Calibrations with the " $4 \pi$ " Gamma lonization Chamber and Other Radioactivity Calibration Capabilities PB88123708

SP 250-11 Dosimetry for High Dose Applications PB88201587

SP 250-12 Neutron Personnel Dosimetry PB87227617

SP 250-13 Activation Foil Irradiation with Californium Fission Sources PB88217443

SP 250-14 Activation Foil Irradiation by Reactor Cavity Fission Sources PB88217435

SP 250-15 Photometric Calibrations PB88153747

SP 250-16 Calibration of X-Ray and Gamma-Ray Measuring Instruments PB88211826

SP 250-17 The NBS Photodetector Spectral Response Calibration Transfer Program PB88201595

SP 250-18 Neutron Source Strength Calibrations PB88211818

SP 250-19 Calibration of Gamma-Ray-Emitting Brachytherapy Sources PB89193858

SP 250-20 Spectral Irradiance Calibrations PB88123781
SP 250-21 Calibration of Beta-Particle Radiation Instrumentation PB88201579

SP 250-22 Platinum Resistance Thermometer Calibrations PB88138367

SP 250-23 Liquid-in-Glass Thermometer Calibration Service PB89128888

SP 250-24 Standard Cell Calibrations PB88123690

SP 250-25 Calibration Service for Inductive Voltage Dividers

SP 250-26 NBS Phase Angle Calibration Services PB88225636

SP 250-27 AC-DC Difference Calibrations PB892222616

SP 250-28 Solid-State DC Voltage Standard Calibrations PB88168703

SP 250-29 Traceable Frequency Calibrations PB88168364

SP 250-30 GOES Satellite Time Code Dissemination: Description and Operation PB88168760

SP 250-31 Mass Calibrations PB89153894

SP 250-32 A Calibration Service for $30 \mathrm{MHz}$ Attenuation and Phase Shift PB88238324

SP 250-33 A Calibration Service for Voltage Transformers and High-Voltage Capacitors PB882252903

SP 250-34 High Vacuum Standard and Its Use PB89193841

SP 250-35 The Calibration of Thermocouples and Thermocouple Materials PB89209340

SP 250-36 A Calibration Service for Current Transformers PB91216770

SP 250-37 Photometric Calibrations PB97148472

SP 250-38 NIST Leak Calibration Service PB92149772

SP 250-39 NIST Pressure Calibration Service PB94164043

SP 250-40 Absorbed-Dose Calibration of Ionization Chambers in a ${ }^{60} \mathrm{Co}$ Gamma-Ray Beam SN003-003-03034-1 \$2.00

* Entries containing a stock number (SN003-003-) and price can be purchased from the Superintendent of Documents, U.S. Government Printing Office, Washington, DC 20402. GPO will accept checks, money orders, VISA, and MasterCard. For more infomation, or to place an order, call (202) $512-1800$. Be sure to cite the stock number on all orders.

Entries containing PB numbers can be purchased from the National Technical Information Service, Springfield, VA 22161. NTIS will accept American Express in addition to the payment methods listed for GPO. For more information call (703)487-4650; to place an order call (800) 553-6487. Fax: (703) 321-8547. Be sure to cite the PB number on all orders.

Entries without stock or PB numbers are in preparation. 


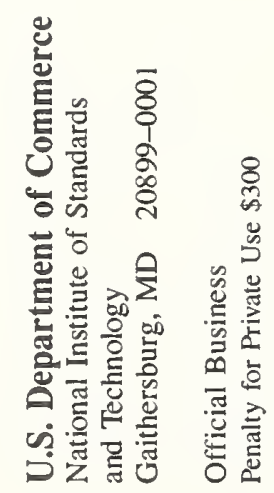

